\title{
Solvent Refined Coal-II (SRC-II) Detailed Environmental Plan
}

Prepared by Staff of the Coal Liquefaction Environmental Research Program

October 1980

Prepared for the U.S. Department of Energy under Contract DE-AC06-76RLO 1830

Pacific Northwest Laboratory Operated for the U.S. Department of Energy by Battelle Memorial Institute 


\title{
NOTICE
}

This report was prepared as an account of work sponsored by the United States Government. Neither the United States nor the Department of Energy, nor any of their employees, nor any of their contractors, subcontractors, or their employees, makes any warranty, express or implied, or assumes any legal liability or responsibility for the accuracy, completeness or usefulness of any information, apparatus, product or process disclosed, or represents that its use would not infringe privately owned rights.

The views, opinions and conclusions contained in this report are those of the contractor and do not necessarily represent those of the United States Government or the United States Department of Energy.

\author{
PACIFIC NORTHWEST LABORATORY \\ operated by \\ BATTELLE \\ for the \\ UNITED STATES DEPARTMENT OF ENERGY \\ Under Contract EY-76-C-06-1830
}

Printed in the United States of America Available from

National Technical Information Service

United States Department of Commerce

5285 Port Royal Road

Springfield, Virginia 22151

Price: Printed Copy $\$$

$\because$ Microfiche $\$ \mathbf{\$ 3 . 0 0}$

*Pages $\quad$ Selling Price
-Pas

$001-025 \quad \$ 4.00$

$026-050 \quad \$ 4.50$

$051-075 \quad \$ 5.25$

$076-100 \quad \$ 6.00$

$101-125 \quad \$ 6.50$

$126-150 \quad \$ 7.25$

$151-175 \quad \$ 8,00$

$176-200 \quad \$ 9.00$

$201-225 \quad \$ 9.25$

$226-250 \quad \$ 9.50$

$251-275 \quad \$ 10.75$

$276-300 \quad \$ 11.00$ 


\section{7}

SOLVENT REFINED COAL-I I

(SRC-II) DETAILED

ENVIRONMENTAL PLAN

Prepared by Staff of the Coal Liquefaction Environmental Research Program

October 1980

Prepared for the U.S. Department of Energy under Contract DE-AC06-76RLO 1830

Pacific Northwest Laboratory Richland, Washington 99352 


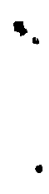

$\cdot$
.

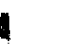
4 
This document describes a detailed plan to aid development of an environmentally acceptable solvent refined coal (SRC-II) conversion process. Most of the document was prepared by the staff of the Pacific Northwest Laboratory (PNL) under the direction of the Coal Liquefaction Environmental Research Program (CLERP) office. Other organizations that contributed include:

Environmental Research and Technology, Inc.

PP. 9-23 SRC-II Process, (excerpted from "Solvent Refined Coal (SRC-II) Technology: Materials for Environmental and Health Characterization." Environmental Research and Technology, Inc., July 1980.

Pittsburg \& Midway Coal Mining Co.

p. 59 Eye Irritation, Dermal Sensitization, Aspiration Hazard

pp. 60-63 Industrial Hygiene, Phase I

pp. 83-84 Industrial Hygiene, Phases II-IV 


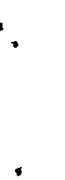




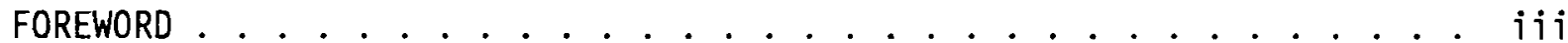

EXECUTIVE SUMMARY . . . . . . . . . . . . . . . . . . . . . . . . . . . xi

INTRODUCTION . . . . . . . . . . . . . . . . . . . . . . . . . 1

PROGRAM ORGANIZATION AND MANAGEMENT . . . . . . . . . . . . . . . 3

SRC-II PROCESS . . . . . . . . . . . . . . . . . . . . . . 9

PROCESS DESCRIPTION . . . . . . . . . . . . . . . . . . . . . . . 9

COAL LIQUEFACTION . . . . . . . . . . . . . . . . . . . . . . 9

HYDROGEN PRODUCTION . . . . . . . . . . . . . . . . . . . . . . . . . 11

ENVIRONMENTAL CONTROL SYSTEMS ................ . . 11

Gas Purification ................. 11

Wastewater Treatment . . . . . . . . . . . . . 11

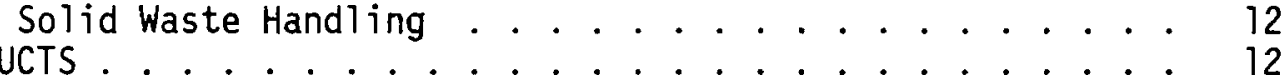

SUPPORT SYSTEMS ..................... . . . . 12

SOURCES, AVAİLABILITY, AND RELEVANCE OF MATERIALS . . . . . . . . . . 13

SOURCES OF MATERIALS .................... 13

PROCESS INTERMEDIATES .. . . . . . . . . . . . . . . . . . . 19

ENVIRONMENTAL CONTROL SYSTEM MATERIALS . . . . . . . . . . . . 20

Flare And Controlled Combustion . . . . . . . . . . 21

SOLID WASTES ...................... 21

BY-PRODUCTS . . . . . . . . . . . . . . . . . 21

PRODUCTS . . . . . . . . . . . . . . . . . . . 22

END-USE MATERIALS . . . . . . . . . . . . . . . . . . . 23

STUDY PLAN . . . . . . . . . . . . . . . . . . . . . . . . . 25

SAMPLE COLLECTION AND STORAGE . . . . . . . . . . . . . . . . . . . 27

SAMPLE COLLECTION . . . . . . . . . . . . . . . . . . 27

SAMPLE STORAGE AND QUALITY CONTROL . . . . . . . . . . . 29

DATATRIEVE - DATA MANAGEMENT SYSTEM . . . . . . . . . . . . . 29

PHASE I . . . . . . . . . . . . . . . . . . . . . . . . 37

BIOMEDICAL STUDIES AND CHEMISTRY . . . . . . . . . . . . . . . 37

In Vitro Assay For Liquid Process Streams and Products . 39

Ames Assay . . . . . . . . . . . . . . . . . 39

Salmonella Forward Mutation ......... . 41

Other Microbial Assays . . . . . . . . . . . . . . . 41

Prophage $(\lambda)$ Induction (Inductest) . . . . . 42

Saccharomyces cerevisiae ........ . . . 42

Bacillus subtilis (Kada) Bioassay System . . . 42

Mammalian Cell Transformation . . . . . . . . . . . 42

Mammalian Cell Culture Mutagenicity . . . . . . . 43

Chinese Hamster Ovary (CHO) Cell Mutation . . . 43

Unscheduled DNA Synthesis.......... 44

Sister Chromatid Exchange . . . . . . . . . . . 44

Chemical Analyses For Liquid Streams And Products . . . . 44

Fractionation . . . . . . . . . . . . . 44

Acid-Base-Neutral Solvent Extraction . . . . 45

High-Performance Liquid Chromatography (HPLC). 45

Partition Chromatography ........ . 45

Thin-Layer Chromatography (TLC)... . . . . 48

Data On Fractionated Materials . . . . . . 48 
Organic Chemical Analyses . . . . . . . . . . . . 48

Gas Chromatography (GC) ........... 49

High-Performance Liquid Chromatography (HPLC) . 50

Gas Chromatography - Low-Resolution Mass

Spectrometry (GCMS) . . . . . . . . 50

High-Resolution Mass Spectrometry (HRMS) . . . 51

Summary of Results ............ . 51

Sol id Process Streams And Wastes . . . . . . . . . 51

Sample Extraction ............. 51

Organic-Rich Materials . . . . . . . . 51

Mineral-Rich Solids ............ 53

In Vitro Tests And Chemistry . . . . . . . . . . . 54

Organic-Rich Materials . . . . . . . . . 54

Mineral-Rich Solids............ 54

Process Waters And Treated Process Waters . . . . . . . 56

Sample Extraction ........... . . 54

Evaporative Condensation ........ 54

Solvent Extraction .......... . . 57

Preconcentration ........... 57

In Vitro Assays And Chemistry . . . . . . . . . 59

Short-Term In Vivo Bioassay . . . . . . . . . . 57

Acute Oral Toxicity . . . . . . . . . . 57

Acute Dermal Toxicity . . . . . . . . . . . . 59

Eye Irritation . . . . . . . . . . . . 59

Dermal Sensitization . . . . . . . . . 59

Aspiration Hazard . . . . . . . . . . . . . 59

Teratogenicity . . . . . . . . . . . . . . 59

Results To Date .............. . 60

Industrial Hygiene - Phase I . . . . . . . . . 60

Worker Education ............ 61

Medical Surveillance ........... . 63

Industrial Hygiene Monitoring . . . . . . . . . . . 63

Toxicological Determinations . . . . . . . 63

ECOLOGICAL STUDIES AND CHEMISTRY . . . . . . . . . . . . . 63

Liquids ................. . . 64

Aquatic Screening Studies . . . . . . . . . 64

Algal Test System ........... 66

Daphnid Test System . . . . . . . . . . 66

Detritivore Test System . . . . . . . . . 67

Fish Test System . . . . . . . . . . 67

Behavioral Studies . . . . . . . 67

Organic Analytical Chemistry For Aquatic

Screening Studies........... . . 68

Preliminary Results . . . . . . . . . 69

Terrestrial Screening .......... . . 70

Plant Growth And Rooting . . . . . . . . 70

Solids ................. . . . 70

Aquatic Screening ........... . . 72

Terrestrial Screening . . . . . . . . 72

ENVIRONMENTAL ASSESSMENT/RISK ANALYSES - PHASE I . . . . . 72

PHASE II . . . . . . . . . . . . . . . 75

BIOMEDICAL STUDIES. . . . . . . . . . . . . . 76

Dermal Carcinogenicity . . . . . . . . . . 76

Liquid Process Streams And Products. . . . . . . . 76 
Solid Process Streams And Wastes. . . . . . . . 76

Inhalation Toxicology . . . . . . . . . . . . . . . . . 78

Liquid Process Streams And Products . . . . . . . . 78

Solid Process Streams And Wastes . . . . . . . . . . 78

Dominant Lethality . . . . . . . . . . . . . . . . 79

Transplacental Carcinogenesis . . . . . . . . . 79

Developmental Toxicology . . . . . . . . . . . . . 79

Neurobehavioral Toxicology .............. . 81

Conditioned Taste Aversion . . . . . . . . . . . . . 81

Conditioned Avoidance Behavior . . . . . . . . . . . 81

Learning And Memory . . . . . . . . . . . . . 81

Open Field Activity .. . . . . . . . . . . . . . 82

Physical Endurance............... 82

Research Needs . . . . . . . . . . . . . . 82

Dosimetry ................. . 82

Factors Affecting Dermal Carcinogenicity . . . . . 82

Dose Fractionation . . . . . . . . . . . . 82

Removal of Dose From Skin.......... 83

Ultraviolet Light Exposure . . . . . . . . 83

Preventative Treatment . . . . . . . . . 83

Cardiovascular Effects . . . . . . . . . . . 83

Degenerative Diseases . . . . . . . . . . . 83

Pulmonary Physiology .............. . 83

INDUSTRIAL HYGIENE - PHASES II-IV . . . . . . . . . . . . . . 83

ECOLOGICAL STUDIES . . . . . . . . . . . . . . . . 84

Biological Fate In The Aquatic Environment . . . . . . 84

Bioconcentration............. 85

Bioaccumulation/Biomagnification ........ . 86

Water. . . . . . . . . . . . . . 86

Sediments............... 86

Tissues . . . . . . . . . . . . . . . . . 87

Biological Fate In The Terrestrial Environment . . . . . 87

Multispecies Testing In Aquatic Systems . . . . . . . . 88

Laboratory Studies On Revegetation of Solid Wastes . . . 88

Chemical And Microbial Fate In Sediment And Soil Systems 89

Chemical Characterization Of Water-Soluble Species . 89

Soil And Sediment Interaction . . . . . . . . . 89

Microbial Processes . . . . . . . . . . . . . . . . 93

ENVIRONMENTAL ASSESSMENT/RISK ANALYSES - PHASE II . . . . . . 94

Enviromental Pathways Modeling . . . . . . . . . . . . 94

Atmospheric Modeling ............. . 95

Chemical Fate Modeling . . . . . . . . . . . 95

Hydrological Modeling .. . . . . . . . . . . . 95

Food-Chain Modeling . . . . . . . . . . . . . . . . 98

Biomedical Assessment . . . . . . . . . . . . . . . 99

Ecological Assessment . . . . . . . . . . . . . . . . . 99

Example of Phase II Environmental Assessment/Risk
Analyses........................... 100

PHASE III . . . . . . . . . . . . . . . . . . . . . . . . . . 103

UPGRADED PRODUCTS ..................... 103

BOILING-POINT FRACTIONS . . . . . . . . . . . . . . . . 104

ENVIRONMENTAL ASSESSMENT/RISK ANALYSES . . . . . . . . . . 104

PHASE IV . . . . . . . . . . . . . . . . . . . . . . 105

HEALTH EFFECTS MONITORING . . . . . . . . . . . . . . . . . . 105 
ECOLOGICAL MONITORING - FIELD STUDIES ......... 105

Aquatic Field Monitoring . . . . . . . . . . . 106

Biological Sampling Criteria ....... 108

Chemical Measurements On Biological Specimens . . 108

Other Measurements And Samples. . . . . . . . . 108

Terrestrial Field Monitoring .......... 109

Terrestrial Environment At Ft. Martin . . . . . . 109

Field Experiments . . . . . . . . . 110

Field Plots ............... . 110

Other Measurements And Samples ......... 111

Revegetation ........... 111

Forest Monitoring ........... . 111

Photographic Interpretation . . . . . . 111

Visible Injury . . . . . . . . . . 111

Indicator Species . . . . . . . . . 111

Litterfall ............. 111

Leaf Decomposition . . . . . . . . . 112

Wildlife Monitoring. . . . . . . . . . . . 112

Chemical Transport And Fate . . . . . . . . . . . 112

Task I - Preliminary Evaluation of Existing Water

Quality And Hydrological Data ......... 113

Task II - Limited Onsite Field Program . . . . . . 113

Product Spills - Ft. Lewis ......... 114

Solid Waste Disposal - Fort Martin . . . . . 115

Task II - Comprehensive Field Program . . . . . . 115

Task IV - Modeling. . . . . . . . . . . 116

ENVIRONMENTAL ASSESSMENT/RISK ANALYSES . . . . . . . . . . . . 117

TIME-LINES . . . . . . . . . . . . . . . . . . . . . . . . . . 119 
1. Sources, Relevance and Availability of SRC-II Pre-DemonstrationFacility Materials for Biomedical and Ecological Testing . . . . . 14

2. SRC-II Materials for Biomedical and Ecological Investigations . . 28

3. Protocol for Analyses to Observe Stability of Research Materials During Storage................ 30

4. A Partial List of Source Materials and Their English Equivalents . 32

5. A Partial List of Test Codes and Their English Equivalents. (This list represents only some of the major test categories within the various research departments.) ............. 33

6. Sample Source Material Audit Report for One Material . . . . . 34

7. Test Status Report Arranged by Test Category to Identify the Status of Individual Tests on all Materials......... 35

8. Test Status Report Arranged by Test Material to Identify the Status of all Tests Applied to that Material ........ 35

9. Phase I In Vitro Assays: Liquid Materials . . . . . . . . . . 40

10. Comparison of the Mutagenicity of Solvent Refined Coal Materials, Shale 0ils, and Crude Petroleums in Salmonella typhimurium TA98.

11. Comparative Transformation Properties in Syrian Hamster Embryo Cells of Complex Organic Mixtures . . . . . . . . . . .

12. Recovery of Ames Assay Mutagenic Activity in Fractions Derived by Acid-Base-Neutral Solvent Extraction of SRC-II Heavy Distillate .

13. Phase I In Vitro Assays: Solid Materials . . . . . . . . . . 52

14. Aqueous Leaching Solutions .............. 53

15. Analytical Methodologies for Biologically Active Metals ..... 55

16. Phase I In Vitro Assays: Waters . . . . . . . . . . 56

17. Phase I In Vivo Assays ............... 58

18. Comparison of the Acute and Repeated Dose Toxicities of SRC Materials in the Female Wistar Rat . . . . . . . . . . . 61

19. Maternal and Fetal Toxicity in Rats Following Dosing with SRC-II Materials From 12-16 Days of Exposure . . . . . . . . . . . 


\section{TABLES (Continued)}

20. Phase I Ecological Screening Assays: Liquid Materials . . . . . 65

21. Phase I Ecological Screening Assays: Solid Materials . . . . . . 71

22. Phase II In Vivo Assays . . . . . . . . . . . . . . . . . . 80

23. Anatomic and Functional Measures of Postnatal Maturation . . . . 85

24. Phase II Biological Fate Studies: Liquid and Solid Materials . . . 85

25. Analyses of Solid and Liquid Phases . . . . . . . . . . . . . 90

FIGURES

Page

1. SRC Organization at PNL .................... 4

2. Organization of Environmental Program Team (EPT) . . . . . . . . . 6

3. Schematic Diagram of the SRC-II Demonstration Plant Process . . . . 10

4. Flow Chart for Phase I In Vitro Assay: Integrated Chemical Fractionation and Characterization . . . . . . . . . . . 38

5. Acid-Base-Neutral Fractionation of SRC-II Materials . . . . . . 46

6. Sephadex LH-20 Fractionation .................. 47

7. General Physicochemical Fractionation Scheme for Waters, Solids, and Biological Tissues from Environmental and Laboratory Studies. The application of common fractionation and analytical methods with emphasis on solubles allows identification of mobile, biologically available compounds, intercomparability of diverse environments, and integration of research. . . . . . . . . . 9 91

8. Environmental Dose Assessment Model . . . . . . . . . . . . 96

9. Map of SRC-II Demonstration Site. Monitoring stations used to collect data for Environmental Impact Statements are shown . . . 107

10. Estimated Time to Complete Phase I Biomedical and Ecological Studies, Assuming Receipt of Materials at Time Zero . . . . . . . 120

11. Estimated Time to Complete Phase II Biomedical Studies, Assuming Receipt of Materials at Time Zero . . . . . . . . . . . . 121

12. Estimated Time to Complete Phase II Ecological Studies, Assuming Receipt of Materials at Time Zero............... . 122 
EXECUTIVE SUMMARY: SOLVENT REFINED COAL-II (SRC-II)

DETAILED ENVIRONMENTAL PLAN

This document describes environmental research which will:

- aid in the development of an environmentally acceptable SRC-II process, and

- provide data for environmental assessment of the process.

The document provides a management plan which involves the cognizant offices of the Department of Energy (Assistant Secretary for the Environment and Assistant Secretary for Fossil Energy (ASFE), Oak Ridge Operations office), the developers of the SRC-II process, and environmental research groups. The SRC-II process is described, criteria for selection of samples to undergo environmental analyses are given, and approximate timelines are presented for obtaining pertinent samples.

At this time, the SRC-II process is at the pilot-plant stage of development and a demonstration facility is scheduled to begin operation in 1984 . Since design criteria may change, the environmental research described in this document is organized in four phases which correlate with and will provide information early in process development.

Phase I research (screening) evaluates samples from existing SRC-II facilities (pilot, process demonstration unit [PDU], bench) which may bracket potential demonstration/commercial practice in terms of physical and chemical criteria. The samples are being subjected to a battery of short-term biomedical and ecological assays. Chemical fractionation and analys is are being performed to determine compounds and compound classes of potential concern. In some cases, chemical fractionation/manipulation is required to provide materials amenable to biological and ecological testing. Phase I research provides a first estimate of potential environmental properties of SRC-II materials. As such, Phase I aids in:

- setting research priorities for the second phase of work which involves longer-term, more-extensive biomedical and ecological assays and chemical analyses;

- providing initial data on materials and chemical entities that may require ameliorative action during process development;

- providing first, qualititative analyses for assessing environmental risk to be expected from deployment of the SRC -II process.

Phase II (baseline) research will evaluate SRC-II materials which are considered most representative of potential demonstration/commercial practice. These materials will be subjected to longer-term, more-extensive biological and ecological analyses relative to effects and environmental fate. Chemical fractionation and analyses will again be used to: 1) provide materials amenable to bioassay, and 2) determine compounds and compound classes of concern. Resuits from this research phase will provide: 
- a reasonable estimate of which materials of concern may require regulation;

- correlation analyses between short-term, inexpensive, in vitro and selected in vivo assays (Phase I) and longer-term, more expensive, in vivo assays and ecological studies (Phase II);

- a basis for development of control technologies and management procedures which may ameliorate environmental risk;

- a second and more quantitative assessment of potential environmental risk.

Phase III research will examine effects of process modification, control technologies and changing operational conditions on potential environmental properties of SRC-II materials. Short-term biological and ecological analyses (Phase I), which have been shown to correlate with longer-term analyses (Phase II), will be used in Phase III. Integrated chemical fractionation and analysis methods (selected in Phase I), will be used to determine compounds and compound classes of environmental concern. Data from Phase III will provide:

- a basis for determining effectiveness of control technology, process modification, etc. relative to decreasing potential environmental effect,

- a third analysis of environmental risk which would consider effects of altered plant operations.

Phase IV research (onsite monitoring) will develop methods and initiate environmental monitoring for effects at the SRC-II demonstration facility and potential commercial sites. Data from Phases I, II and III may provide indicators of biological and ecological effects, and a basis for assays for potentially harmful chemical entities which should be monitored in the work-place and local environments. Phase IV research efforts will include intensive studies of environmental fate and transport for SRC-II materials. Data from demonstration facility monitoring should allow:

- development of more-effective environmental management procedures in the areas of waste disposal and industrial hygiene, for both the demonstration and commercial SRC-II facilities;

- quantitative environmental risk assessment which is more appropriate to a commercial SRC-II process.

This document also describes industrial hygiene programs which must occur throughout SRC-II process development. Present studies concerning potential end-use of SRC-II materials are also discussed. Since end-use of SRC-II products is still under consideration, environmental effects relevant to end-use will be considered in later versions of this environmental program. It is anticipated that research on end-use, especially that involving utilization of SRC-II materials as refinery and petrochemical feedstocks, will proceed in phases similar to those already described. Efforts to assess control technologies will be described in a separate document. 
Summaries are provided of ongoing efforts and results to date on research in Phases I, II and III. The current program is defined most specifically in Phase I, with decreasing levels of specific description in Phase II, and little specificity in Phases III and IV. Phases III and IV are contingent on process development and results of Phases I and II. Therefore, the plan will be routinely updated to more specifically define later-phase research efforts. Studies suggested in the plan are consonant with the Environmental Concerns and Requirements stated in the Environmental Development Plan for Coal Liquefaction and in the Program Environmental Plan for SRC processes. 


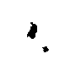




\section{INTRODUCTION}

Three coal liquefaction processes are being developed by industry, with the aid of the U.S. Department of Energy (DOE), and may be ready for commercialization by the 1990s. These include the Solvent Refined Coal-II (SRC-II), $\mathrm{H}$-coal, and donor solvent processes. Another SRC process (SRC-I), which produces a low-sulfur, low-ash, solid fuel for use in electric power production, is also expected to undergo commercialization within the same time frame.

SRC-I and -II are currently in a more advanced stage of development than are the $\mathrm{H}$-coal or donor solvent processes. Demonstration facility designs are being prepared for both SRC options, and construction of demonstration facilities will be initiated by 1981. Both process options are being studied at a 50-ton/day, pilot plant in Ft. Lewis, WA. The SRC-I process is also being evaluated at a 6-ton/day pilot plant in Wilsonville, AL. H-coal and donor solvent pilot plants were scheduled for operation in 1979-1980 and 1980-82, respectively, and large-scale process demonstration unit (PDU)/pilot plants for these processes recently became available for research on potential environmental effects.

In the spring of 1978, the Environmental Coordinating Committee for Coal Liquefaction of the Office of the Assistant Secretary for the Environment (ASEV) asked the Pacific Northwest Laboratory (PNL) to prepare environmental research plans for the solvent refined coal processes (SRC-I and II). In the fall of 1978, discussions were held with Assistant Secretary for Energy Technology (ASET) personnel and personnel representing operators (the Pittsburg \& Midway Coal Mining Co. [P\&M] and Gulf Mineral Resources Co.) of the SRC pilot plant. These companies may also be responsible for operation of the SRC-II demonstration facility. Through a series of meetings and further discussions, a joint effort was begun among personnel representing process developers and PNL to initiate environmental research and integrate process information with the environmental research program. This document is a result of these joint efforts and of research experience on the SRC-II process. 


\section{$\checkmark$}

. 
PROGRAM ORGANIZATION AND MANAGEMENT

The current program represents research in progress at PNL, under the aegis of ASEV/DOE; P\&M efforts at the site of the potential SRC-II demonstration facility; and P\&M's work relative to SRC-II research and development at the Ft. Lewis pilot plant and the Merriam, KS PDU. The latter programs are also sponsored by ASFE/DOE under program offices for demonstration facilities and research and development, respectively.

The organization of SRC coal liquefaction environmental programs at PNL is shown in Figure 1. The SRC-II program is administered through PNL's Coal Liquefaction Environmental Research Program (CLERP). Personnel report administratively to Drs. H. Drucker and S. Marks of the PNL-DOE Program Office. Drs. Drucker and Marks provide administrative support in the organization-wide effort required for implementation of this plan. Dr. Drucker serves as manager of coal liquefaction research at PNL, and will be aided in his activities by an associate manager, Dr. R. H. Gray. This coordinating group will serve to integrate research and reporting activities for the research tasks that presently comprise the PNL SRC program and other coal liquefaction environmental activities. The group will also function as liaison for program/task/ project development with cognizant offices of DOE.

Three tasks in the PNL program (chemical characterization and monitoring, biomedical evaluation, and ecological evaluation), which are defined by present DOE-ASEV funding documents, will be performed at PNL. One task (biomedical and environmental assessment) is not expected to receive funding until $F Y$ 1981. This task will involve input from the three PNL departments presently participating in the program (Biology, Ecological Sciences, and Physical Sciences), and two other PNL departments (Atmospheric Sciences, and Water and Land Resources). PNL will provide source-term data for determining dose and effects to ecosystems and dose to occupationally and environmentally exposed human populations. Evaluation of the SRC-II process relevant to risk analyses will be provided by Environmental Research and Technology, Inc. (ERT), contracting to the Fossil Energy Division of DOE. Science Research Systems, Inc. will aid in extrapolating dose-effect relationships to man, as measured in experimental systems. PNL will have primary technical and managerial responsibility for the SRC-II environmental assessment.

Task leaders representing key program elements will develop programs applicable to determination of environmental effects of demonstration and commercial SRC-II facilities. Research will provide data relevant to the environmental Concerns and Requirements stated in the Coal Liquefaction Environmental Development Plan and in the SRC-II Program Environmental Plan.

A technical advisory committee (TAC) will be established to aid in technical review and in setting research priorities for environmental studies. The TAC will include senior PNL scientists from programs other than coal liquefaction, and consultants drawn from outside PNL. This committee will meet twice yearly to provide independent review of technical progress, quality, and priorities.

A major biomedical/environmental research program, funded by ASFE, is also being conducted on SRC-II under the P\&M pilot-plant contract. The PNL 


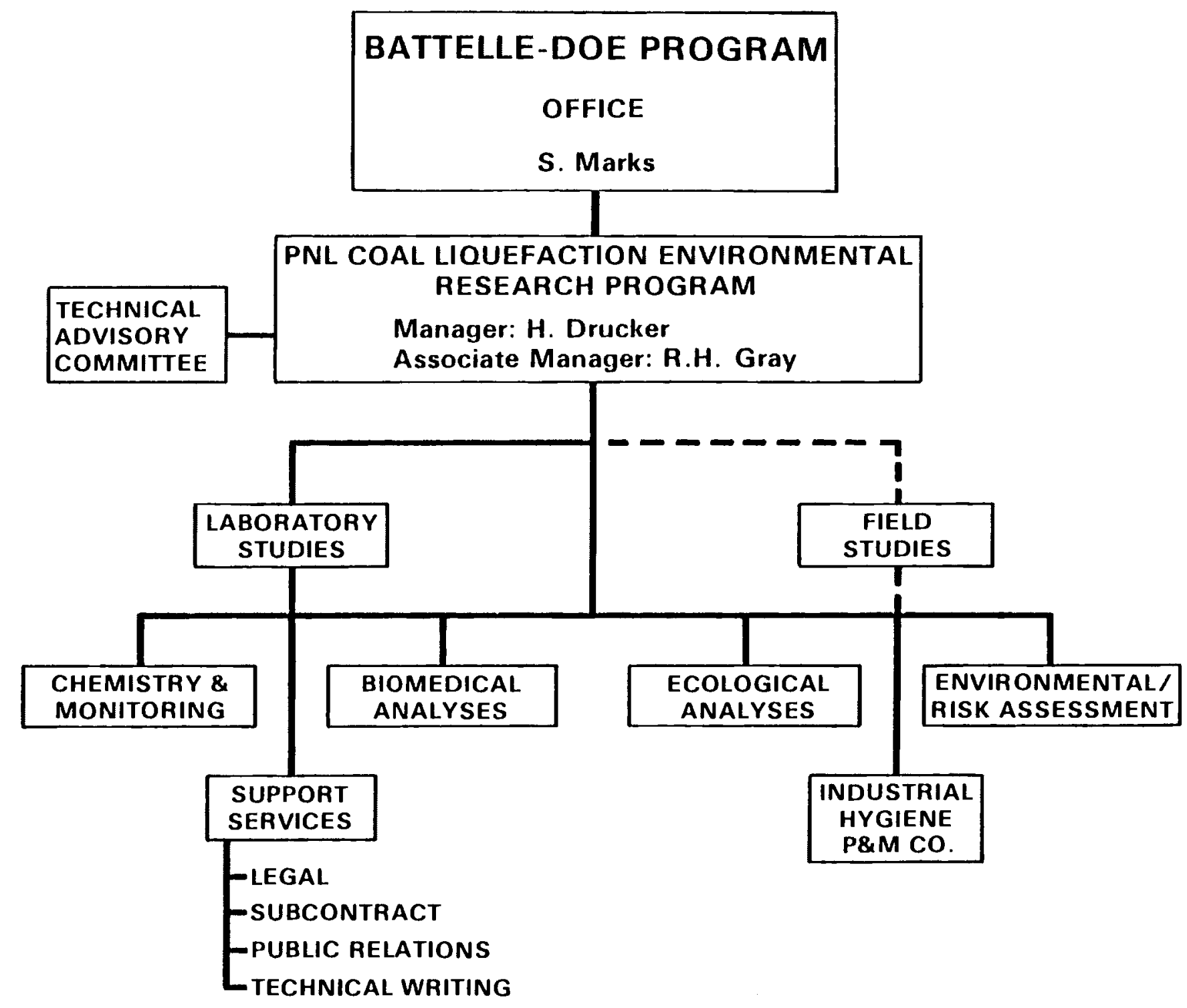

Figure 1. SRC Organization at Pacific Northwest Laboratory (PNL) 
and P\&M programs were designed to complement each other and to avoid duplication of effort.

PNL research at the SRC-II demonstration facility will be coordinated with the P\&M Demonstration Project and the office of Dr. J. Reafsnyder, Oak Ridge Operations (ORO, the DOE field office with overview responsibilities for SRC operations). The research will also involve collaboration with personnel of Stearns-Roger, Inc., Consulting Engineers, acting for the P\&M Demonstration Project, and personnel of Oak Ridge National Laboratories (ORNL), acting as consultants to ORO.

The PNL program requires extensive engineering analyses of SRC-II demonstration facility designs, and of smaller-scale facilities to develop operational conditions for small-scale units which might yield samples relevant to demonstration and commercial practice. Engineering analyses will be performed by P\&M and ERT personnel. PNL staff will participate in these efforts in order to obtain representative samples and establish research priorities.

Provision is made by the organization outlined in Figure 2 for: 1) integration of environmental research performed through the major program elements (PNL, P\&M pilot-plant operations and P\&M demonstration project), and 2) communication among DOE personnel responsible for project management and these elements.

An SRC-II Environmental Program Team (EPT), was established to aid in developing and maintaining a coordinated research effort (see organizational scheme, Figure 2) on the environmental acceptability of the SRC-II process. The EPT is composed of managers representing major program elements. Committee chairmen are representatives of ASFE and ASEV. The committee will also have permanent representatives from ORO and the technology developers. Suggested responsibilities of the ad hoc committee are to:

- aid in integrating SRC-II process development with environmental research;

- maintain ongoing overview of SRC-II environmental research and minimize undesirable duplication of effort;

- $\quad$ serve as an informal scientific and peer review mechanism for reports and communications on SRC work. (Note: The committee will be advisory and informational, not a clearance or approval mechanism.);

- inform DOE-ORO of study results and future plans, and aid in providing information for use in the permitting, licensing, and regulatory processes for development of the SRC-II demonstration program;

- aid the DOE Environmental Coordinating Committee and the DOE COal Liquefaction Commercialization Task Force in analyzing available information;

- advise on the need for and arrange informational meetings among scientists working on SRC-II programs, both on a regularly scheduled and as-required basis. 


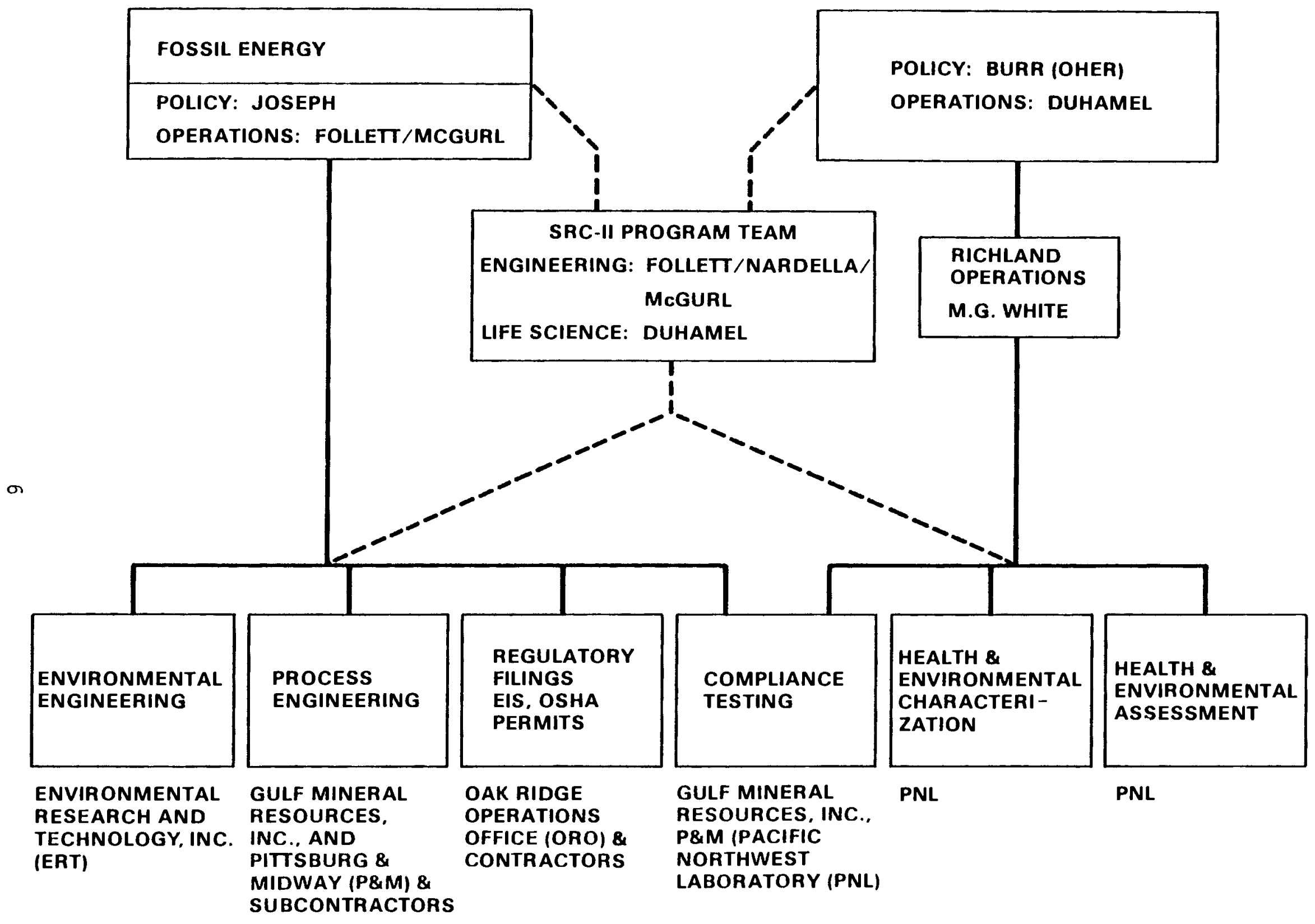

Figure 2. Organization of Environmental Program Team (EPT) 
Reports generated by the research programs and required under the terms of contractual obligations to DOE will be submitted in draft form to the committee for information and comment.

To assure that pertinent information is received in a timely fashion by all program participants, the following report/meeting schedule is suggested:

1. short, monthly, highlight reports to all pertinent participants in the program, emphasizing significant research results;

2. quarterly reports on program performance, including research status and information relevant to task completion and proposed timelines (to be submitted as public documents);

3. semiannual meetings involving key scientists in the program. These meetings should be held under the aegis of the EPT to provide for continuing, informal, critical review of work in progress.

The schedule described is in addition to reports and meetings required under terms of contracts between DOE and elements of the research program. 
-

•. 
SRC-II PROCESS

The SRC-II process is designed to produce primarily low-sulfur, low-ash fuel oils from the liquefaction of high-sulfur bituminous coals. Principal products (other than fuel oils) include synthetic natural gas, liquefied propane, mixed-butanes, and naphtha. Byproducts recovered from process waters and acid gases include anhydrous ammonia and tar acids, and elemental sulfur, respectively. The process has been tested at bench-, PDU- and pilot plant scale, and the detailed demonstration facility design is being developed.

\section{PROCESS DESCRIPTION}

The SRC-II process, shown schematically in Figure 3, involves noncatalytic, direct hydrogenation coal liquefaction. The "Phase Zero" demonstration-facility design prepared by P\&M is the basis for the following discussion. However, process options being considered during detailed demonstration-facility design are also discussed as they relate to identification of materials for biomedical and ecological testing.

\section{COAL LIQUEFACTION}

The SRC-II demonstration facility is designed to process 6000 tons per day of high-sulfur bituminous coal. Pulverized and dried coal is mixed with recycled, process-derived hydrocarbon solvent and mineral-rich slurry. The feed slurry is pumped to the system pressure of 22000 psi, mixed with hydrogenrich gas, and heated in a fuel-fired preheater before entering the dissolver reactor. Coal dissolution and depolymerization reactions mostly occur in the preheater. Hydrocracking of heavy coal liquids and final conversion to products occur in the dissolver. Portions of coal-bound $N, S$, and 0 are converted to $\mathrm{NH}_{3}, \mathrm{H}_{2} \mathrm{~S}$, and $\mathrm{H}_{2} \mathrm{O}$, respectively. Smaller amounts of $\mathrm{HCN}, \mathrm{COS}$, and $\mathrm{CS}_{2}$ are also produced. Unreacted coal mineral matter, liquid and gaseous products, and gaseous contaminants exit from the dissolver at $\sim 860^{\circ} \mathrm{F}$ and proceed to cooling and phase separation.

Dissolver effluent is partially quenched with a process-derived middleboiling-range oil from the high-pressure separation section. Noncondensable gases containing unreacted hydrogen, carbon oxides, light hydrocarbons and acid gases are removed through the high-pressure section of the system and proceed to gas purification. The mineral-rich hydrocarbon slurry is removed through the low-pressure section of the system. A significant fraction of the slurry is combined with hydrocarbon solvent and recycled to prepare the feed coal slurry. The remainder of the slurry is sent to vacuum distillation. Three intermediate hydrocarbon liquid streams leave the system and proceed to atmospheric fractionation. Sour waters, from both high- and low-pressure systems, proceed to wastewater treatment for byproduct recovery.

The fractionation system separates liquid products from other coalderived hydrocarbons and the mineral-rich hydrocarbon slurry. High-boilingrange distillate is removed from the mineral-rich hydrocarbon slurry in a two-stage vacuum distillation system. An atmospheric distillation system 


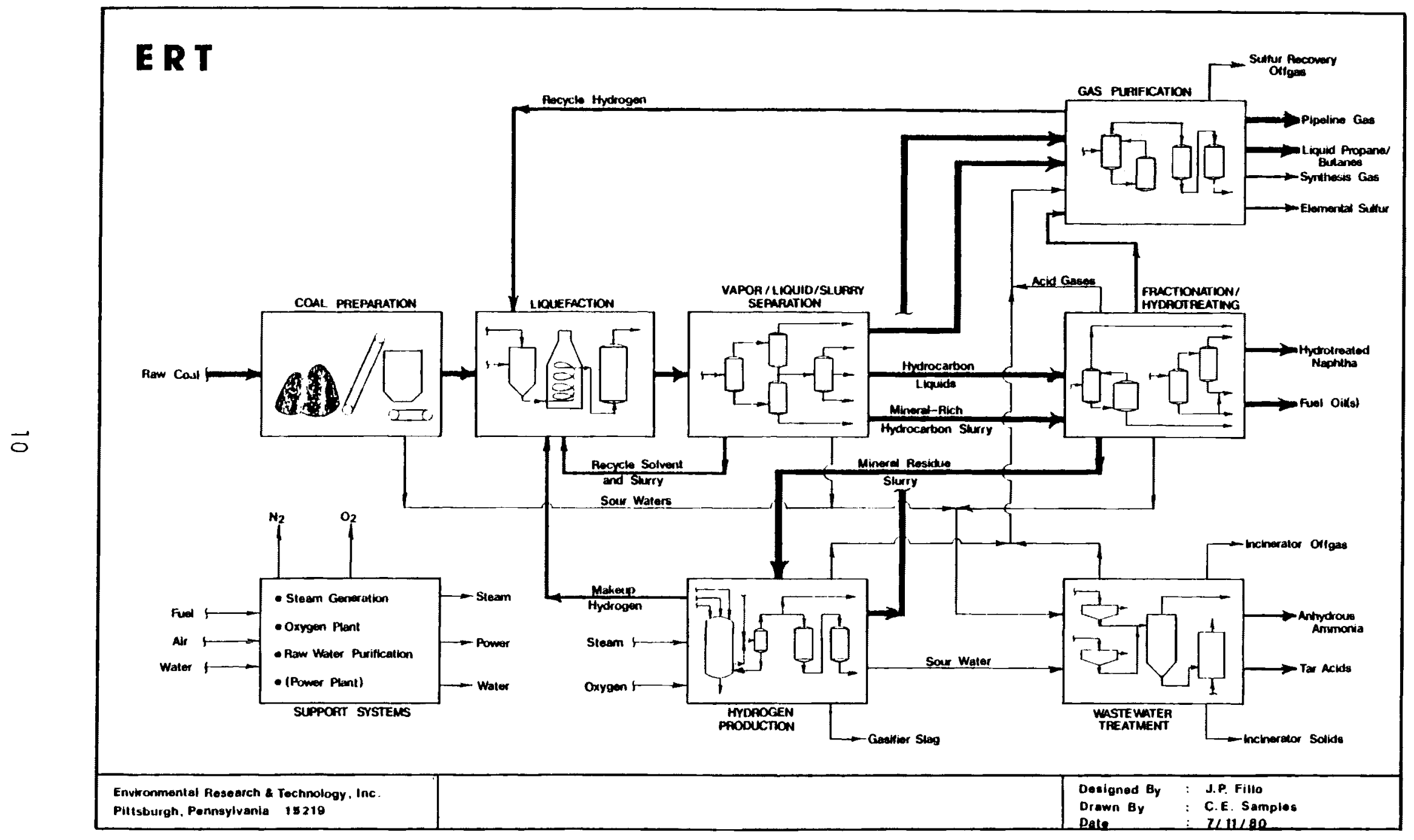

Figure 3. Schematic of the SRC-II Demonstration Facility Process 
produces light and heavy fuel oils, and separates butane and lighter hydrocarbons from the raw naphtha. Raw naphtha is subsequently hydrodesulfurized onsite.

\section{HYDROGEN PRODUCTION}

A source of hydrogen is required for coal liquefaction and naphtha hydrotreating. Hydrogen is most economically obtained by gasification of the mineral residue slurry. Molten residue, steam and oxygen are fed at high pressure to the proprietary Texaco partial oxidation gasifier. Heavy hydrocarbons in the mineral residue slurry are gasified at high temperature and residual coal mineral matter is converted to molten slag. Synthesis gas is partially quenched and molten slag is solidified in the lower portion of the gasifier. Synthesis gas is catalytically converted to hydrogen via the water-gas shift reaction. Excess synthesis gas is used for plant fuel. Solidified slag is sluiced from the base of the gasifier for subsequent dewatering and disposal.

\section{ENVIRONMENTAL CONTROL SYSTEMS}

\section{Gas Purification}

Acid gases are generated during 1 iquefaction and gasification processing and must be recovered and treated prior to reuse or venting of process-derived gaseous streams. Acid gases are recovered from hydrogen-rich recycle gas, synthesis gas and make-up hydrogen from gasification, and low-pressure light hydrocarbon gases from fractionation, using either aqueous diethanol amine (DEA) solution or Benfield (i.e., aqueous potassium carbonate solution) systems. The Benfield system is used exclusively on gasifier-derived gas streams. Elemental sulfur is recovered from acid gases, including streams from raw naphtha hydrodesulfurization and sour water ammonia recovery, using the Claus process in conjunction with a Shell Super-SCOT tailgas cleanup system. SCOT unit tailgas is incinerated and vented to the atmosphere.

\section{Wastewater Treatment}

The design for wastewater treatment in the SRC-II demonstration plant specifies zero discharge. This is achieved by collecting and treating a 1 waste waters from the plant area (i.e., those which are process-derived, and run-off from storage and process areas) for reuse in the process. By-product ammonia and tar acids are recovered from liquefaction waste waters. All plant waste waters undergo varying levels of physical and/or chemical treatment (e.g., pH neutralization, solids/organics removal) prior to evaporation, followed by incineration of treatment sludges and evaporator brines. Evaporator distillate is processed through a wet cooling-tower system prior to reuse. Solid incinerator residues are disposed on site; incinerator offgas is vented to the atmosphere. 
Solid Waste Handling

Solid wastes generated by the SRC-II demonstration facility are currentiy slated for disposal in a secure, on-site landfill. The largest amount of solid waste is $\sim 800$ tons per day of slag, generated during gasification of mineral residue slurry. Incineration of wastewater treatment sludges and brines produces about 100 times less solid than the slag.

\section{PRODUCTS}

Major products from the SRC-II demonstration facility are fuel oils suitable for use by the electric utility industry. Both light (i.e., $\sim 350^{\circ}-$ to $550^{\circ}$-boiling-range hydrocarbons) and heavy (i.e., $\sim 550^{\circ}-$ to $900^{\circ} \mathrm{F}$-boilingrange hydrocarbons) fuel oils are produced individually from fractionation, and can be blended on site to produce a full boiling range fuel. Fuel oils will be stored on site and shipped in bulk by rail.

Product naphtha (i.e., $\mathrm{C}_{5}$ to $350^{\circ} \mathrm{F}$-boiling-range hydrocarbons) is produced for use in-plant and/or as a refinery feedstock. Raw naphtha from fractionation is hydrotreated for stability against oxidation and to remove sulfur as $\mathrm{H}_{2} \mathrm{~S}$. Naphtha will be shipped by tank truck.

The final set of products includes synthetic natural gas (SNG), liquefied propane and mixed butanes. These are derived from the gas purification section of the demonstration facility. Butane and lighter hydrocarbons, recovered from product fractionation and recycle hydrogen upgrading, are fractionated to produce liquefied gases. Synthesis gas in excess of that required to fulfill plant fuel requirements is purified and catalytically methanated. Ethane and lighter hydrocarbons from recycle hydrogen upgrading and liquefied product fractionation are also processed by methanation. SNG is shipped by pipeline; liquefied gases, by tank truck.

\section{SUPPORT SYSTEMS}

Numerous systems are required to maintain operation of the demonstration facility, including coal storage and handling, steam generation, an oxygen source and raw make-up water treatment. Electric power will be supplied by the local utility. An elevated flare system is also required for combustion of hydrocarbon materials during emergencies. However, due to the complex nature of coal-derived hydrocarbons, a controlled combustor system is specified to ensure complete combustion of emergency releases. 
SOURCES, AVAILABILITY, AND RELEVANCE OF MATERIALS

SRC-II materials to be used for initial biomedical and ecological assay must currently be obtained from small, sub-commercial-scale facilities and be representative of materials anticipated from larger-scale facilities. The relationship of pre-demonstration-scale materials to those projected for the demonstration facility varies. In some cases, representative materials can be directly identified. In other instances, while demonstration-scale analogs cannot be rigorously identified, they can be reasonably simulated. Similarities in physical plant configuration or chemical characteristics of materials from existing facilities can be exploited. Sometimes it is not possible to generate an analogous material. Regardless of the source, the relevance of each material to projected demonstration facility operations must be assessed to accurately interpret the biomedical and ecological database that is generated.

Sources, availability, and relevance of pre-demonstration-scale materials for biomedical and ecological testing are shown in Table 1. Correspondence of these materials with characteristics of projected demonstration facility materials is discussed with respect to the "Phase Zero" design and options for the detailed demonstration-facility design.

\section{SOURCES OF MATERIALS}

Biomedical and ecological testing programs will utilize relevant materials from PDU-, pilot- and eventualiy demonstration-scale units. Thus, needs for environmental control can be defined early in process development and maximum and effective control can be implemented before design reaches commercial scale.

Three major facilities are currently available to provide materials for biomedical and ecological testing, including:

1. SRC-II Pilot Plant - 30-ton-per-day coal liquefaction facility, located in Fort Lewis, WA; operated by P\&M.

2. P99 - 1-ton-per-day coal liquefaction PDU, located in Harmarville, PA; operated by Gulf Research and Development Company.

3. Texaco Pilot Plant-12-ton-per-day partial oxidation gasifier, located in Montebe110, CA; operated by Texaco Development Corporation.

Additional POU- and pilot-scale facilities are needed, and should be made available for generating relevant SRC-II materials. These include units for hydrotreating, refinery upgrading, by-product recovery, wastewater treatment and end-use applications. By-product recovery units should be available following definitive choice of options for the demonstration facility. Wastewater treatment could include evaporator/incinerator, physical/chemical treatment and biological treatment systems, and is partially dependent upon options pursued in detailed demonstration facility design. 
TABLE 1. Sources, Availability, and Relevance of SRC-II Pre-Demonstration-Facility Materials for Biomedical and Ecological Testing.

Pre-Demonstration-Facility Testing Source Materials

SRC-II PP(a) Coal Slurry Recycle Slurry

Raw Naphtha Middle Distillate Heavy Distillate Vacuum Bottoms
Relation to DemonstrationFacility Materials and Configuration

\section{PROCESS INTERMEDIATES}

Slurry composition may differ due to contrasts with demonstration-facility vapor/ liquid/slurry separation system configuration. Heavy distillate used as slurry pump seal flush.

Fractionation configuration different; distillate boiling ranges are variable and may not copfespond exactly with demo specifications ${ }^{(b)}$ :

$$
\begin{array}{lr}
\text { - naphtha } & \mathrm{C}_{5}-350^{\circ} \mathrm{F} \\
\text { - middle distillate } & 350-550^{\circ} \mathrm{F} \\
\text { - heavy distillate } & 550-900^{\circ} \mathrm{F}
\end{array}
$$

Vacuum flash system operates at a lower severity, resulting in a maximum heavy distillate end point in the range $800^{-}$ $850^{\circ} \mathrm{F}$.

Reactor configuration (i.e., length/ diameter ratio, velocities) different, may affect reactor hydrodynamics and kinetics, resulting in differences in product yields.
Material Availability

Distillates and naphtha obtained 1Q 1978 for screening studies.

Slurries, naphtha, distillates, and process water obtained 201980 for baseline studies.

All materials, $4 Q 1980$ and later.

(a) SRC-II PP: 30 ton per day SRC-II pilot plant in Fort Lewis, WA.

(b) Demonstration-plant specifications are those defined in the Phase Zero detailed conceptual design. 
TABLE 1. (continued)

$\frac{\text { Pre-Demonstration-Facility Testing }}{\text { Source }}$

Process Water

pg9 (c)

Coal Slurry

Recycle Slurry

Raw Naphtha

$400^{\circ} \mathrm{F}$ Distillate

Vacuum Bottoms
Relation to DemonstrationFacility Materials and Configuration

Process water recycled as a dissolver effluent quench which is different from demonstration-facility configuration and may affect composition.

Slurry composition may differ due to contrasts with demonstration-plant vapor/ liquid/slurry separation system configuration. Mineral oil used as slurry pump seal flush.

Fractionation corresponds better to demo system than to pilot plant, but provides only $\sim 400^{\circ} \mathrm{F}^{-}$and $\sim 400^{\circ} \mathrm{F}^{+}$distillates.

Vaccum flash system operation flexible, can açieve up to $\sim 1000^{\circ} \mathrm{F}$ endpoint on $400^{\circ} \mathrm{F}^{+}$distillate.

Reactor configuration (i.e., diameter, length/diameter ratio) variable, can investigate effects on product yields.

$50^{\circ} \mathrm{F}$ Boiling

Fractions

Process Water
Prepared by controlled fractionation of 400 to $975^{\circ} \mathrm{F}$ distillate into $50^{\circ} \mathrm{F}$ boiling cuts.

Water quench corresponds better than pilot plant with demonstration facility configuration, can vary use of fresh makeup water.
Material

Availability

All materials, $4 Q 1980$ and later.

301980

4Q 1980 and later.

(c) P99: 1-ton-per-day SRC-II P99 PDU in Harmarville, PA 
TABLE 1. (continued)

Pre-Demonstration-Facility Testing Source

Texaco Pp $(d)$

Process Waters

Biotreatment Bench Units

\begin{tabular}{|c|c|}
\hline $\begin{array}{l}\text { Byproduct } \\
\text { Recovery Pi- } \\
\text { lot Units }\end{array}$ & $\begin{array}{l}\text { Treated Waters } \\
\text { Absorber Solu- } \\
\text { tions }\end{array}$ \\
\hline SRC-II PP & $\begin{array}{l}\text { Stretford Solu- } \\
\text { tion }\end{array}$ \\
\hline
\end{tabular}

Treated Process Waters

Texaco PP Gasifier Slag
Relation to DemonstrationFacility Materials and Configuration

Correspondence between pilot- and demonstration-facility systems cannot be identified here due to proprietary nature of demonstration plant design.

\section{ENVIRONMENTAL CONTROL SYSTEM MATERIALS}

Ammonia and tar acid recovery systems to be finalized for detailed demonstrationplant design.

Potential utilization in demonstration plant not similar to pilot plant, application not specifically defined.

Biological treatment system not specified in Phase Zero demonstration plant design, but retained as option.

All significant demo-related sour-water streams not available from existing pilot and PDU facilities.

\section{SOLID WASTES}

Correspondence between pilot and demonstration plant systems not identified here due to proprietary nature of demonstration plant design.

Kentucky $9 / 14$ coal not currently planned for use in the demonstration plant.
Materials are currently unavailable.

4Q 1980 and later.

Bench unit tests must be defined.
Slag from gasification of Kentucky 9/14 coalderived vacuum bottoms produced 1Q 1978.

Slag from gasification of Powhatan \#5 coalderived vacuum bottoms produced 1Q 1980.

${ }^{(d)}$ Texaco PP: 12-ton-per-day Texaco pilot plant gasifier in Montebello, CA 
TABLE 1. (continued)

\begin{tabular}{|c|c|}
\hline Source & Materials \\
\hline $\begin{array}{l}\text { Evaporator/ } \\
\text { Incinerator } \\
\text { PDUs }\end{array}$ & $\begin{array}{l}\text { Incinerator } \\
\text { Solids }\end{array}$ \\
\hline $\begin{array}{l}\text { Biotreatment } \\
\text { Bench Units }\end{array}$ & $\begin{array}{l}\text { Biotreatment } \\
\text { Sludge }\end{array}$ \\
\hline
\end{tabular}

$\vec{\nabla} \quad \begin{aligned} & \text { Byproduct } \\ & \text { Recovery } \mathrm{Pi}- \\ & \text { lot Units } \\ & \text { SRC-II PP }\end{aligned}$

Upgrading

Pilot Units
Relation to DemonstrationFacility Materials and Configuration

All significant raw and treated demorelated sour-water streams not available from existing pilot and PDU facilities.

Biological treatment system not specified in Phase Zero design but is an option for the commercial facility.

All significant sour-water streams not currently from existing pilot plants and PDUs.

\section{BYPRODUCTS}

Ammonia and tar acid recovery systems to be finalized for detailed demonstration facility design.

Potential utilization in demonstration facility not similar to pilot plant, application not specifically defined.

\section{PRODUCTS}

Raw naphtha boiling ranges for SRC-II pilot plant and PDU variable with respect to demonstration facility (i.e., $\mathrm{C}_{5}-350^{\circ} \mathrm{F}$.

Hydrotreating levels typical of demonstration plant must be identified.

\section{Material} Availability

Incinerator testing studies must be $\mathrm{de}^{-}$ fined.

Bench unit test must be defined.

Studies must be defined.

4Q 1980 and later.

Hydrotreatment studies must be defined. 
TABLE 1. (continued)

Pre-Demonstration-Facility Testing Source

Materials

SRC-II PP

Middle/Heavy Distillate Blend

P99

Fuel $0 \mathrm{il}$

Boiler, Combustor, Turbine PDUs

Combustion Particulate and offgases

Hydrotreating Pilot

Units

Refinery Upgrading $\mathrm{Pi}$ lot Units
Relation to DemonstrationFacility Materials and Configuration

Blend based on pilot-plant product yields different from blend defined to achieve demonstration-facility liquid product specifications.

Consists of $400^{\circ} \mathrm{F}^{+}$boiling distillate representative of P99-produced product.

\section{END-USE MATERIALS}

Performance and environmental characteristics in end-use testing systems are satisfactory to date.

Performance of slurries, distillates and vacuum bottoms in a controlled combustor system (i.e., part of demonstrationfacility emergency flare system) needs to be identified.

Hydrotreating of product fuel oils not planned for demonstration facility.

Extensive use of demo-produced fuel oils as refinery feedstocks not planned, but to be investigated for potential end use of commercially produced materials.
Material Availability

Distillates available for blending $2 Q 1980$.

4Q 1980 and later.

Additional end-use testing studies must be defined.

Fuel-oil blend tested by UOP, 1979.

Further fuel-oil hydrotreating studies being investigated.

Fuel-oil upgrading studies being investigated. 


\section{PROCESS INTERMEDIATES}

Certain intermediate process materials can be obtained directly from operating SRC-II facilities. Coals representative of those slated for use in the demonstration facility can also be obtained. Coal slurry, recycle slurries, mineral residue slurry (i.e., vacuum bottoms) and raw naphtha can be obtained from both the SRC-II pilot plant and P99.

Intermediate hydrocarbon streams in the demonstration facility that lack direct pre-demonstration analogs include dissolver effluent, low- and highpressure hydrocarbons (i.e., three streams), effluent separator quench, recycle solvent, fractionator recycle (i.e., slurry pump seal flush), and lean and rich scrubber oils (i.e., for removal of hydrocarbons from recycle hydrogen). Although the chemical and physical nature of each stream is not precisely represented, raw naphtha, middle distillates and heavy distillates from the SRC-II pilot plant can represent the boiling range and chemical composition of these demonstration facility materials. Precise boiling-range fractions ${ }_{+}$(i.e., in $50^{\circ} \mathrm{F}$ increments) of raw naphtha and distillates prepared from $400^{\circ} \mathrm{F}^{+}$distillate from the $P 99$ can be characterized. These materials were prepared to evaluate chemical, physical and thermodynamic properties, and are currently available for biomedical and ecological testing.

Process waters analogous to SRC-II demonstration facility operations can be generated only to a limited extent. Although sour waters from coal liquefaction can be obtained from the SRC-II pilot plant and P99, they may not be representative of demonstration facility operations. Analogs of gasifier sour waters can be obtained from the Texaco pilot plant.

Materials from the SRC-II pilot plant may differ from demonstration facility streams for three reasons:

1. Dissolver configuration - Dimensional differences (i.e., diameter, length/diameter ratio) between pilot- and demonstrationfacility dissolver reactors may affect yields of specific coal-derived chemical components.

2. Vapor/liquid/slurry separation - Because the physical configuration and operation of pilot and demonstration facility systems differ, they may affect the compositions of both recycle slurry (and therefore, coal slurry) and process water.

3. Fractionation - Inefficiencies in operation of the pilot plant's vacuum flash system result in a portion of heavy distillate going to the vacuum bottoms. Typically, naphtha and distillate boiling ranges do not correspond exactly in pilot and demonstration facilities.

The differences listed above are important if they alter the chemical, biomedical or ecological properties of specific materials. Materials have been obtained from the SRC-II pilot plant during the first quarter of 1978 and the second quarter of 1980 . Additional materials generated using various coals at different process conditions will be available for characterization throughout demonstration facility construction. 
Differences between $P 99$ and demonstration-facility materials may also result from differences in separation and fractionation systems. In particular, use of mineral oil as the slurry pump seal flush affects coal slurry composition. Although the water quench system corresponds more closely with that for the demonstration facility, compositional differences may occur due to lack of specific wastewater streams (e.g., from fractionation, hydrodesulfurization). The fractionation system is 1 imited in that only two boiling-range fractions are separated (i.e., naphtha and $400^{\circ} \mathrm{F}$ boiling-range distillate). However, the vacuum flash system is sufficiently flexible to produce virtually any heavy distillate with an endpoint $<1000^{\circ} \mathrm{F}$. The $\mathrm{Pg} 9$ is generally suited for performing controlled studies to evaluate effects of coal type, reaction conditions, reactor configuration and distillate endpoint. Materials for environmental and health testing will be available from late 1980 through at least 1983. The $50^{\circ} \mathrm{F}$ boiling-range fractions of $400^{\circ} \mathrm{F}$ distillate are currently available from the Harmarville, PA facility.

Process waters, produced during gasification of vacuum bottoms derived from Powhatan No. 5 coal (i.e., produced from the SRC-II pilot plant) in the Texaco gasifier, were recently characterized by Hydroscience, Inc. The proprietary nature of the Texaco process precludes discussion of the pilot-plant samples ${ }^{1}$ relevance. Specific plans for further testing of vacuum bottoms in the Texaco gasifier have not been defined.

\section{ENVIRONMENTAL CONTROL SYSTEM MATERIALS}

By-product recovery systems, including ammonia and tar acid recovery from liquefaction process waters and elemental sulfur from acid gases, are sources of environmental control system materials. In general, materials include treated process waters and absorption solutions for which pre-demonstrationscale analogs can be identified. Environmental issues include not only system performance, but removal and/or buildup of trace contaminants (i.e., metals, organics, inorganics) from coal-liquefaction-derived acid gases and wastewaters. In the cases of physical/chemical treatment, completely analogous effluent, evaporator distillate, oil wash and acid gas recovery solutions are difficult, if not impossible, to obtain. If a Stretford system is specified for sulfur recovery, an analogous system is currently in operation at the SRC-II pilot plant.

Relevance of these materials depends on availability of process waters for treating and the definition of specific treatment methods for the demonstration facility. Typically, not all major contributing process streams are available for integrated treatment system testing (i.e., byproduct recovery, physical/chemical separation, evaporation). However, selected process wastewaters are available from the SRC-II pilot plant, P99, and the Texaco gasifier for treatment in relevant demonstration facility systems. Process wastewater should be available from late 1980 through demonstration facility construction.

Treatment methods to be defined during detailed demonstration facility design include byproduct recovery systems and specific wastewater treatment schemes. Although Chem Pro and Phosam $W$ were specified in the conceptual design, final choice of the specific process has not been made. Selexol is being considered as an alternative to the Benfield system for acid gas recovery in hydrogen production. Biological treatment, which was not included 
in the conceptual design, is now being considered in the detailed design. Bench-scale test units are available for performing these studies. Testing of evaporation systems will be necessary when specific input waste waters have been defined. Materials for biomedical and ecological testing will probably be available between 1981 and 1983, and will depend on choice of treatment.

\section{Flare And Controlled Combustion}

The demonstration facility flare system is of particular interest from a biomedical and ecological standpoint. A reliable flare system must be available to insure complete combustion of complex, coal-derived hydrocarbons (i.e., gaseous, liquid and slurry streams), and to minimize potential emergency releases. Since a controlled combustor system is specified for the demonstration facility, the performance characteristics of the full range of coal-derived materials (i.e., naphtha, distillates, slurries) must be identified. This may be particularly important in the case of the combustion of slurries containing significant levels of solids. Conventional and trace pollutant emissions from these systems must be quantified. Combustor systems are available for testing, and studies must be defined.

\section{SOLID WASTES}

The major solid waste expected from the demonstration facility (i.e., $98^{+}$ percent of the total) is slag from gasification of mineral residue slurry. This material has been obtained from the Texaco pilot plant on two occasions: 1) during the first quarter of 1978 from gasification of Kentucky No. 9/14 coal-derived vacuum bottoms, and 2) during the first quarter of 1980 from gasification of Powhatan No. 5 coal-derived vacuum bottoms. Extensive leach testing has been performed by ORNL on the former materials. Results suggested the material is nontoxic according to Resource Conservation and Recovery Act (RCRA) criteria. If true, and results are similar for the Powhatan coalderived slag, waste disposal could be substantially simplified. However, additional biomedical and ecological testing is still necessary, and can commence as soon as proprietary rights agreements are executed with Texaco Development Corporation.

Solids are generated during incineration of wastewater treatment sludges and evaporator brines, and may also be generated during potential biological treatment. Evaporator/incinerator and biological treatment system testing is not currently scheduled. Representative wastewater streams and detailed design bases for the demonstration facility are needed to design treatment studies for generation of relevant solid-waste materials (i.e., inorganic salts and/or biological treatment sludge). Toxic properties of solid wastes slated for disposal must be identified prior to demonstration facility operation.

\section{BY-PRODUCTS}

Pre-demonstration-scale analogs of ammonia and tar acid byproducts are not currently available. Definition of specific systems will occur during the early stages of detailed design. The demonstration facility's sulfur recovery 
system may be changed from Claus to Stretford. If so, elemental sulfur will be available for testing from the SRC-II pilot plant.

\section{PRODUCTS}

Distillate fuel oils and raw naphtha can be obtained for biomedical and ecological testing. Light and heavy fuel-oil analogs include middle and heavy distillates, respectively, from the SRC-II pilot plant. These materials were obtained in the first quarter of 1978 for biomedical and ecological screening studies. More-representative materials (i.e., coal feedstock and pilot-plant process conditions) were obtained in the first quarter of 1980 and are being analyzed. The relevance of these materials hinges on whether they correspond with final demonstration-facility material specifications (e.g., boiling-point ranges), particularly in the case of heavy distillate, where pilot-plant material is limited to a maximum endpoint of $\sim 850^{\circ} \mathrm{F}$.

A full-boiling-point-range fuel oil can be synthesized by blending middle and heavy distillates from available SRC-II pilot plant materials. The blending ratio for this fuel $0 i 1$ must be specified, but is likely to be based on weighted boiling-range specifications for demonstration-facility fuel oil. Additional quantities of product distillates should be available from late 1980 through demonstration facility construction.

The Pgg facility is particularly suited for generating SRC-II materials. Although the unit currently produces only $400^{\circ} \mathrm{F}^{-}$and $400^{\circ} \mathrm{F}$ distillates, future modifications may enable generation of middle- and heavy-boiling-range fractions. Product materials should be available from the P9g from late 1980 through 1983.

Raw naphtha from the SRC-II pilot plant was obtained during the first quarters of 1978 and 1980 for biomedical and ecological testing. Further characterization must be performed on a relevant product material that has been hydrodesulfurized. Hydrotreatment studies must still be defined, at levels expected for the demonstration facility, before product naphtha characterization can begin.

Major options in the demonstration-facility design may significantly affect the final product slate. Options hinge on the precise utilization and specifications of mineral residue slurry for hydrogen production. Naphtha, synthesis gas and liquefied propane/butanes are all potential plant fuels, and availability of synthesis gas is crucial to their eventual utilization. Lowering the endpoint on heavy fuel oil (e.g., from 900 to $850^{\circ} \mathrm{F}$ ) decreases fuel oil product and provides an additional increment of mineral residue slurry for gasification. This would result in availability of more synthesis gas for plant fuel and/or methanation (and thereby enable marketing of additional naphtha product), and may have significant impact on the chemical and biological properties of heavy and full-boiling range fuel oil products. The fuel balance, and ultimately the final product slate, are currently being optimized for the detailed demonstration-facility design. 


\section{END-USE MATERIALS}

The primary end use for demonstration facility fuel oils is in electric utility applications. Results to date indicate satisfactory performance, both operationally and environmentally, for conventionally regulated pollutants (i.e., $\mathrm{SO}_{2}$, $\mathrm{NO}_{x}, \mathrm{CO}$, particulate, and volatile hydrocarbons). Various applications (e.g., package boilers, fired-tube boilers, turbines) have been investigated, in addition to studies of novel burner configurations to mitigate environmental emissions. Due to differences between petroleum- and coal-derived distillate fuels, characteristics of trace contaminant emissions need to be identified (i.e., gaseous and particulate-borne trace metals and heavy hydrocarbons). End-use testing facilities are available for characterization, and studies must be defined. Distillates from the SRC-II pilot plant can be obtained from late 1980 through demonstration facility construction.

Alternative end uses for SRC-II products are as refinery feedstocks. Demonstration-facility naphtha product is already being considered for use as a feedstock for catalytic reforming. Although more applicable to the SRC-II commercial facility, fuel oils (properly hydrotreated) could be used as feedstocks for refinery processes such as hydrocracking and fluidized bed catalytic cracking. Previous studies conducted by Universal 0il Products (UOP), Chevron and the Bartlesville Energy Technology Center (BETC) during 1978 and 1979 on various distillates from the SRC-II pilot plant showed that these materials could be treated (although under more severe conditions than petroleum-

derived distillates). Limited screening studies by BETC and PNL suggest that a reduction in biological activity of these coal-derived distillates is possible. 


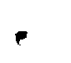


The SRC-II Study Plan will be performed in four phases which chronologically overlap. Phase I research (screening) will evaluate materials from existing SRC-II facilities (bench, PDU, pilot) which may bracket potential demonstration or commercial practice in terms of physical and chemical properties. These materials will be subjected to a battery of short-term biomedical and ecological assays. Chemical fractionation and analys is will be performed to determine compounds and compound classes of potential concern. In some cases, chemical fractionation is required to provide materials amenable to biomedical and ecological testing. Phase I research provides a first estimate for potential environmental properties of SRC-II materials, thereby:

- setting research priorities for Phase II, which involves longer-term, more-extensive bioassays and chemical analyses of environmental fate;

- providing initial data on materials that may require ameliorative action during process development;

- providing a first, qualitative analysis for assessing environmental risk anticipated from utilization of the SRC-II process.

Phase II research (baseline) will evaluate SRC-II materials which are considered most representative of potential demonstration or commercial practice. These materials will be subjected to longer-term, more-extensive biomedical and ecological analyses relative to effects and environmental fate. Again, chemical fractionation and analyses will: 1) provide materials amenable to bioassay, and 2) determine compounds and compound classes of concern. Results from this research phase will provide:

- a reasonable estimate of the materials of concern which may require regulation;

- correlation analyses between short-term, inexpensive, in vitro and selected in vivo assays (Phase I) and longer-term, more-expensive, in vivo assays and ecological studies (Phase II);

- a basis for development of control technologies and management procedures which may reduce environmental risk;

- a second and more quantitative assessment of potential environmental risk.

Phase III research will examine the influence of process modifications, control technologies and changing operational conditions on potential environmental effects of SRC-II materials. Short-term biomedical and ecological analyses (Phase I) which correlate with longer-term analyses (Phase II) will be used in Phase III. Integrated chemical fractionation and analysis methods (as indicated in Phase I), will be used to determine compounds and compound classes of environmental concern. Data from Phase III will provide: 
- a basis for determining effectiveness of control technology, process modification, etc. relative to decreasing potential environmental effect;

- a third analysis of environmental risk to consider effects of altered plant operations.

Phase IV research (onsite monitoring) will develop methods and initiate environmental monitoring to study effects at the SRC-II demonstration and commercial facility sites. Data from Phases I, II and III may provide indicators of biomedical and ecological effects, and a basis for assays for potentially harmful chemical entities which should be monitored in the workplace (i.e., by (P\&M) and local environment. Phase IV research efforts will include intensive studies of environmental fate and transport of SRC-II materials. Data from demonstration facility monitoring should allow:

- development of more-effective environmental management procedures, for waste disposal and industrial hygiene, at demonstration and commercial SRC-II facilities;

- quantitative environmental risk assessment more appropriate to a commercial SRC-II process.

The chronological overlap of research phases is due to a number of factors. Materials (products, wastes, etc.) of potential biomedical and ecological concern may be available in forms considered most representative of potential demonstration or commercial practice in Phase I. This would allow concurrent Phase I and II analyses. Certain materials (i.e., process waters) may not be available in forms considered appropriate for screening until Phase II, which would change the timing of all phases of research on these materials. Little is known about compounds and compound types potentially responsible for specific biomedical or ecological effects. Therefore, Phase IV monitoring will include sample collection, archiving, and later analys is for specific compounds and compound classes shown in Phases I, II and III to cause significant biomedical or ecological effects. Sample collection will be concurrent with Phase I efforts. Finally, method development may be necessary before comprehensive studies can be initiated (e.g., for Phase II bioaccumulation, multispecies, and fate and transport studies.

Work will proceed as follows. Materials representing the range of materials that may be produced by demonstration or commercial facilities will be analyzed in Phase I. Tentative identification will be made of compounds and compound classes of concern, and appropriate laboratory studies on bioaccumulation and environmental fate and transport of these agents will be initiated early in Phase II. As materials considered most representative become available, Phase II biomedical and ecological analyses will begin, and results from Phase I and II assays will be correlated. This should result in a battery of inexpensive, quick assays which can be used in Phase III to evaluate effects of process modification and control technology applications. Data from all phases will be used in designing appropriate site-monitoring methods to determine levels of compounds and compound classes known or suspected to cause biomedical or ecological effect. The data will also be used, in Phase IV studies, as a basis for determining whether biomedical or ecological effects may result from demonstration facility operations. 
Sampling of coal liquefaction materials involves three operations: collection, storage, and distribution. Collection is engineering-dependent. As processes change, or modifications are made to the facility, collection points and the selection of materials to be collected will change. Current emphasis is on collecting materials from processes operating under conditions representative of those anticipated for the demonstration facility. The section entitled, "SRC-II Process" (pp. 9-23) describes engineering strategies for obtaining representative samples for Phases I and II. A general description of materials which might be assayed in Phase III is also provided. Potential time-lines for sampling are shown in the section on Cost and Time-Lines.

Samples that must be stored for current and subsequent investigation will be limited primarily to those: a) for which long-term characterization may be required, b) which will be used in extensive biological or ecological testing, or c) which are representative of well-defined process conditions and, as such, can be utilized to develop a data base that relates to a series of process variables. Storage facilities must be adequate to maintain sample integrity. Large quantities of selected materials must be maintained for biomedical and ecological testing, and chemically analyzed throughout the study to eliminate a potential source of interpretive error.

Distribution requires cataloguing and control of source materials to assure that their location and use is documented. Samples collected from an SRC facility will be distributed to authorized investigators at PNL, or at the laboratories of subcontractors included in the program. Additional distribution or use of PNL-catalogued materials will be at the request of DOE through the appropriate ASEV and ASFE program offices. Administrative control will include maintenance of records concerning sample availability, sample distribution, status of work being done, and names and locations of the responsible investigators.

\section{SAMPLE COLLECTION}

Sample collection will be limited to materials (products, process streams, solid and liquid wastes, fugitive emissions) which are representative of anticipated demonstration facility operating conditions. Selection of appropriate samples will be made by PNL in concert with ERT, P\&M, and Gulf Mineral Resources Co. SRC-II materials selected for biomedical and ecological investigations are shown in Table 2.

Sample collection, usually in containers provided by PNL, will be performed by P\&M and witnessed by appropriate PNL personnel. In general, projected sample use dictates collection procedures. Liquid samples for chemical characterization of organic constituents or Phase II biomedical testing are collected either in 1-gallon glass bottles with teflon-lined caps or in 6- or 15-gallon, teflon-lined, stainless steel drums. Larger samples for long-term ecological investigations are collected either in multiple 15-gallon, teflonlined, stainless steel drums or in 55-gallon, polymer-coated steel drums (provided by P\&M). Small-volume samples are returned immediately to PNL and, after cooling, are blanketed with $\mathrm{N}_{2}$ in the headspace above the liquid. 
TABLE 2. SRC-II Materials for Biomedical and Ecological Investigations

\author{
LIQUIDS \\ Raw Naphtha \\ Hydrodesulfurized Naphtha \\ Middle Distillate \\ Heavy Distillate \\ SRC-II Liquid Products \\ Process Feed Water \\ Process Water \\ Treated Effluent Water
}

SOLIDS

\author{
Coal Slurry \\ Raw Sulfur \\ Stripper Tower Bottoms \\ Vacuum Bottoms \\ Gasifier Slag, coarse \\ Gasifier Slag, fine \\ Wastewater Incinerator Solids
}

Large-volume (55-gal) samples are generally stored on-site at the pilot plant prior to shipment to PNL. These samples are also blanketed with $\mathrm{N}_{2}$ after cooling and prior to shipment. Samples taken primarily for inorganic analysis are collected in perfluoroethylene (PFE), 1-liter bottles.

Samples of solid materials are generally collected in metal, slip-top cans (sizes vary from 1 quart to 5 gallons, depending on end use). If these samples are to be analyzed for metal content, they are collected in plasticlined metal containers. Solid samples for chemical characterization will be collected in $5-\mathrm{kg}$ blended lots. For biological and ecological testing that requires leaching studies, samples will be collected in 50-gallon, plasticlined, steel or fiber drums. 
Currently, we do not plan to collect air or aerosol samples. If future research requires collection of gaseous materials, procedures will be as follows: Vent gases would be collected, generally as grab samples, in PFE-lined, stainless steel gas bottles. Ambient plant vapors would be collected on polymeric adsorption traps (TENAX and XAD-2, or XE-347, depending on results of laboratory studies which would be performed if vapor sampling is contemplated), or charcoal. Ambient particulate samples would be collected on clean glassfiber filters using HIVOL techniques. Data from HIVOL cascade impactors would give size distribution of collected particles and provide total particulate concentration in a given gas volume. If metal speciation experiments on vent gases are needed, adsorbent traps, specific for the metal species of interest, would be used for collection. Generally, vent gas and ambient gas samples would be collected primarily for chemical characterization studies. However, ambient-air samples might be taken from areas around the pilot plant where workers may be exposed to fugitive emissions or to emissions generated during certain in-plant operations; for example, fumes emanating from certain maintenance operations and cleanup procedures. These efforts may aid development of improved site and personnel monitors for compounds and compound classes of biomedical concern.

\section{SAMPLE STORAGE AND QUALITY CONTROL}

PNL-acquired samples are generally stored at $4^{\circ} \mathrm{C}$ until all studies are completed. Liquid samples are stored under $\mathrm{N}_{2}$. Large-quantity liquid samples ( 6 gallons or more) are thoroughly mixed and are subsampled immediately after receipt to provide a $250-\mathrm{ml}$ al iquot that is used to monitor sample stability during storage. Large-volume samples are also thoroughly mixed prior to any subsequent subsampling. The sample handling protocol and analysis procedures to evaluate sample stability are given in Table 3 . Basically, the procedure consists of periodic analyses to determine gross changes in chemical composition or physical properties. Changes in of minor or trace constituents will not be detected. However, the analyses do provide an adequate, general, chemical characterization and a data base for comparison, should a re-examination of materials distributed for biomedical or ecological studies be necessary.

\section{DATATRIEVE - DATA MANAGEMENT SYSTEM}

A computerized data management system (DATATRIEVE) on the PNL Biometrics Computer Center's PDP $11 / 70$ has been designed to record and monitor location and use of materials received and distributed to the chemistry, biology, and ecology research programs. The system utilizes a set of interactive DATATRIEVE procedures to store information as it becomes available and to generate reports as required.

The system is centered around codes which identify materials and tests; each material or combination of materials is identified by a unique MATERIAL CODE; each test is identified by a unique TEST CODE. The codes are used by DATATRIEVE to store and retrieve the status of a test, or to procure an audit trail for each material.

Two files, labeled TEST CODE DICTIONARY and SOURCE MATERIAL CODE DICTION$A R Y$, have been established so that investigators may cross-reference codes 
TABLE 3. Protocol for Analyses to Observe Stability of Research Materials During Storage

1. Receive sample in teflon-lined, stainless-steel barrel.

2. Mix thoroughly and subsample $500 \mathrm{ml}$ into a brown glass bottle with a teflon-lined cap (alternate: teflon-lined, stainless steel bottle). Blanket stock sample and subsamples with $\mathrm{N}_{2}$.

3. Store both samples under identical conditions in chilled facility at approximately $4^{\circ} \mathrm{C}$.

4. Perform initial and intermittent long-term characterizations on small subsamples.

5. Analyses will include:
a. density,
b. boiling point curve,
c. capillary column gas chromatography; SE-52; splitless injection; flame ionization detection (FID); initial temperature, $35^{\circ} \mathrm{C}$. Quan- tify major peaks.
d. high-performance liquid chromatography (HPLC) separation, ternary gradient on $\mathrm{NH}_{2}$ column or binary gradient on $\mathrm{C}-18$ column. Quantify major peaks.
e. molecular weight distribution by HPLC on steric exclusion column. Quantify distribution pattern.

6. These analyses will be performed on each material semiannually for 1 year and annually thereafter.

7. At each major sampling of material (for ecological, biological or chemical research) from the large reservoir, these same characterizations will be performed, unless these analyses have been completed within the previous 6 months.

8. A data file will be maintained and updated for each research material in the inventory. 
with their English equivalents. Table 4 is a partial list of material codes and their English equivalents, contained in the SOURCE MATERIAL CODE DICTIONARY. Table 5 is a partial 1 ist of test codes and their English equivalents, contained in the TEST CODE DICTIONARY.

The SOURCE MATERIAL AUDIT FILE contains a record of transactions on each material or material combination. Each record contains, as a minimum, the material code, material accession number, and date the material was sampled. The material accession number, consisting of the log book and page number, refers to the chemistry ledger, where additional information may be found. The accession number also includes a batch number that has been assigned to distinguish different samples of the same material type. When a material is received from off-site, the date of receipt and a transaction remark, indicating the amount received and the current amount of material in storage, is also recorded. When a material is assigned for biological or ecological study, the following information is recorded: date of assignment, initials of the investigator assigned the material, the number of the investigator's log book where additional information can be found, and a transaction remark that indicates the amount assigned and the total amount currently in storage. Table 6 is a sample audit report (for one material), which can be generated at any time.

The TEST STATUS FILE contains the status of each test on each material. Test status is identified by test code, material code, material accession number, investigator's initials, proposed test start date, actual start date, completion date and the log book containing test results. Investigators are required to provide information on a quarterly basis. The TEST STATUS FILE can be updated at any time to reflect the current test status. Reports can be generated in two ways:

1) for each test category, to identify the status of individual tests on all materials; and

2) for each test material, to identify the status of all tests applied to that material.

Tables 7 and 8 are examples of the two types of reports that may be generated. 
TABLE 4. A Partial List of Source Materials and Their English Equivalents

\begin{tabular}{|c|c|}
\hline MATERIAL CODE & MATERIAL NAME \\
\hline II - AP & II-Ambient Particulates \\
\hline II-AV & II-Ambient Vapors \\
\hline I I-CS & II-Coal Slurry \\
\hline II-FO & II-Fuel $0 i 1$ \\
\hline II $-F O A$ & II-Fuel 0 il Acid \\
\hline II-FOAT & II-Fuel 0 il Acid Tar \\
\hline II-FOB & II-Fuel 0il Basic \\
\hline II-FOBT & II-Fuel oil Basic Tar \\
\hline II-FON & II-Fuel 0 il Neutral \\
\hline I I-FONT & II-Fuel 0il Neutral Tar \\
\hline II-FOB & II-Fuel 0il PNA \\
\hline II-GB & II-Gasifier Bottoms \\
\hline I I - GFA & II-Gasifier Fly Ash \\
\hline I I-HD & II-Heavy Distillate \\
\hline II-IS & II-Incinerator Solids \\
\hline II-MD & II-Middle Distillate \\
\hline I I $-\mathrm{N}$ & I I-Naphtha \\
\hline II-STB & II-Stripper Tower Bottoms \\
\hline II-VB & II-Vacuum Bottoms \\
\hline
\end{tabular}


TABLE 5. A Partial List of Test Codes and Their English Equivalents. (This list represents only some of the major test categories.)

TEST CODE

TEST NAME

B1

Cellular Studies

$B 1 A$

Microbial Mutagenesis (Ames' Assay)

$B 1 B$

Mammalian Cell Toxicity and Transformation

B1C

Mutagenic Studies in Chinese Hamster Cells

BID

Yeast Mutagenesis

B1E

Unscheduled DNA Synthesis

$B 1 F$

Chromosomal Abnormalities

B2

Oral Studies

$B 2 A$

Acute Toxicity

C1

Initial Chemical Characterization

CIA

Inorganic Element Analysis

$C 1 B$

Speciation Measurements

C1C

Solid Waste Aqueous Leaching

CID

Extraction of Solid Wastes with Solvents

CIE

Simulation Diagenesis Investigations

CIF

Initial Organic Analysis

C2

Organic Class Fractionation and Bio/Eco Assay

C2A

$\mathrm{C} 2 \mathrm{~B}$

Fractionation

E1

Identification of Biologically Active Agents

EIA

Liquids

$E 1 B$

Acute Screening

Chronic Screening

EIC

System Level Screening

EID

Field Validation

E2

Solids

$E 2 A$

Field Lysimeters

$\mathrm{E} 2 \mathrm{~B}$

Comparative RCRA Bioassay

E2C

SRC-I Solid Product Spills

E2D

Residual Fate and Behavior 
TABLE 6. Sample Source Material Audit Report for One Material

\begin{tabular}{|c|c|c|c|c|c|c|c|}
\hline $\begin{array}{l}\text { MATL } \\
\text { CODE }\end{array}$ & $\begin{array}{c}\text { MATL } \\
\text { ACCESSION } \\
\end{array}$ & $\begin{array}{c}\text { DATE } \\
\text { SAMPLED } \\
\end{array}$ & $\begin{array}{l}\text { TRANSACTION } \\
\text { DATE } \\
\end{array}$ & $\begin{array}{l}\text { INV } \\
\text { INIT } \\
\end{array}$ & $\begin{array}{c}\text { TEST } \\
\text { CATEGORY } \\
\end{array}$ & $\begin{array}{c}\text { INV LOG } \\
\text { BOOK }\end{array}$ & TRANSACTION REMARK \\
\hline \multirow[t]{4}{*}{ II-F0 } & 145300100 & 781112 & 781212 & & & & $\begin{array}{l}4.0 \mathrm{~L} \text { received by stores } \\
4.0 \mathrm{~L} \text { total in storage }\end{array}$ \\
\hline & 145300101 & 781112 & 790101 & $x x x$ & $1 \mathrm{~A}$ & 3333 & $\begin{array}{l}1.2 \mathrm{~L} \text { given to } \mathrm{XXX} / \mathrm{BI} 0 \text {, } \\
2.8 \mathrm{~L} \text { total in storage }\end{array}$ \\
\hline & 145300102 & 781112 & 790223 & $x x x$ & $2 \mathrm{~B}$ & 2555 & $\begin{array}{l}1.5 \text { given to } X X X / E C 0, \\
1.3 \text { L total in storage }\end{array}$ \\
\hline & 145300102 & 781112 & 790301 & $x x x$ & $2 A, 2 B$ & 3529 & $\begin{array}{l}1.0 \mathrm{~L} \text { given to } X X X / E C 0, \\
0.3 \mathrm{~L} \text { total in storage }\end{array}$ \\
\hline
\end{tabular}

NOTE: The report above illustrates only format. 
TABLE 7. Test Status Report Arranged by Test Category to Identify the Status of Individual Tests on all Materials

\begin{tabular}{|c|c|c|c|c|c|c|c|c|}
\hline$\underline{D E P T}$ & TEST & $\begin{array}{l}\text { MATL } \\
\text { CODE }\end{array}$ & $\begin{array}{c}\text { MATL } \\
\text { ACCESSION } \\
\end{array}$ & $\begin{array}{l}\text { INV } \\
\text { INIT } \\
\end{array}$ & $\begin{array}{l}\text { PROPOSED } \\
\text { DATE } \\
\end{array}$ & $\begin{array}{l}\text { START } \\
\text { DATE } \\
\end{array}$ & $\begin{array}{l}\text { FINISH } \\
\text { DATE } \\
\end{array}$ & LOG BOOK \\
\hline \multirow[t]{6}{*}{ B } & $1 \mathrm{~A}$ & $I-M R$ & 145303200 & $X X X$ & 790101 & 790201 & 790210 & 2341 \\
\hline & & $I-S$ & 123512301 & $x x x$ & 790915 & & & 2450 \\
\hline & & $I-W S$ & 134201112 & $x x x$ & 790520 & 790525 & Canc. & 2341 \\
\hline & & I I-MD & 342300101 & $x x x$ & 790701 & 790701 & & 2351 \\
\hline & $4 A$ & I I-HD & 134212900 & $x X X$ & 790801 & & & 2351 \\
\hline & & I I-MD & 342300102 & $x x x$ & 790901 & & & 2351 \\
\hline
\end{tabular}

NOTE: The report above illustrates only format.

TABLE 8. Test Status Report Arranged by Test Material to Identify the Status of all Tests Applied to that Material

\begin{tabular}{|c|c|c|c|c|c|c|c|c|}
\hline DEPT & TEST & $\begin{array}{l}\text { CODE } \\
\text { MATL } \\
\end{array}$ & $\begin{array}{c}\text { MATL } \\
\text { ACCESSION } \\
\end{array}$ & $\begin{array}{l}\text { INV } \\
\text { INIT } \\
\end{array}$ & $\begin{array}{l}\text { PROPOSED } \\
\text { DATE } \\
\end{array}$ & $\begin{array}{l}\text { START } \\
\text { DATE } \\
\end{array}$ & $\begin{array}{l}\text { FINISH } \\
\text { DATE } \\
\end{array}$ & $\underline{\text { LOG BOOK }}$ \\
\hline \multirow[t]{6}{*}{ B } & $1 \mathrm{~A}$ & I-MR & 145303200 & $x x x$ & 790101 & 790201 & & 2341 \\
\hline & $1 \mathrm{~A}$ & $I-S$ & 123512301 & $x X X$ & 790915 & & & 2450 \\
\hline & $1 \mathrm{~A}$ & I-WS & 234201112 & $x x x$ & 790520 & 790525 & Canc. & 2341 \\
\hline & $1 \mathrm{~A}$ & I I-HD & 134212900 & $x x x$ & 790801 & & & 2351 \\
\hline & $1 \mathrm{~A}$ & $\mathrm{II}-\mathrm{HD}$ & 342300101 & $x X X$ & 790701 & 790701 & & 2351 \\
\hline & $4 A$ & & 342400102 & $x x x$ & 790901 & & & 2351 \\
\hline
\end{tabular}

NOTE: The report above illustrates only format. 



\section{PHASE I}

The following sections describe short-term studies which utilize a battery of submammalian and mammalian cell in vitro assays for genotoxicants and acute and chronic toxicity assays for potential ecological effects. The sections also describe chemical methods of fractionation and extraction used to provide samples for in vitro bioassays and ecological studies, and methods for determining compounds and compound classes causing effects. This section is divided into:

$$
\begin{aligned}
& \text { - studies on liquid process streams and products, } \\
& \text { - studies on solid process streams and effluents, and } \\
& \text { - studies on process waters. }
\end{aligned}
$$

Short-term assays and accompanying chemical analyses provide a first and approximate estimate for the genotoxic and ecological effects of SRC-II materials. As such, they will be used as one criterion to select materials for longer-term animal bioassays and ecosystem studies to be performed in Phase II. A range of assays will be employed since it is possible and, indeed, probable that no single assay will correlate with results from Phase II animal bioassays or ecosystem studies. Because of their relative speed and low cost, in vitro assays and acute and chronic ecological assays are the likely methods for correlating genotoxic and ecological effects with specific chemical compounds and compound classes in SRC-II materials. Correlation is of vital importance: Phase I tests which correlate with Phase II tests will be the methods of choice for determining effects of SRC-II process and control technology changes on biomedical and ecological properties of SRC-II materials (studies to be performed in Phase III). Results of these tests and accompanying chemical analyses may also be the basis for determining specific compounds and compound classes which should be monitored during SRC-II facility operations (studies to be performed in Phase IV). Phase I studies will also provide the first data base for assessment.

\section{BIOMEDICAL STUDIES AND CHEMISTRY}

Before detailed discussion of biomedical assays and accompanying chemical analyses, we will discuss sample preparation, chemical fractionation and analyses for a given material (Figure 4).

Liquid materials or extracts/solutions prepared from solid materials or aqueous wastes will be analyzed by a battery of in vitro assays with different genetic endpoints (e.g., Ames mutagenesis). Concurrent bioassays will be performed on unfractionated materials and materials fractionated by highperformance liquid chromatography (HPLC). Negative results for unfractionated material and HPLC fractions (normally, six fractions of different polarity will be analyzed) will be considered indicative of no genotoxicity and no further analyses will be performed.

A positive response in unfractionated material or HPLC fractions will be considered evidence for genotoxicity of the material in that assay system. 


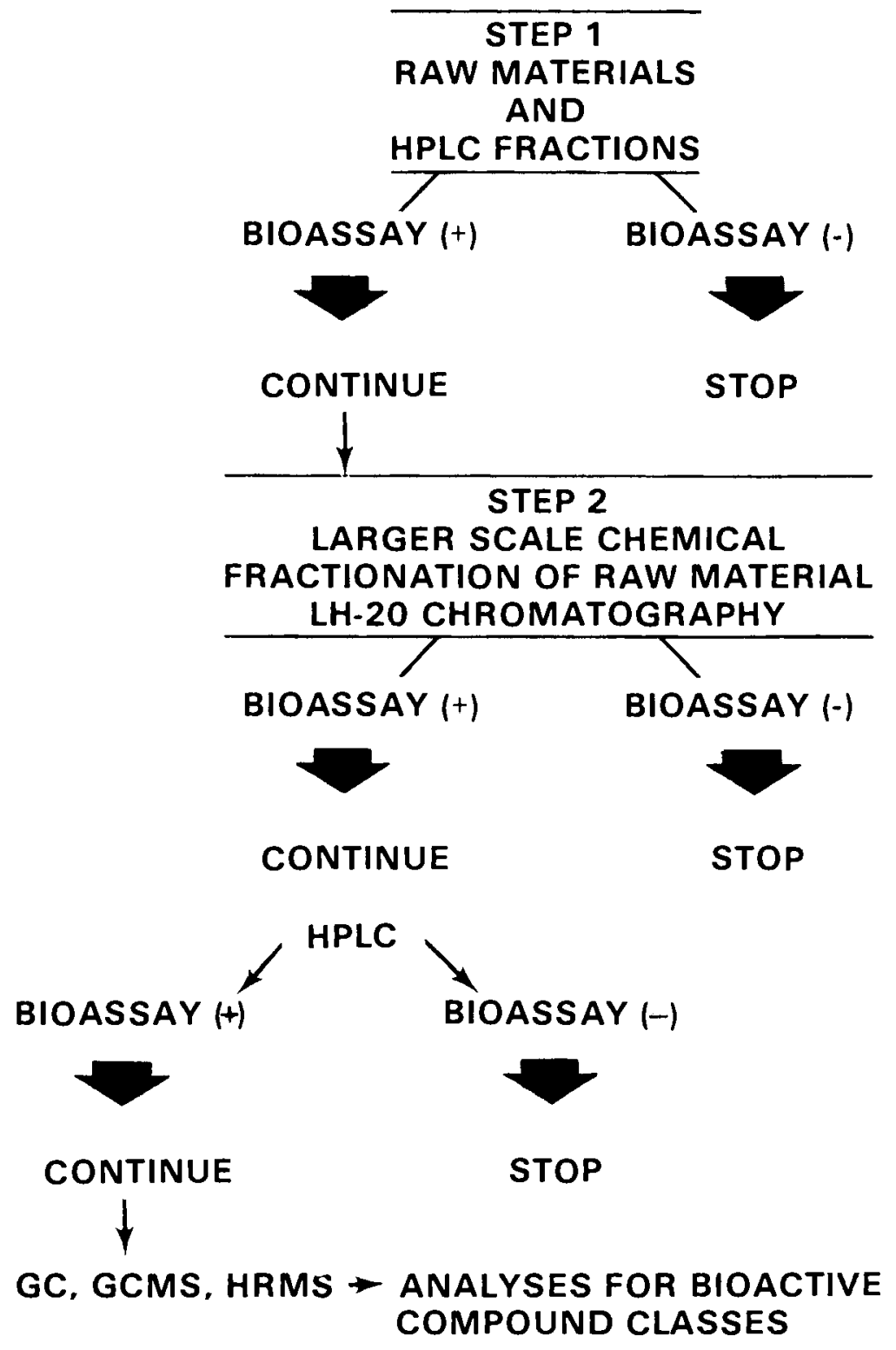

Figure 4. Flow Chart for Phase I In Vitro Assay: Chemical Fractionation and Characterization 
The material will then be subjected to LH-20 chromatography to provide sufficient concentrated bioactive material for in vitro assays and chemical analyses. Subfractions from LH-20 chromatography showing genotoxicity will be further fractionated by HPLC. These samples will be analyzed by in vitro assay, and fractions showing mutagenic activity will be subjected to chemical analyses. Gas chromatography (GC) and/or gas chromatography-mass spectrometry (GCMS) will be used to aid identification of specifically genotoxic compounds and compound classes. High-molecular-weight or highly polar subfractions which cannot be assayed by GC will be analyzed by high-resolution mass spectrometry (HRMS), or by HPLC, to determine compounds potentially responsible for genotoxicity. In some cases, contingent on experimental difficulties and conditions, alternative fractionation methods and chemical analyses will be used.

\section{In Vitro Assay for Liquid Process Streams and Products}

Based on present design considerations, the liquid process streams (raw naphtha, middle distillate and heavy distillate, as provided by the $\mathrm{Ft}$. Lewis pilot plant) and derived fractions will be analyzed by in vitro assay and integrated chemistry. Potential SRC-II liquid product mixtures, and hydrodesulfurized naphtha will also be analyzed. Analyses to be performed on these materials and derived fractions are shown in Table 9.

\section{Ames Assay}

The Ames microbial assay uses strains of Salmonella possessing genetically defined mutations in a gene for biosynthesis of the amino acid, histidine (they require this for growth). Ames strains used include: Salmonella typhimurium TA98 and TA1538 (frameshift mutants); TA100 (an R-factor-containing point mutant that responds to both point- and frameshift mutagens); and TA1535 (responds only to point mutagens). Ease of use, speed, low cost, requirement for small amounts of test material, and high correlation (at present, > 0.90 ) with carcinogenicity in the case of pure compounds make this a desirable and useful test for screening a large number of materials. The assay is performed by mixing test material with the organism in the presence or absence of mammalian liver microsomal ( 59 ) enzymes and determining the number of organisms which revert from dependency on histidine in the medium to nondependency, a mutational event. Assay in the presence of $S 9$ detects mutagens which require metabolic activation. Assay in the absence of $\$ 9$ detects mutagens which do not require metabolic activation. Ames assays can be performed on raw SRC-II liquids.

Examples of data obtained with a number of crude materials are shown in Table 10. Of the three major materials from the SRC-II process, heavy distillate ([HD] high-boiling-range material) is the most mutagenically active. Light and middle distillates showed no detectable mutagenic activity. The known chemical carcinogen, benzo[a]pyrene (BaP), showed about three times the activity of heavy distillate, while another well-known chemical carcinogen, 2-aminoanthracene (2-AA), was about 100 times as active. Raw shale oil showed some activity, but crude petroleum showed no activity in the Ames system. 
TABLE 9. Phase I In Vitro Assays: Liquid Materials

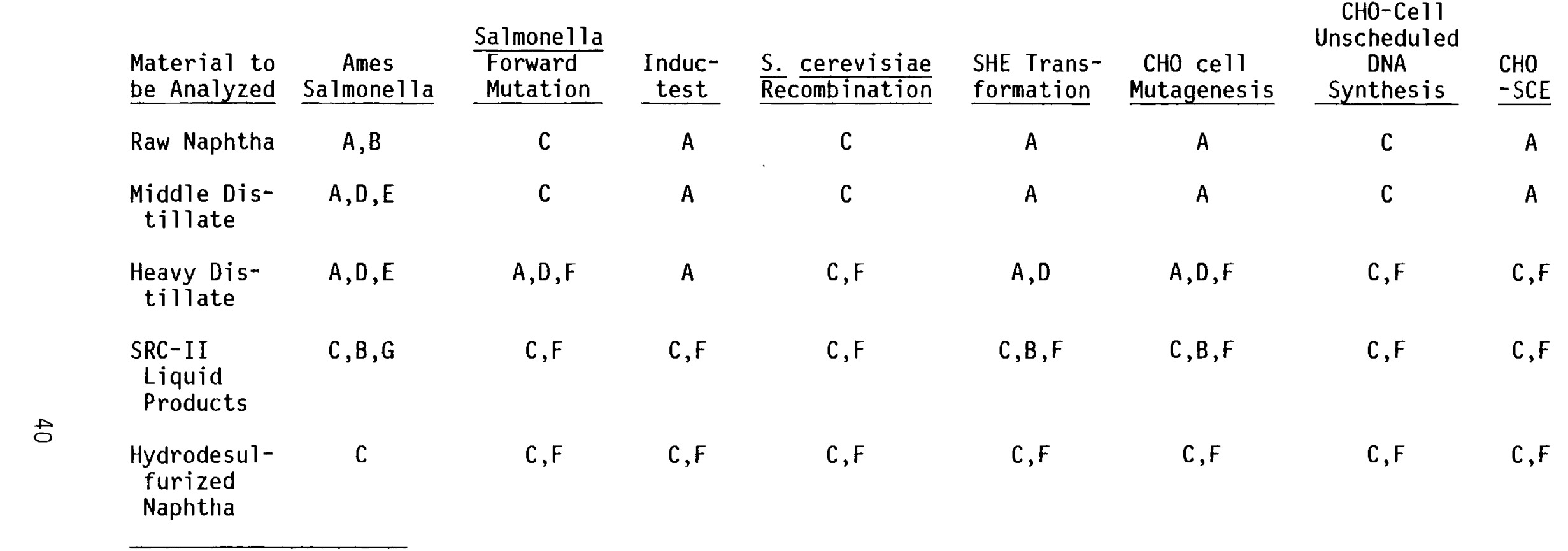

$A=$ performed on raw materials

$B=$ to be performed on at least one set of fractions

$C=$ to be performed on raw materials

$D=$ performed on at least one set of fractions

$E=$ chemical analyses performed

$F=$ extent of chemical fractionation/analyses to be decided by earlier assay results

$G=$ integrated chemical analyses to be performed 
TABLE 10. Comparison of the Mutagenicity of Solvent Refined Coal Materials, Shale 0ils, and Crude Petroleums in Salmonella typhimurium TA98

\author{
Materials \\ SRC-I I \\ Heavy distillate \\ Middle Distillate \\ Light distillate
}

Revertants/ug of Material

$40.0 \pm 23$

$<0.01$

$<0.01$

Shale 0 il

Paraho-16

Paraho-504

$0.60 \pm 0.19$

Livermore L01

$0.59 \pm 0.13$

$0.65 \pm 0.22$

Crude Petroleum

Prudhoe Bay

$<0.01$

Wilmington

$<0.01$

Pure Carcinogens

Benzo[a]pyrene

2-Aminoanthracene

$114 \pm 5$

$5430 \pm 394$

\section{Salmonella Forward Mutation}

Forward mutation to 8 -azaguanine $(8-\mathrm{Ag})$ resistance in Salmonella is, in some cases, more sensitive to weak mutagens (e.g., procarbazine, mitomycin c, perylene) than the Ames test. Histidine revertants derived from Ames (histid ine-requiring) strains will be used to compare forward mutation (8-Ag test) with reverse mutation (Ames test).

The $8-\mathrm{Ag}$ test is performed in much the same way as the Ames assay. Agents to be tested are assayed in the presence and absence of 59 enzymes; aliquots of exposed culture are plated on media containing 8-Ag. Colony formation in the presence of $8-\mathrm{Ag}$ is the endpoint of the test. The assay is presently being used with certain SRC-II liquid materials.

\section{Other Microbial Assays}

Although the Ames/Salmonella assay detects most types of mutagens/ carcinogens, it does not detect all of them (e.g., compounds that act by cross-linking DNA). To overcome this problem, several assay systems have been developed that detect mutagens not detectable in the Ames system. Generally, these assays are based on primary chemical damage to DNA, rather than mutation. In these assays, large segments of the chromosome, including the entire chromosome, are the genetic target. In theory, all types of damage should be 
detectable because the increased target size offers essentially all combinations of DNA bases.

Prophage $(\lambda)$ Induction (inductest). Prophage induction is particularly sensitive for measuring primary DNA damage. The inductest, because of the biological amplifications afforded, measures both direct and indirectacting mutagens, including frameshift and point mutagens, and mutagens that act by DNA cross-linking. The inductest will be applied to SRC-II liquid materials.

The test is performed with Escherichia coli, $K_{12}$, strain 6340 , which carries a lysogenic derivative of $\lambda$ phage. The organism is exposed to test material in the presence or absence of $\$ 9$ enzymes. DNA damage results in phage induction. Induced phage are detected by plating them on a lawn of indicator strain E. coli, $K_{12}$, strain 8177 , an organism which lyses in the presence of $\lambda$ phage. The assay is quantitated by counting plaques (zones of clearing caused by cell lysis) on the plate. Preliminary results with SRC-II liquids suggest that positive response in this assay may correlate with positive response in the Ames assay.

Saccharomyces cerevisiae. In addition to mutation and primary DNA damage, recombination induced by exposure to SRC-II materials will be determined. Both reciprocal mitotic recombination and nonreciprocal recombination (gene conversion) will be measured using S. cerevisiae, strains $D-3$ and $D-4$. Cells will be exposed to test materials in the presence or absence of 59 enzymes. Mitotic recombination will be detected by colony color change resulting from homozygosity at certain mutant adenine genes in strain $D-3$. Gene conversion will be detected with strain D-4 by change from tryptophan auxotrophy (cells require tryptophan in culture medium for growth) to tryptophan sufficiency (cells no longer require added tryptophan for growth). Formation of colored colonies, due to changes in the genotype at various adenine loci, will also indicate gene conversion.

Bacillus subtilis (Kada) Bioassay System. B. subtilis (Kada) strains will be used selectively to screen for genotoxic agents that may not be detectable, or that are poorly detected in other in vitro assays. The assay employs DNA recombination-deficient (REC-) strains that are highly sensitive to chemicals that damage DNA. The assay is capable of detecting genetically active metals whose effects are poorly resolved by other submammalian assay systems. The Kada test detects differential killing of the REC- B. subtilis strain compared to its recombination-sufficient (REC+) counterpart (i.e., the parent organism from which it was derived).

\section{Mammalian Cell Transformation}

Cell culture methods are being used to evaluate the ability of test materials to transform mammalian cells into a neoplastic state. Second-passage mammalian cell cultures. (Syrian hamster embryo [SHE] cells) are exposed to test materials in the presence and absence of $\$ 9$ enzymes. Cultures are monitored to determine cell transformation (i.e., morphological and biochemical changes that result in unrestricted growth in vitro). Representative colonies of transformed cells are inoculated into nude mice to evaluate their tumorforming ability in vivo. Tumor development in nude mice inoculated with transformed cells provides evidence that test materials are potential carcinogens. 
Results to date (Table 11) suggest that SRC-II HD is capable of transforming SHE cells. Dose-effect relationships, expressed as specific activity measurement (number of transformants/ $\mu$ g test material) for $H D$, are similar to those observed for a shale oil and benzo(a)pyrene, but are of greater magnitude than those observed for crude petroleums.

TABLE 11. Comparative Transformation Properties in Syrian Hamster Embryo Cells of Complex Organic Mixtures

\begin{tabular}{|c|c|c|}
\hline Material & $\begin{array}{c}\text { Number of } \\
\text { Transformants } \\
\text { per } \mu \mathrm{g} \text { of Test Material (a) }\end{array}$ & $\begin{array}{l}\text { Range of } \\
\text { Linear Portion } \\
\text { of Concentration } \\
\text { Response Curve } \\
\end{array}$ \\
\hline DMSO Control (0.1\%) & 0 & -- \\
\hline Prudhoe Bay Crude & $\sim 0.002$ & $100-200$ \\
\hline Wilmington Crude & $\sim 0.002$ & $75-150$ \\
\hline SRC-II Heavy Distillate & 0.7 & $5-20$ \\
\hline Shale 0 il (LERC) & 0.3 & $1-10$ \\
\hline Benzo[a]pyrene & 0.76 & $1-20$ \\
\hline
\end{tabular}

\section{Mammalian Cell Culture Mutagenicity}

Chinese Hamster Ovary (CHO) Cell Mutation. Mutation assays with CHO cells use the purine analog, 6-thioguanine (TG), to quantitate induction of forward mutation at the gene coding for the enzyme, hypoxanthine guanine phosphoribosyl transferase (HGPRT). In the system, TG is converted to a nucleotide by HGPRT of normal wild-type cells. The resulting nucleotide (or its metabolites) is (are) lethal to the cell. However, mutants lacking HGPRT are able to survive and grow in the presence of TG. Mutants are scored by counting the number of colonies. Mutagenicity with pure compounds (about 150 compounds have been tested to date) follows linear dosimetry. To properly interpret mutation frequency, cellular cloning efficiencies must also be determined to provide a measure of toxicity. Materials are characterized as direct (requiring no metabolic activation by microsomal enzymes) or indirect (requiring metabolic activation) mutagens. Several SRC-II liquid materials are presently being assayed in the system. 
Unscheduled DNA Synthesis. CHO cells can also be used to determine whether test materials cause lesions in DNA involving unscheduled DNA synthesis. This is measured by determining the level of tritiated thymidine incorporated into the damaged DNA molecule under conditions in which de novo cellular DNA synthes is does not occur. To prevent de novo DNA synthesis, cells are incubated in arginine-deficient medium for 2 or 3 days before exposure to test material and tritiated thymidine. Arginine deprivation blocks the G1 to $S$ phase conversion without affecting the cell's ability to initiate repair. Cells are then exposed to SRC-II materials which may interact and damage nuclear DNA. Autoradiography is used to evaluate incorporation of tritiated thymidine into the DNA of individual cells. Use of this assay will be contingent on results obtained from microbial analyses and $\mathrm{CHO}$ cell mutagenesis.

Sister Chromatid Exchange (SCE). SCE, observed by differential staining of DNA, is a measure of chemicalily or physically induced DNA damage in mammalian cells. In this assay, high correlation exists between concentrations of known mutagens/carcinogens and numbers of exchanges between sister chromatids. SCE can be applied to established cell lines or cells exposed in vivo.

We will determine SCE and forward mutation in CHO cells exposed to SRC-II materials. This will allow a comparison of primary DNA damage and forward mutation under similar assay conditions. The SCE will be quantitated by differential staining of chromatids with Hoechst 33258 fluorochrome and Giemsa stain after one or two cell divisions in a medium containing SRC-II materials and 5-bromodeoxyuridine. The SCE assay may also be used with cells derived from animals exposed, either acutely or chronically, to SRC-II materials.

\section{Chemical Analyses for Liquid Streams and Products}

\section{Fractionation}

All liquid product and process stream materials will be subjected to chemical fractionation. Fractionation is essential for removing substances which may interfere in bioanalyses and for concentrating mutagenic/carcinogenic materials. Fractionation also provides a qualitative measure for determining chemical classes causing biological effect. Stoichiometry for fractions versus intact material provides information on potential biological synergisms/ antagonisms in intact material. methods:

Three main considerations have guided us in selecting fractionation

1) Procedures must produce useful samples for chemical analyses.

2) Procedures must yield suitable samples for bioassay.

3) Procedures should be rapid, and applicable to large numbers of SRC-II materials.

The following fractionation procedures are equally compatible for chemical and biological assay. However, they differ in rapidity, amounts of fractionated material that can be generated, and degree of chemical definition. 
The particular fractionation method selected is a function of biological test purposes. For example, the large quantities of material required for animal testing (see subsequent section) necessitates use of solvent fractionation or, with considerable effort, preparative-scale HPLC. Most methods provide quantities of materials suitable for in vitro analyses. Partition chromatography and HPLC are the most appropriate fractionation methods for our purposes, based on: 1) recovery of mutagenic activity present in unfractionated samples, 2) elimination or reduction of inhibitory or antagonistic effects, and 3) suitability of fractions for subsequent chemical analysis.

Acid-Base-Neutral Solvent Extraction. The solvent fractionation scheme is a modification of the method of Swain et al. for chemical class fractionation of cigarette-smoke condensates. The procedure involves sequential extraction (see Figure 5) of the sample in iso-octane with $1 \mathrm{~N} H C l$, $1 \mathrm{~N}$ $\mathrm{NaOH}$, and dimethylsulfoxide (DMSO). Fractions produced include pölynuclear aromatic hydrocarbon (PAH), neutral, iso-octane insoluble tar, basic, acidinduced tar, acidic, and base-induced tar. Use of iso-octane in place of ether as the primary solvent yields more-quantitative recovery of low-boiling neutral compounds and also provides more-quantitative separation of the PAH fraction.

This solvent fractionation procedure provides the large quantities of sample materials needed for in vivo animal testing, and will eventually allow correlation between in vitro and in vivo analyses. However, when applied to coal distillates, all solvent extraction procedures result in large quantities of insoluble tars. Also, the procedure is laborious and time-consuming, and results are difficult to replicate. Recoveries of biological activity are variable, and may range from $60-100 \%$.

High-Performance Liquid Chromatography (HPLC). HPLC is performed on a normal-phase $\mathrm{NH}_{2}$ column. The undiluted sample, or a sample diluted in solvent (e.g., hexane or hexane:methylene chloride), is applied to the column and eluted by a continuous ternary gradient. The eluting solvent is changed from the initial $100 \%$ hexane to $100 \%$ methlyene chloride, and subsequently to $100 \%$ isopropanol. This elution sequence separates sample constituents into three principal fractions. The first fraction contains neutral hydrocarbon and aromatic constituents. The second fraction consists of more-polar components, including nitrogenous bases and amines. The third fraction contains the most-polar (acidic and phenolic) constituents.

This fractionation method is rapid and highly reproducible, and has greater mixture-component resolving power than other methods described here. Because of the method's speed and reproducibility, composite fraction samples can be generated from a number of runs. The composite samples provide sufficient material for all planned in vitro assays. The method routinely provides quantitative recovery of both biological activity and mass for a given synfuel material. Although present equipment does not allow preparation of fractionated samples in sufficient quantities for animal bioassay, preparative-scale HPLC could do so, with considerable effort.

Partition Chromatography. Partition chromatographic separation involves Sephadex $\mathrm{LH}-20$, and is a modification of the technique (Figure 6) of Klimisch and Stadler, which was further developed by Jones et al. The Sephadex LH-20 is first swelled in methanol:water (85:15). The sample is then applied 


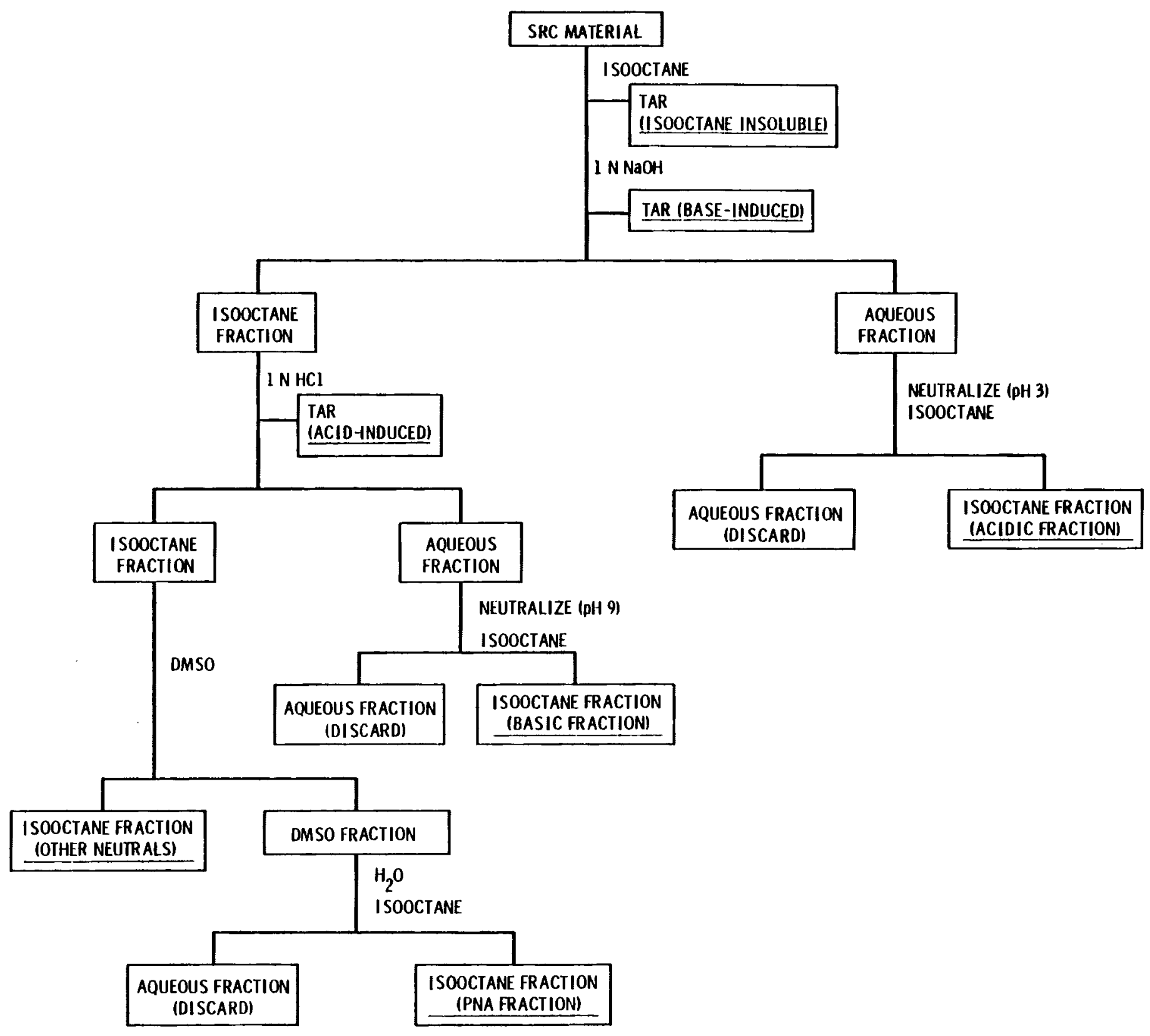

Figure 5. Acid-Base-Neutral Fractionation of SRC-II Materials 


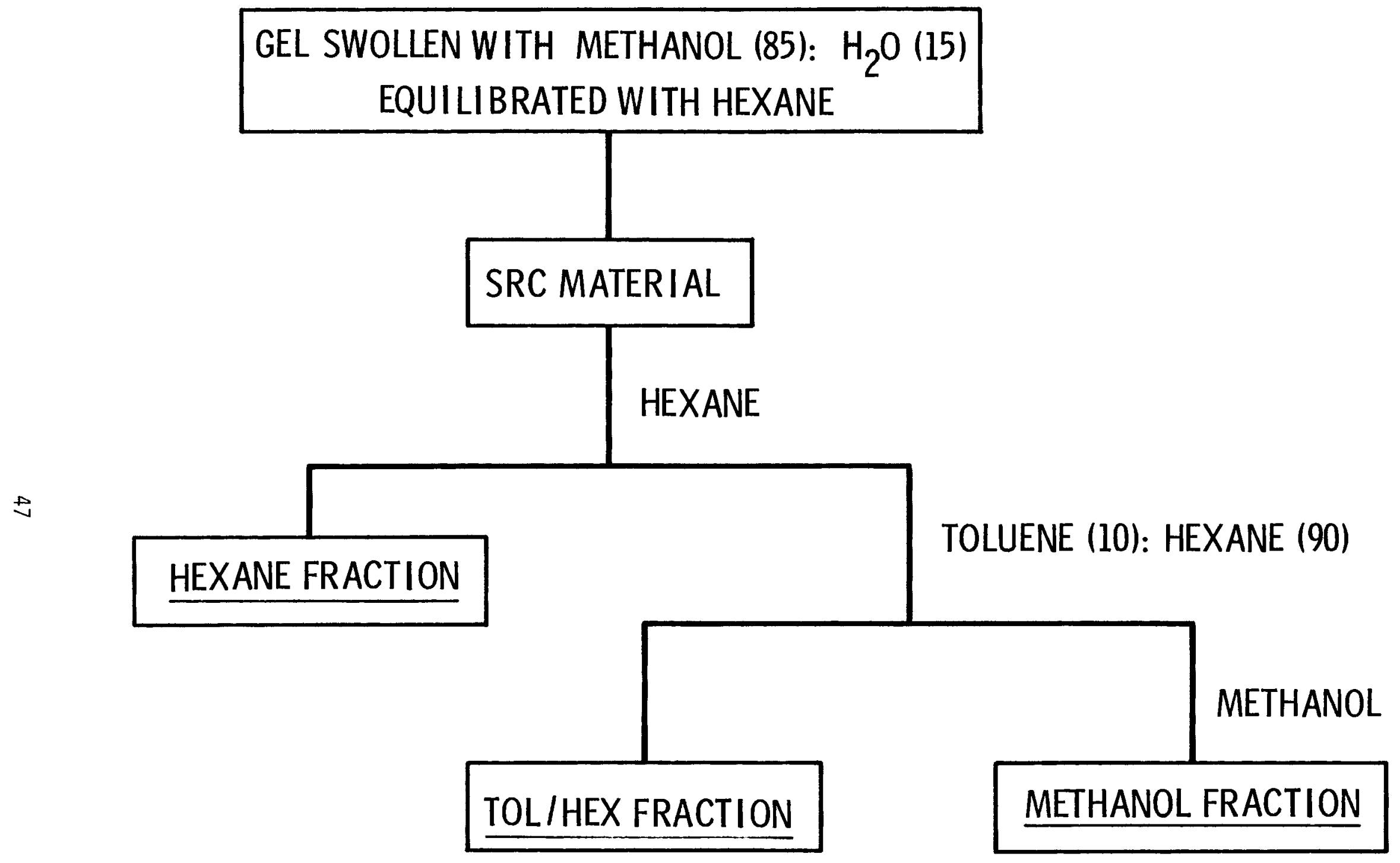

Figure 6. Sephadex LH-20 Fractionation 
and sequentially eluted with 100\% hexane, toluene: hexane (10:90), and 100\% methanol. This elution sequence separates constituents, based on polarity. The hexane fraction contains aliphatic and aromatic hydrocarbons, other neutrals, and S- and 0- containing heterocycles. The toluene/hexane fraction contains, for the most part, moderately polar constituents, including some azaheterocycles. The methanol fraction contains the most-polar constituents, including most primary amines and phenolic components.

A combination of Sephadex LH-20 partition chromatography and HPLC has been applied to some SRC-II materials. The three major fractions from Sephadex chromatography were re-separated by ternary gradient HPLC, which resulted in large increases in specific biological activity.

Partition chromatography allows fractionation of comparatively large amounts of materials (i.e., 100 times more than HPLC but 20 times less than solvent fractionation). The method also concentrates biological activity by factors of 10 or greater (e.g., increases specific mutagenic activity 10-fold relative to unfractionated material) with high yield of total biological activity.

Thin-Layer Chromatography (TLC). TLC separations of SRC-II materials are performed on silica gel plates, using a solvent system of acetone: hexane:methanol $(1: 9: 0.25)$. The method has mainly been applied to fractions derived by solvent extraction to aid in chemical identification of biologically active components in SRC-II liquids (see below). Although the method must be considered primarily an analytical tool, it can be applied to fairly large amounts (1-2 grams) of SRC materials or fractions, when necessary. The technique is rapid and reproducible, but recoveries of biological activity tend to be less than $100 \%$.

Data on Fractionated Materials. Fractions obtained from procedures described above have been subjected to Ames assay. Solvent extraction fractions have also been subjected to the inductest and Salmonella 8-Ag resistance tests. Results from Ames assay of solvent extracted fractions are shown in Table 12. The basic fraction derived from SRC-II HD had the highest specific activity (revertants $/ \mu \mathrm{g}$ ) in all assays. However, tar fractions derived from solvent fractionation were also active and, although of lower specific mutagenic activity, contributed the bulk of total activity associated with the crude, unfractionated material.

Mammalian cell transformation results tend to substantiate results of microbial assays. However, unlike microbial assays, the mammalian cell transformation assay shows biological response to the PNA fraction of SRC-II HD.

\section{Organic Chemical Analyses}

SRC-II materials and fractions showing biological activity in in vitro assays are chemically analyzed to determine compounds and compound classes capable of causing biological effects. To date, analyses have involved gas chromatography/low-resolution mass spectrometry. A battery of chemical techniques will be used in the future, the form of which will depend on chemical and physical properties of the sample and results of bioassay. Thus far, analytical emphasis has been placed on PAHs, $\mathrm{N}$ - heterocycles, and primary aromatic amines (PAAs). 
TABLE 12. Recovery of Ames Assay Mutagenic Activity in Fractions Derived by Acid-Base-Neutral Solvent Extraction of SRC-II Heavy Distillate

\begin{tabular}{|c|c|c|c|c|}
\hline & $\begin{array}{c}\begin{array}{c}\text { Relative } \\
\text { Weight }\end{array} \\
\text { (\% of Total) } \\
\end{array}$ & 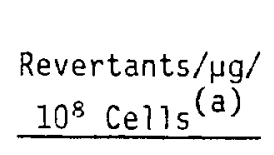 & $\begin{array}{l}\text { Weighted } \\
\text { Activity (b) } \\
\end{array}$ & Sum \& Recovery \\
\hline SRC-II Basic & 1 & 400 & 4 & \\
\hline $\begin{array}{l}\text { SRC-II Heavy Distillate } \\
\text { Basic Tar }\end{array}$ & 24 & 66 & 16 & $S=48$ \\
\hline $\begin{array}{l}\text { SRC-II Heavy Distillate } \\
\text { Neutral Tar }\end{array}$ & 26 & 108 & 28 & \\
\hline SRC-II Heavy Distillate & 100 & 40 & 40 & $\frac{48}{40} \times 100=120 \%$ \\
\hline $\begin{array}{l}\text { (a) Data for S. typhimuri } \\
\text { (b) Relative weight } \\
\frac{100}{} \times \mathrm{r}\end{array}$ & $\begin{array}{l}\text { TA98, from } \\
\text { ertants } / \mu \mathrm{g} / 1\end{array}$ & $\begin{array}{l}\text { les } 1 \text { and } 3 \\
\text { cells }\end{array}$ & & \\
\hline
\end{tabular}

Gas Chromatography (GC). High-resolution capillary column gas chromatographic analysis will be performed on standard commercial instruments using either a $60 \mathrm{~m} \times 0.25 \mathrm{~mm}$ ID WCOT coated with SP-2250 liquid phase or a specially prepared $25 \mathrm{~m} \times 0.25 \mathrm{~mm}$ ID WCOT glass column coated with SE-52 or SE-54 phase. The column effluent is split, and both FID and either $\mathrm{N}^{-}$or S-specific detectors are employed for simultaneous peak detection. The FID trace is automatically integrated for peak quantitation.

The method yields exceptionally high resolution of compounds in complex mixtures, and will be used primarily to analyze biologically active fractions from various SRC-II distillates. Resolution of single compounds in complex mixtures is not uncommon by this means and, based on retention time, it should be possible to obtain confirmatory qualitative and quantitative evidence for compounds of biological interest in SRC-II liquids.

Nitrogen-containing compounds (e.g., aromatic amines, $\mathrm{N}$-heterocycles) will be analyzed in fractions/subfractions by simultaneous use of the $\mathrm{N}$ detector and FID. To determine standards for GC, materials will first be qualitatively analyzed for organic compound composition by GCMS low-resolution methods described below. Tentative compound identification, based on GCMS results, will be used to select appropriate standards.

S-containing compounds (e.g., S-heterocycles) will be analyzed by simultaneous use of an S-detector and FID. S-containing compounds of potential biological interest, and required as standards in GC and other analyses, will be synthesized as needed. 
Phenols obtained by caustic extraction of SRC-II materials can be readily isolated by addition of acetic anhydride to a subsample, and extracting the acetylated phenols into hexane. Although catechols and other polyfunctional phenols are not completely analyzed by this procedure, its simplicity outweighs the disadvantage of some loss in analytical detail. Alternatively, phenols in organic solvents will be derivatized using pyridine/acetic anhydride or trifluoroacetic anhydride. These derivatives produce characteristic fragments in the mass spectrometer and are easily identified in complex mixtures. Underivatized phenols can be separated on some of the newer fusedquartz capillary columns, and can be detected using mass spectrometry. The latter technique will be used to analyze nonacidic fractions for the presence of phenolic contaminants. Various mono- and dicyclic phenols are readily available as quantitative standards.

Use to date suggests that SE-52 liquid phase will allow separation of all compound classes discussed above. Other columns, phases, and conditions may be necessary, depending on the material being analyzed. Not all analyses will be performed on all derived fractions. Biological results and the nature of major chemical constituents known or suspected to be present in fractions will be prime factors in determining type and need for analyses.

High-Performance Liquid Chromatography (HPLC). Separation of constituents is performed with a Spectro-Physics 8000 chromatograph or comparable instrument. Columns include normal-phase $\mathrm{NH}_{2}$ columns, silica gel columns, and reverse-phase C-18 columns. Sample components are eluted from the normal-phase column with a ternary solvent system (i.e., hexane, methylene chloride, and isopropanol). Fractions from the $\mathrm{NH}_{2}$ column are rechromatographed with an acetonitrile/water solvent mixture on the $\mathrm{C}-18$ column to provide additional resolution of sample constituents. Alternatively, samples may be run directly on silica gel columns. Samples analyzed by HPLC include both crude materials and fractions obtained from one of the separation methods discussed above and will include principally those that are biologically active. Fluorescence, UV absorbance, and electrochemical detectors may be employed, depending on specific compound types of interest. Component identification is achieved both through retention-time comparisons with standards and GCMS analys is of HPLC fractions. HPLC analyses are suitable for nearly all sample types, and are particularly well suited for high-molecular-weight constituents that are difficult to analyze by gas chromatography, highly polar materials, and temperaturesensitive materials.

Gas Chromatography - Low Resolution Mass Spectrometry (GCMS). Electron impact (EI) and chemical ionization (CI) mode GCMS analyses are performed on either a Hewlett Packard 5985 A or 5980 A GCMS system, using either a $60 \mathrm{~m} x$ $0.25 \mathrm{~mm}$ ID WCOT glass column coated with SP-2250 liquid phase, or a specially prepared $25 \mathrm{~m} \times 0.25 \mathrm{~mm}$ ID WCOT glass column with SE-52 or SE-54 phase. Splitless mode injection is used with these capillary columns. The eluate stream may be split to allow simultaneous FID and mass spectrometric detection. The FID trace is automatically integrated for GC peak quantitation and the MS data are used for peak identification. The PAH concentrations are determined both directly and in the $\mathrm{PAH}$ fractions. The PAA and $\mathrm{N}$-heterocycle concentrations are estimated from the basic and tar fractions on both the SP-2250 and SE-52 columns. Concentrations of phenol, aromatic and hydroaromatic compounds are determined in intact materials, using the SE-52 column. 
High-Resolution Mass Spectrometry (HRMS). HRMS analysis provides accurate molecular weights for constituents in complex mixtures, thus allowing assignment of elemental composition. Ionization modes available on the VG Micromass $Z A B$ IF include EI, CI, field ionization (FI), and field desorption (FD). The latter, with the extended mass range, allows analys is of non-gaschromatographable components with molecular weights up to 3000 atomic mass units (amu). Negative and metastable ion analysis may also be used when necessary. The latter are two of several recently developed techniques, including FD and high resolution multiple detection, which may be used for analysis of ultra, trace, or refractory compounds.

Initially, samples analyzed by these methods will be fractions comprised of higher-molecular-weight materials and especially those containing $N$, $S$, and 0 functional groups. Generally, we will first obtain elemental composition by high resolution. Structural features may then be studied, using metastable analysis and derivatization, as well as comparison to standards, when such standards exist.

Summary of Results. TLC was used to separate mutagenically active components of the basic, basic tar, and neutral tar fractions of SRC-II HD from other components in this complex material. For the three fractions tested, mutagenic activity was localized in about the same TLC regions. The GCMS analysis of the eluates from TLC regions exhibiting enhanced mutagenic activity showed that the relative concentrations of PAAs (obtained by measuring peak areas for the $[M+1]$ ion in the CI mode) followed a distribution similar to that of mutagenic activity. The PAAs in the active regions included aminonaphthalenes, aminobiphenyls, aminoanthracenes, aminophenanthrenes, aminopyrenes, aminochrysenes, and their alkyl homologues. Except for small amounts of aminonaphthalene, PAAs were not found in TLC regions that lacked mutagenic activity.

Concentrations of PAA with two to four fused rings increased and decreased commensurate with mutagenic activity in TLC eluates of the basic fraction. Mutagenically active TLC eluates from the basic and neutral tar fractions contained smaller concentrations of two-ring PAAs, while having relatively higher amounts of three- and four-ring compounds such as aminophenanthrenes and aminopyrenes. Concentrations of PAA again correlated with mutagenic activity.

\section{Sol id Process Streams and Wastes}

Several solid materials (raw sulfur, vacuum bottoms, stripper tower bottoms, coal slurry, gasifier slag, wastewater solids) will be subjected to in vitro bioassay and chemistry. Methods of extracting these materials, the bioassays to be employed and the chemical analyses to be performed are described below. Assays to be performed on these materials are shown in Table 13.

\section{Sample Extraction}

Organic-Rich Materials. SRC-II vacuum bottoms, stripper tower bottoms, and coal slurry are rich in organic compounds. These materials must be extracted or dissolved prior to analyses in in vitro bioassays. Boundary conditions for solution/extraction are as follows: 
TABLE 13. Phase I - In Vitro Assays: Solid Materials

\begin{tabular}{|c|c|c|c|c|}
\hline $\begin{array}{l}\text { Material to } \\
\text { be Analyzed }\end{array}$ & $\begin{array}{c}\text { Ames } \\
\text { Salmonella }\end{array}$ & $\frac{\text { Bacillus }}{\text { KADA Subtilis }}$ & $\begin{array}{l}\text { Mammalian } \\
\text { Cell Transfor- } \\
\text { mation }\end{array}$ & Other \\
\hline Vacuum Bottoms & $A, B$ & $A, B$ & $A, B$ & $c$ \\
\hline $\begin{array}{l}\text { Stripper Tower } \\
\text { Bottoms }\end{array}$ & $A, B$ & $A, B$ & $A, B$ & c \\
\hline Coal Slurry & $A, B$ & $A, B$ & $A, B$ & c \\
\hline Raw Sulfur & $C, D$ & $C, D$ & $C, D$ & c \\
\hline $\begin{array}{l}\text { Gasifier Slag: } \\
\quad \text { Coarse }\end{array}$ & $C, D, E$ & $C, D, E$ & $C, D, E$ & c \\
\hline $\begin{array}{l}\text { Gasifier Slag: } \\
\quad \text { Fine }\end{array}$ & $D$ & D & D & c \\
\hline $\begin{array}{l}\text { Waste Water } \\
\text { Incinerator Solids }\end{array}$ & $C, D, E$ & $C, D, E$ & $C, D, E$ & c \\
\hline \multicolumn{5}{|c|}{$\begin{aligned} A= & \text { to be performed on all organic extracts and serum, } \mathrm{HCl} \text {, and simulated lung } \\
& \text { fluid extracts. }\end{aligned}$} \\
\hline \multicolumn{5}{|c|}{$\begin{aligned} & B= \text { organic fractionation and analyses to be performed on extracts containing } \\
& \text { biological activity. }\end{aligned}$} \\
\hline \multicolumn{5}{|c|}{$\begin{aligned} C= & \text { extent of chemical fractionation/analyses to be decided by earlier assay } \\
& \text { results. Other bioassays (Table } 8 \text { ) may be used depending upon results of } \\
& \text { this assay slate. }\end{aligned}$} \\
\hline \multicolumn{5}{|c|}{$\begin{aligned} & D= \text { to be performed on all organic extracts and all aqueous leaching solutions } \\
& \text { in Table } 14 .\end{aligned}$} \\
\hline
\end{tabular}


1) Organic solvents of varying polarity (hexane, toluene, methanol, acetone and methylene chloride) will be used to effect maximum dissolution/extraction. Bioassay results with the extracts represent worst-case estimates since it is doubtful that animals exposed to organic-rich materials via inhalation or dermal contact would be capable of totally dissolving or extracting all organic compounds in these solids.

2) Solvents representing simulated or actual body fluids will also be used (Table 14). Extracts from these materials may represent potential physiological dissolution.

\section{TABLE 14. Aqueous Leaching Solutions}

Solution $\mathrm{pH}$ Values:

Solution Salt Concentrations:

Salts:

Additional Solutions:
$1,5,9,11$

$0.005 M$ and $0.5 M$

$\mathrm{NH}_{4} \mathrm{NO}_{3} \quad$ (plus or minus $0.002 \mathrm{M}$ EDTA

$\mathrm{HCl}$

for $\mathrm{pH}$ range 5-9)

Serum

Simulated Lung Fluid

Stripper tower bottoms and coal slurry cannot be easily ground to give powders suitable for dissolution. These materials will be brought to liquid nitrogen temperatures, shattered, and sieved to particles in the 200- to 400-mesh range. Vacuum bottoms will be ground and sieved; resulting powders will be extracted in each of the organic solvents. Solution-to-solid ratios and mixing conditions will be adjusted to effect maximum dissolution in a given solvent. Concentrations will be expressed as percent of solid dissolved.

Actual or simulated body fluids will include serum, $0.1 \mathrm{~N} \mathrm{HCl}$, and simulated lung fluids (Table 14), as decribed by Moss. Serum has been used to extract combustion particulates from operations of diesel- and coal-fired facilities for in vitro assays. Hydrochloric acid solution represents a solvent with $\mathrm{pH}$ of gastric fluid. Simulated lung fluids have been used to estimate physiological dissolution for various potentially respirable particulates. Extraction conditions are as described above.

Mineral-Rich Solids. Coarse and fine gasifier slag, wastewater incinerator solids, and raw sulfur will be extracted in each of the organic solvents listed above. This represents worst-case conditions for traceorganic material dissolution from mineral-rich solids. 
These materials will also be extracted in aqueous solutions (Table 13) containing from $0.005 \mathrm{M}$ to $0.5 \mathrm{M}$ salt and varying in $\mathrm{pH}$ from 1 to 11 . Extractions at $\mathrm{pH} 5$ and 9 , minus or plus 0.002M EDTA, will allow maximal metal removal. These solutions represent worst-case conditions for analyses of biological effects of metals in solids. Again, serum and simulated lung fluid will be used to represent physiological extraction.

In Vitro Tests and Chemistry

Organic-Rich Materials. Chemical fractionation and analytical methods and in vitro bioassays will be performed as described for 1 iquid products and process streams ( $\mathrm{pp}$. 39-51). Routine in vitro bioassays will be performed using the Ames system and mammalian cell transformation. We anticipate that organic chemical entities of concern in these materials may be similar to those found in liquid products and process streams. If this is not the case, further analyses may be indicated.

Mineral-Rich Solids. Bioassays of organic extracts and aqueous leachates from mineral-rich solids will be performed as described previously. One additional bacterial bioassay system useful for detecting metal-induced DNA damage will also be used since extracts and/or leachates from mineral-rich solids may contain high concentrations of metals relative to coal liquids or organic-rich solids. As discussed on p. 42, this assay is based on the sensitivity of recombination-deficient (REC-) strains of $B$. subtilis to DNA damage induced by organics or metal compounds.

Organic materials from mineral-rich solids will be fractionated as previously described. If results from the $B$. subtilis assay suggest the presence of direct-acting mutagens and Ames results do not, the possibility of metal or metal-containing genotoxicants must be examined. Appropriate analytical methods for metals of greatest potential biological concern are listed in Table 15.

\section{Process Waters and Treated Process Waters}

SRC-II process waters may be the most difficult of the materials to obtain in representative form. Therefore, biomedical studies on process water will be limited to screening assays until waters more representative of potential demonstration or commercial operations are available.

Depending on content of organic and inorganic materials, process waters and treated process waters may require extraction and/or concentration before in vitro assay. Three techniques will initially be used to provide suitable samples. Results from bioassays will aid in determining the most suitable method. Assays to be used are shown in Table 16.

\section{Sample Extraction}

Evaporative Condensation. Process water and treated process water will be evaporated in a rotoevaporator or a Kdurna Danish evaporator. Total organic carbon (TOC) content in the condensate will be determined. These samples may represent total carbon load (except for volatile constituents) in a volume usable for in vitro bioassays. 
TABLE 15. Analytical Methods for Determining Biologically Active Metals

$\underline{\text { Element Determined }}$

As

B

$\mathrm{Cr}$

$\mathrm{Cd}$

Co

$\mathrm{Cu}$

$\mathrm{Hg}$

$\mathrm{Ni}$

$\mathrm{Pb}$

$\mathrm{Sb}$

Se

Sn

T)

V

$\mathrm{Zn}$
Analytical Method

Electrochemical techniques, dc-coupled plasma emission, neutron activation, atomic absorption

Plasma emission spectroscopy

Neutron activation, electrochemical techniques

Electrochemical techniques, atomic absorption, plasma emission

Atomic absorption, neutron activation

Electrochemical techniques, atomic absorption, plasma emission

Flameless atomic absorption, plasma emission

Electrochemical techniques, atomic absorption, plasma emission

Electrochemical techniques, atomic absorption, plasma emission

Electrochemical techniques, neutron activation

Electrochemical techniques, neutron activation, atomic absorption

Atomic absorption, plasma emission

Neutron activation, electrochemical techniques

Electrochemical techniques, neutron activation, Plasma emission

Electrochemical techniques, neutron activation, atomic absorption, plasma emission 
TABLE 16. Phase I In Vitro Assays: Waters

\begin{tabular}{|c|c|c|c|c|c|c|c|c|c|}
\hline $\begin{array}{l}\text { Material } \\
\text { to be } \\
\text { Analyzed } \\
\end{array}$ & $\begin{array}{c}\text { Ames } \\
\text { Salmonella }\end{array}$ & $\begin{array}{l}\text { Salmonella } \\
\text { Forward } \\
\text { Mutation } \\
\end{array}$ & $\begin{array}{l}\text { Induc- } \\
\text { test } \\
\end{array}$ & $\frac{\text { S. }}{\text { Recerevisiae }}$ combination & $\frac{\text { subtilis }}{\text { KADA }}$ & $\begin{array}{l}\text { SHE } \\
\text { Transfor- } \\
\text { mation } \\
\end{array}$ & $\begin{array}{l}\text { CHO Muta- } \\
\text { genicity }\end{array}$ & $\begin{array}{c}\text { CHO Un- } \\
\text { scheduled } \\
\text { DNA } \\
\text { Synthesis }\end{array}$ & $\begin{array}{r}\text { CHO } \\
- \text { SCE } \\
\end{array}$ \\
\hline $\begin{array}{l}\text { Process } \\
\text { Water }\end{array}$ & B & C & C & C & C & C & C & C & C \\
\hline $\begin{array}{l}\text { Treated } \\
\text { Process } \\
\text { Water }\end{array}$ & B & $c$ & C & $c$ & B & B & C & C & $C$ \\
\hline
\end{tabular}

$A=$ Analyses on raw material and limited number extracts; extent of chemical extraction/analyses expected to be minimal.

$B=$ Analyses on all extracts and raw material; extent of chemical fractionation and analyses dependent upon results.

$C=$ Analyses on extracts and raw materials contingent upon earlier assay results.

$D=$ Number of samples is undetermined; dependent on water treatment options employed. 
Solvent Extraction. Two organic solvents (hexane and methylene chloride) having differing polarity will be used to extract nonpolar and polar organic compounds from process water and treated process water. Weight of material extracted will be determined by evaporation to constant weight.

Preconcentration onto Adsorption Resins. Process water and treated process water will be passed through small beds of either XAD-2 (polystyrene divinylbenzene resin) or XE-347 (carbonaceous resin). Adsorption on XAD-2 resin is a standard method of preconcentration for trace organic materials in natural waters. Recent evidence indicates that XE-347 is more effective for removing trace concentrations of polar organic compounds from water than is XAD-2.

After adsorption, the resin will be Soxhlet-extracted with hexane, folowed by methylene chloride extraction. Weight of material extracted will be determined by evaporation to dryness, and corrected for resin degradation.

In Vitro Assays and Chemistry

In vitro assays to be employed are described on pp. 39-44. Chemical fractionation methods and organic analyses coupled to bioassay needs are described on pp. 44-51.

\section{Short-Term In Vivo Bioassay}

Short-term in vivo assays are, in many cases, essential to develop conditions for use in the longer-term, more-definitive, whole-animal studies to be performed in Phase II. Additionally, these assays provide data on potential biological effects which may result from single-incident, high-dose exposures to SRC-II materials which may be encountered in the workplace or environment. Measures of teratogenicity, described below, provide initial data on determining whether fetal tissue may be subjected to unique risk after maternal exposure to SRC-II materials. Assays to be performed are shown in Table 17.

\section{Acute Oral Toxicity}

Acute oral studies usually involve single exposures of animals to test material, followed by observations of death, weight change, clinical symptoms and, in some cases, hematologic changes. Short-term, repeated-dose (subchronic) studies involve exposures to test materials for up to 3 weeks. Results of acute and subchronic toxicity studies are generally used to establish doses for chronic studies (i.e., dominant lethality, transplacental carcinogenicity, etc.). Mice and rats are usual test organisms.

Wistar rats and DBA mice will be given varying doses of the liquid, either diluted in corn oil or undiluted, by gavage. Solid materials (gasifier slag, vacuum bottoms, stripper tower bottoms) will be suspended in carboxymethyl cellulose and administered by gavage. Five to 15 animals of each sex will be exposed per dose in two to four replicates. Animals will be fasted overnight prior to exposure. 
TABLE 17. Phase I In Vivo Assays

\begin{tabular}{|c|c|c|c|c|c|c|}
\hline $\begin{array}{l}\text { Material to } \\
\text { be Analyzed }\end{array}$ & $\begin{array}{c}\text { Acute Oral } \\
\text { Toxicity } \\
\text { (rats \& mice) } \\
\end{array}$ & $\begin{array}{c}\text { Acute Dermal } \\
\text { Toxicity } \\
\text { (Mice) } \\
\end{array}$ & $\begin{array}{c}\text { Eye } \\
\text { Irritation } \\
\end{array}$ & $\begin{array}{c}\text { Guinea Pig } \\
\text { Skin } \\
\text { Sensitization } \\
\end{array}$ & $\begin{array}{l}\text { Aspiration } \\
\text { Hazard } \\
\end{array}$ & $\begin{array}{l}\text { Terato- } \\
\text { genicity }\end{array}$ \\
\hline Raw Naphtha & A & A & B & B & B & A \\
\hline Middle Distillate & A & B & B & B & B & A \\
\hline Heavy Distillate & A & A & B & B & B & c \\
\hline Vacuum Bottoms & D & D & D & D & D & D \\
\hline $\begin{array}{l}\text { Stripper Tower } \\
\text { Bottoms }\end{array}$ & D & D & D & D & D & D \\
\hline Coal Slurry & D & D & D & D & D & D \\
\hline Raw Sulfur & E & $\mathrm{E}$ & D & D & D & $\mathrm{E}$ \\
\hline $\begin{array}{l}\text { SRC-II Liquid } \\
\text { Product }\end{array}$ & D & D & D & D & D & D \\
\hline $\begin{array}{l}\text { Hydrodesulfurized } \\
\text { Naphtha }\end{array}$ & E & $\mathrm{E}$ & B & B & B & $\mathrm{E}$ \\
\hline Gasifier Slag & $E$ & $\mathrm{E}$ & $\mathrm{E}$ & B & B & $\mathrm{E}$ \\
\hline Process Water & $\mathrm{E}$ & $\mathrm{E}$ & $\mathrm{E}$ & B & B & $\mathrm{E}$ \\
\hline $\begin{array}{l}\text { Waste Water } \\
\text { Incinerator } \\
\text { Solids }\end{array}$ & E & $\mathrm{E}$ & E & B & B & $\mathrm{E}$ \\
\hline
\end{tabular}

$A=$ performed and data available

$B=$ will not be analyzed with this assay

$\mathrm{C}=$ to be performed on fractions

$D=$ to be performed by P\&M

$E=$ to be performed by PNL 
For acute studies, dose administration will be one-time-only, and animals will be observed during the next 3 days for mortalities and other changes, including weight loss, appearance of neurological changes, etc. Mortalities will be recorded during the first 3 days postadministration. However, surviving animals will be observed for an additional week to determine if recovery from acute symptoms occurs. If latent mortality occurs in initial studies, the observation period will be extended.

Short-term, repeated-dose studies will follow the same procedure, except that animals will be administered test material once per day for 5 consecutive days. Again, mortality, weight changes, neurological symptoms, and other clinical signs will be observed during the first week following the last exposure. This type of exposure will sometimes be performed in conjunction with studies on effects of materials on prenatal development.

\section{Acute Dermal Toxicity}

Liquid materials will be administered either undiluted, or diluted in an appropriate solvent (acetone, methanol, etc.). Solid materials will be suspended in an appropriate organic or aqueous solvent as determined by analyses described on pp. 51-54. Dose for mineral-rich solids may be determined from the maximal concentrations that can be dissolved or suspended in the solvent. Five to $15 \mathrm{C} 3 \mathrm{Hf} / \mathrm{HeBd}$ mice of both sexes will be used for each dose group. Materials will be applied to the shaved dorsal skin once per day for 10 consecutive days. Animals will be observed for 14 days after exposure for mortality, weight loss, neurological changes and overt symptoms of skin irritation.

\section{Eye Irritation}

Liquid materials will be administered undiluted. Solid materials will be administered as finely ground powders. New Zealand White rabbits will be used. Materials will be applied and animals observed according to the Proposed Health Effects Test Standards for Toxic Substances Control Act Test Rules (FR 44 44054). Grading and scoring of irritation will be performed in accordance with the method of Draize et al.

\section{Dermal Sensitization}

Liquid materials will be administered undiluted, or diluted with physiological saline. Solid materials will be suspended in a minimal amount of physiological saline. Albino guinea pigs will be used. Materials will be applied according to the method of Landsteiner and Jacobs or, if intradermal injection is impractical, by the method of Buehler. Grading and scoring of reactions will be performed according to the method of Draize et al.

\section{Aspiration Hazard}

Materials will be administered undiluted. Young, Fischer 344 rats will be used. Materials will be administered according to the method of Gerarde.

Teratogenicity

Developmental toxicity studies with mice and rats will- be performed to determine if embryolethality, early embryonic changes, or malformations are 
produced after administration of SRC-II materials to the pregnant female. Test materials will be administered orally, even though other routes of entry (dermal and inhalation) may be more likely in the workplace or general environment. Oral administration is used because: 1) it permits better control of dose, 2) much of the dose after inhalation exposure goes to the gastrointestinal tract, and 3 ) data for other routes of entry can be related to oral administration through pharmacokinetic data.

Typically, test material will be administered to pregnant rats from 7-11 and 12-16 days gestation (dg), and to mice from 6-10 and 11-15 dg. About 15-20 pregnant animals will be used for each dose, in 2-4 replicates. Pregnant females will be killed at $20 \mathrm{dg}$ (rat) or $19 \mathrm{dg}$ (mouse). The uterus will be removed, and fetuses will be examined for gross malformations, and subjected to microdissection for determination of internal malformations. Soft tissue will then be digested away from the skeleton using potassium hydroxide, and the skeleton, stained with alizarin red, will be examined for malformations.

\section{Results to Date}

In studies already conducted, the acute toxicities of SRC-II RN, MD, and HD have been compared to those for shale oil, petroleum crudes, and diesel oil after oral administration. Relative toxicities, expressed as the dose $(\mathrm{g} / \mathrm{kg}$ body weight) required to kill 50\% of the test animals in 3 days, are shown in Table 18. The SRC-II materials would be considered moderately toxic by industrial hygiene standards (Clinical Toxicology of Commercial Products, M76) with a range of $\mathrm{LD}_{50}$ values from 2.3 to $3.8 \mathrm{~g} / \mathrm{kg}$.

Repeated-dose toxicity was determined for RN, MD, and HD. Repeated-dose toxicity values for SRC-II materials were substantially lower than the acute values. These data indicate that either the material or the effects of RN, $M D$, and $H D$ are cumulative.

Administration of RN, MD or HD at 7-11 dg did not significantly increase the incidence of fetal malformations over that in controls. Fetal weight was affected only at doses producing symptoms of maternal toxicity (inhibition of weight gain or death of some females). Prenatal mortalities were increased by all three materials, again at doses producing some maternal toxicity.

These SRC-II materials produced more-severe fetal effects when administered at 12-16 dg than when given at 7-11 dg. Prenatal mortalities were increased by all three materials, and incidence of malformations was increased by HD (Table 19). Although increased prenatal mortalities occurred in the absence of signs of maternal toxicity, increases in incidence of malformations produced by HD were accompanied by inhibited maternal weight gains during pregnancy. Principal malformations observed were cleft palate, immature lung and herniated diaphragms.

\section{INDUSTRIAL HYGIENE - PHASE I}

Previous epidemiologic and laboratory data suggest that coal liquids may pose carcinogenic risk. Therefore, a comprehensive industrial hygiene program was initiated at the Ft. Lewis SRC pilot plant. A brief description of the program follows. 
TABLE 18. Comparison of Acute and Repeated Dose Toxjcjities
of SRC Materials in the Female Wistar Rat of SRC Materials in the Female Wistar Rat
Acute
Repeated
Dose

\begin{tabular}{|c|c|c|}
\hline Material & $\begin{array}{l}\text { Acute } \\
\text { (b) } \\
L D_{50}\end{array}$ & $\begin{array}{c}\text { Repeated } \\
\text { Dose } \\
\text { (b) } \\
L_{50}{ }^{(b)}\end{array}$ \\
\hline Raw naphtha & 2.30 & 0.96 \\
\hline Heavy distillate & 2.98 & 1.19 \\
\hline Middle distillate & 3.75 & 1.48 \\
\hline Shale oil & 9.22 & --- \\
\hline Diesel oil & 11.8 & ---- \\
\hline Crude petroleum & $>12$ & --.- \\
\hline
\end{tabular}

(a) Materials were administered one-time-only by gavage for acute toxicity studies. For subchronic studies, materials were gavaged once daily for 5 consecutive days.

(b) $\mathrm{LD}_{50}$ is defined as the dose, in grams of material per kilogram of body weight, required to $k i 1 l 50 \%$ of the animals. For the acute toxicity study, this value represents a single dose; for the subchronic studies, the value represents a daily dose.

Worker Education

Initially, each employee is advised of the potential harmful effects of materials with which he will be working, the precautions necessary, good industrial hygiene practices, etc. Thereafter he is periodically shown training films and slide presentations and is given lectures on suitable topics by qualified physicians. The educational program is a continuing effort to educate the employee concerning the potential hazards involved, measures being taken to protect him, and what he should do to protect himself. Information generated in the various health programs is made available to the employee as it becomes available.

Each employee is furnished a complete change of clothing daily, and shoes as needed. A change house is provided to prevent possible contamination of street clothes. Showers are mandatory after each shift. Lunchroom facilities are also provided to avoid food contamination.

The training program also addresses use of respirators, protective clothing for specific jobs where exposure to potentially hazardous materials might occur, and work procedures in potentially hazardous areas. 
TABLE 19. Maternal and Fetal Toxicity in Rats Following Dosing with SRC-IIMaterials from 12-16 Days Gestation.

\begin{tabular}{|c|c|c|c|c|c|c|c|c|c|c|}
\hline Agent & $\begin{array}{c}\text { Dose }{ }^{(a)} \\
(g / \mathrm{kg} / \text { day })\end{array}$ & $\begin{array}{l}\text { Number } \\
\text { Dosed }(b)\end{array}$ & $\stackrel{\%}{\text { Dead }}(c)$ & $\begin{array}{l}\text { Number } \\
\text { Pregnant } \\
\text { at } 21 \mathrm{dg}\end{array}$ & $\begin{array}{l}\text { Weight } \\
\text { Gain } \\
\text { to } 21 \mathrm{dg}(\mathrm{d})\end{array}$ & $\underset{\operatorname{Implants}_{\text {Resorbed }}^{\mathcal{X}}(e)}{(e)}$ & $\begin{array}{c}\text { Litters } \\
\text { With } \\
\text { Resorptions }\end{array}$ & $\begin{array}{c}\underset{x}{x} \\
\text { Mal formpd } \\
\text { Fetuses }\end{array}$ & $\begin{array}{l}\text { Litters } \\
\text { With } \\
\text { Malformed } \\
\text { Fetuses } \\
\text { Fet }\end{array}$ & $\begin{array}{l}\text { Fetal } \\
\text { Weight } \\
\text { at } 1 \mathrm{dg}(g)\end{array}$ \\
\hline Corn 0 il & -- & 14 & 0 & 12 & $148 \pm 31$ & $1^{(h)}$ & 1 & 0 & 0 & $5.4 / 0.5$ \\
\hline Aroclor $(\mathrm{b})$ & 0.11 & 13 & 0 & 10 & $101 \pm 24$ & 7 & 5 & 0 & 0 & $4.3 / 0.6$ \\
\hline Raw Naphtha & $\begin{array}{l}0.28 \\
0.56 \\
0.84 \\
1.12 \\
1.41 \\
1.69\end{array}$ & $\begin{array}{r}11 \\
12 \\
14 \\
6 \\
7 \\
5\end{array}$ & $\begin{array}{r}9 \\
8 \\
43 \\
67 \\
86 \\
80\end{array}$ & $\begin{array}{l}8 \\
9 \\
7 \\
1 \\
1 \\
1\end{array}$ & 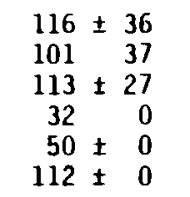 & $\begin{array}{c}4(i) \\
23 \\
4(h) \\
0 \\
0\end{array}$ & \begin{tabular}{c}
4 \\
4 \\
3 \\
\hdashline-- \\
20 \\
0
\end{tabular} & $\begin{array}{c}2 \\
0 \\
1 \\
-- \\
1 \\
0\end{array}$ & \begin{tabular}{c}
1 \\
0 \\
1 \\
\hdashline- \\
0 \\
0
\end{tabular} & $\begin{array}{l}5.5 / 0.6 \\
5.5 / 0.5 \\
5.4 / 0.5 \\
4.7 / 0.2 \\
5.1 / 0.3\end{array}$ \\
\hline $\begin{array}{l}\text { Middle } \\
\text { Distillate }\end{array}$ & $\begin{array}{l}0.33 \\
0.65 \\
0.98 \\
1.30 \\
1.63 \\
1.96\end{array}$ & $\begin{array}{r}9 \\
11 \\
9 \\
6 \\
6 \\
3\end{array}$ & $\begin{array}{r}0 \\
9 \\
11 \\
33 \\
67 \\
100\end{array}$ & $\begin{array}{l}9 \\
7 \\
8 \\
4 \\
2 \\
0\end{array}$ & $\begin{array}{c}127 \pm 43 \\
149 \pm 32 \\
118 \pm 40 \\
126 \pm 19 \\
94 \pm 36 \\
\ldots-\end{array}$ & $\begin{array}{c}5 \\
7 \\
20 \\
0 \\
0(i) \\
64 \\
--\end{array}$ & $\begin{array}{r}5 \\
5 \\
5 \\
0 \\
2 \\
--\end{array}$ & $\begin{array}{l}3 \\
0 \\
0 \\
0 \\
0 \\
-\end{array}$ & $\begin{array}{c}1 \\
0 \\
0 \\
0 \\
0 \\
-\end{array}$ & $\begin{array}{l}5.8 / 0.6 \\
5.8 / 0.6 \\
5.1 / 0.4 \\
4.9 / 0.5 \\
4.5 / 0.4 \\
\ldots\end{array}$ \\
\hline $\begin{array}{l}\text { Heavy } \\
\text { Distillate }\end{array}$ & $\begin{array}{l}0.37 \\
0.73 \\
1.10\end{array}$ & $\begin{array}{l}15 \\
13 \\
12\end{array}$ & $\begin{array}{r}0 \\
0 \\
17\end{array}$ & $\begin{array}{r}4 \\
10 \\
9\end{array}$ & $\begin{array}{r}129 \pm 31 \\
85 \pm 23 \\
76 \pm 23\end{array}$ & $\begin{array}{l}96 \\
669 \\
69\end{array}(i)$ & $\begin{array}{l}7 \\
9 \\
9\end{array}$ & $\begin{array}{r}1 \\
74 \\
60\end{array}$ & $\begin{array}{l}2 \\
5 \\
6\end{array}$ & $\begin{array}{l}5.3 / 0.5 \\
4.3 / 0.7 \\
4.3 / 0.5\end{array}$ \\
\hline
\end{tabular}

\footnotetext{
(a) Administered by gavage once daily for 5 consecutive days; if undiluted, 0.1-1.2 $\mathrm{ml}$ given per $300 \mathrm{~g}$ body weight.

(b) Diluted in corn oil, given at $1 \mathrm{ml}$ per $300 \mathrm{~g}$ body weight.

(c) Includes both pregnant and nompregnant adult females.

(d) Body weight gain between 0 and 21 days of gestation (dg); mean \pm SD.

(e) Calculated on a per fetus rather than a per litter basis; includes resorbed and dead implants.

(f) Combination of soft tissue and skeletal malformations.

(g) Pooled means of each litter.

(h) One or more females delivered prematurely; implant data incomplete and not included.

(i) One or more litters with all implants resorbed.
} 
Medical Surveillance

The medical surveillance program provides periodic examinations and surveillance in sufficient scope to detect, at an early stage, any changes in physiological functions. Each employee is given a complete medical examination initially, and once per year thereafter. The examination consists of a medical history and an extensive physical examination. A complete blood workup is performed, consisting of a white blood cell count, hemoglobin, hematocrit, mean corpuscula, iemoglobin concentration, and differential white cell count. Analysis of blood and urine, including a microscopic examination, is also performed.

The skin is examined carefully for evidence of lesions, and employees are asked to report any unusual skin conditions. The annual skin examination is supplemented by a quarterly skin examination by the Plant Nurse. Any dermatologic problems requiring a physician's care are referred to a Board-certified dermatologist.

Posterior-anterior and lateral chest $X$-rays are taken and interpreted by a Board-certified radiologist. Pulmonary function tests, consisting of forced vital capacity and forced expiratory volume, are performed by the Plant Nurse. Detailed medical records are maintained on each employee for future epidemiological studies.

To date, there have been five mild transient cases of photodermatitis at the Ft. Lewis pilot plant resulting from exposure to coal liquefaction materials. No other identifiable cases of occupational disease have occurred. Continued follow-up will determine if effects occur after long incubation periods among SRC pilot plant employees.

Industrial Hygiene Monitoring

Site- and personnel-monitoring are ongoing at the $\mathrm{Ft}$. Lewis SRC pilot plant. Methods used and results to date are discussed on p. 105.

\section{Toxicological Determinations}

Toxicological measures to be performed, and those performed to date, are described in Phases I and II, Biomedical Program (pp. 37-60 and 76-82). Summaries of available information are also provided. Data from animal studies suggest that heavy coal liquids from the SRC-II process may cause dermal carcinogenesis. Results from Phase I and II studies may define specific compounds and compound classes of concern, and allow development of appropriate control, work-practice procedures, and specific monitoring methods.

\section{ECOLOGICAL STUDIES AND CHEMISTRY}

SRC-II materials may enter the environment by several routes, including: 1) accidental releases of liquid products during handling, storage, and transportation; 2) aqueous leachates from solid waste disposal; 3) unplanned releases of treated and untreated liquid effluents; and 4) fugitive atmospheric 
emissions. Severity and duration of environmental effects will depend on the quantities and rates of releases, and the persistence, behavior, and chemical form(s) of materials released in the environment.

To evaluate the potential fate and effects of SRC-II materials in the environment, research will focus on source materials from pilot plants and will include studies relevant and applicable to demonstration facility site operations. Environmental studies will be phased in the same manner as are biomedical studies. The following section describes studies to be performed in Phase I, utilizing a battery of ecological screening assays. Acute $(a)$ and chronic screening assays will provide data on potential toxicity of SRC-II materials (liquid and solid) released to the environment. Organisms representing various aquatic and terrestrial trophic levels will be tested. Tests described below consider regulatory agency concerns and the needs of process developers.

\section{Liquids}

SRC-II product fuel $0 i 1$ and hydrodesulfurized naphtha may be primary products of SRC-II technology. Because they may be discharged to waters and/or soils as a consequence of shipment or storage, these products will be examined in Phase I screening systems for potential ecological effects, as will both treated and untreated process waters (Table 20). Although the possibility that untreated process water will enter the environment is small, it is essential to establish what effects might occur from an unplanned discharge. Further, these data will aid in establishing the effectiveness of water-treatment systems relative to ecological effect.

\section{Aquatic Screening}

Studies described below will assay complex SRC-II liquids, selected chemical fractions, and/or specific compounds and reference commercial oils. Test organisms include: the freshwater green algae, Selenastrum capricornutum; the zooplankter, Daphnia magna; two sediment-dwelling detritivores, Chironomus tentans and Tanytarsus dissimilis; the fathead minnow, Pimephales promelas; and rainbow trout, Salmo gairdneri. These species are accepted reference test organisms and most have considerable experimental history. The two benthic detritivores were selected as species representative of the water/sediment interface, where coal liquids released to the environment are expected to accumulate. The two fish represent eastern and western species.

Acute toxicity tests serve to: 1) provide a means of screening SRC-II raw liquids and chemical fractions, 2) provide a reference data base likely to be required for the generic environmental impact statement and various federal and state permits, and 3) establish appropriate concentrations for longer-term (e.g., chronic)studies. Chemistry will be integrated with toxicity tests because partitioning of SRC-II liquids into water and sediment in test systems varies with time and compound type. Animals exposed chronically (e.g., 30 days) may be exposed to different toxic compounds from those exposed acutely (e.g., 48 to 96 hours). Toxicity results can be drastically changed through

\footnotetext{
(a) Acute toxicity studies are funded by the U.S. Environmental Protection Agency.
} 
TABLE 20. Phase I Ecological Screening Assays: Liquid Materials

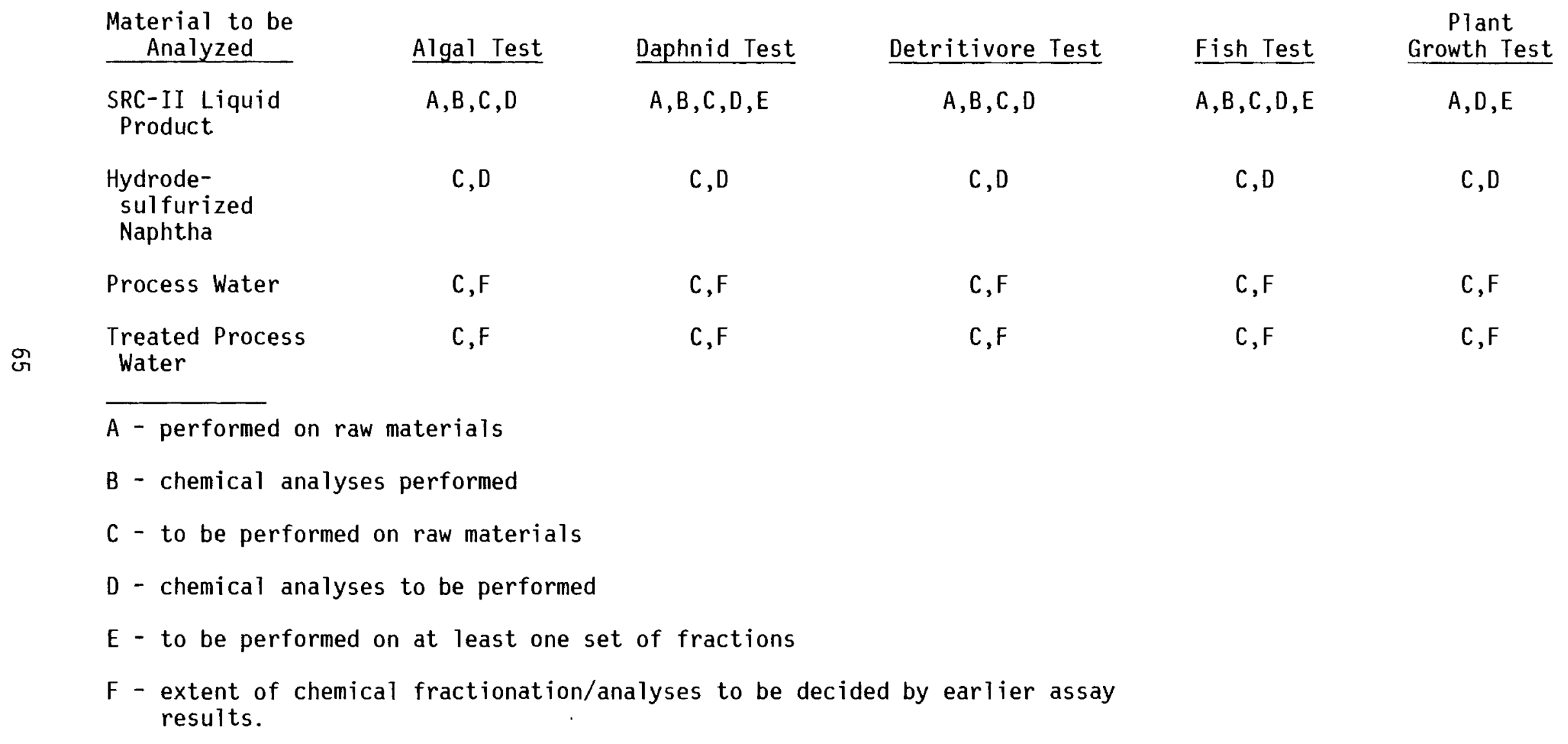


partitioning effects, depending on the kinetic energy of mixing devices used to introduce pollutants to water.

Our mixing system (termed batch, or replacement) provides five sequential extractions of SRC-II oil with dilution water at 2-day intervals. Each aqueous extract is chemically characterized. The first extraction is used as a stock solution for acute toxicity tests. Chronic tests are conducted with both the first and a later extraction to simulate effects of long-term exposures to sublethal concentrations of acute (relative hydrocarbon concentrations after initial contact with water) and chronic (relative hydrocarbon concentrations after prolonged contact with water) mixes. These tests span the range of mixes anticipated for an SRC-II product spill in a river.

Acute toxicity tests will be repeated only as required for comparative purposes (e.g., when other product blends or fractions become available). Chronic toxicity tests will determine long-term survival, growth rate and reproductive potential of organisms exposed to concentrations of test material that are not acutely lethal.

Algal Test System. For some classes of chemicals, primary producers comprise the most sensitive biological community. Accordingly, development of procedures for algal assay and the laboratory use of periphyton communities for toxicity testing is increasing. Algal assays are designed to determine the concentration of test material having no observable toxic effect and are conducted by preparing four replicates of at least five concentrations of test material, and a control. A standard nutrient medium is distributed in replicated flasks with a known number of $S$. capricornutum. Test cultures are incubated under continuous light at $\overline{24}^{\circ} \overline{\mathrm{C}}$ for 5 days. After 5 days exposure, cell counts and chlorophyll a fluorescence are determined. Remaining algal cells are removed by centrifugation and inoculated into flasks containing clean medium and no test material. After a 9-day recovery period, cell counts and chlorophyll a fluorescence are again determined.

Daphnid Test Systems. Acute tests determine the potential effects of test materials over short-term exposures. Dose-response relationships, including the median lethal concentration $\left(L C_{50}\right)$ and lowest concentration producing a toxic response are determined. A 48-hour static approach is employed to assay the effects of six test concentrations, plus controls. Six D. magna are used per test concentration or control. Tests are conducted under selected conditions of water hardness, temperature, dissolved oxygen (DO) and $\mathrm{pH}$ to evaluate the effects of water quality on toxicity. Water (DO, $\mathrm{pH}$, temperature) and chemical variables (total organic carbon, ultraviolet and infrared hydrocarbon measurement) of stock and exposure solutions are monitored during testing to correlate chemistry with effects.

To study long-term effects of concentrations of test material below those that are acutely lethal, a Daphnia population unit is observed over its life cycle. The test procedure employs five concentrations of test material, plus controls. Test concentrations bracket $1 / 10$ the acute $\mathrm{LC}_{50}$. Test organisms are exposed in a static system to the same test concentration for up to 28 days. However, the organisms are transferred three times weekly (standard renewal procedure) to fresh test solution. Long-term survival, growth and reproduction (i.e., timing, number of offspring, etc.) are monitored. 
Detritivore Test Systems. Acute toxicity tests with midge larvae, C. tentans, measure mortality after short-term exposure (48-96 hours) to test materials under selected water-quality conditions as described for $\underline{D}$. magna. Each test chamber contains paper substrate to reduce cannibalism.

Chronic toxicity tests with midge larvae evaluate potential effects of materials on organisms found in sediment and living largely on detritus. The procedure is similar to that described for D. magna and employs five concentrations of test material, plus controls. Test concentrations bracket 1/10 the $\mathrm{LC}_{50}$. Test organisms are transferred three times weekly to fresh test solution and are exposed for up to 21 days. Life-cycle analyses include monitoring survival, reproduction, emergence timing and growth. Because of differences in larval size and timing of various 1 ife-cycle events, $C$. tentans is used to study growth; and I. dissimilis is used to study reproduction and emergence timing.

Fish Test Systems. Acute toxicity tests with fathead minnows, P. promelas, and rainbow trout, $S$. gairdneri, are designed to measure mortality $\left(L_{50}\right)$ after short-term exposure to test materials under selected waterquality conditions, as described for $D$. magna and $C$. tentans. The exposure period is 96 hours, and tests employ flow-through systems to avoid low DO levels resulting from fish metabolism, bacterial oxygen demand, and waste breakdown. To provide data on sublethal effects, observations are also made on swimming behavior, loss of reflex, discoloration, and mucus production.

Chronic toxicity tests with fathead minnows are conducted under flowthrough conditions at five test concentrations which bracket $1 / 10$ the acute $L_{50}$. Eggs or larvae are exposed for up to 30 days, and long-term survival and growth are monitored. Test duration can be extended to include spawning of mature individuals. After spawning, 50 embryos are randomly selected for incubation to determine viability, hatchability, and reproductive success.

For western fish species, tests will be conducted in which the fertile embryos of rainbow trout are exposed for 28 to 60 days. Embryo survival and survival and growth of hatched fish will be determined. Tests will be conducted under flow-through conditions and are designed to determine which toxicant concentrations adversely affect early life stages of fish. The procedure employs five concentrations of test material, plus controls. Test concentrations bracket $1 / 10$ the $L C_{50}$. A dilution factor of not less than 0.5 will be used between treatments.

Behavioral Studies. Organisms in their natural environment may avoid, may be unaware of, or may be attracted to noxious chemicals. Therefore, behavioral studies will be conducted with fathead minnows and, possibly, midge larvae to aid interpretation of acute and chronic toxicity test results. Pollutant concentrations causing death, retarding growth, or limiting reproduction in the laboratory are only important in nature if they are below the avoidance threshold. Avoidance studies with fish will be conducted in circular flow-through systems employing nine chambers surrounding a center drain. The system is designed to allow test organisms to enter or exit ambient water or water contaminated with test material. Delivery systems are designed to allow desired physicochemical partitioning of test material among oil, sediment, and water phases. Visual observations and video recording techniques will document behavior. 
Forty-five fish are placed in the system to start a test. After a 24hour acclimation period, toxicant is introduced to some (randomized) chambers. Observations on fish response (e.g., avoidance/attraction) to SRC-II materials, are made at half-hour intervals for 2-4 days. The effect of other ecological variables (shelter, food, temperature, etc.) on response to SRC-II materials will also be evaluated.

Organic Analytical Chemistry for Aquatic Screening Studies. Chemical analyses associated with aquatic screening studies consist of monitoring concentrations of SRC-II materials as toxicity experiments are conducted, as well as more detailed procedures for determining exposure concentrations of various SRC-II chemical components.

Applicability of individual tests will depend on SRC-II concentrations employed during ecological testing and the quantity of material available for analysis. The following methods and/or analyses will be employed:

1) Dohrman or Beckmann carbon analyses - direct injection of aqueous sample; measures total organic carbon (TOC).

2) IR analysis - extraction of water with carbon tetrachioride followed by determination of the absorbance at $2927 \mathrm{~cm}^{-1}$; estimates hydrocarbon and phenol concentrations.

3) Photometric phenol assay - use of aminoantipyrene to form a colored complex; allows rapid estimation of phenols in aqueous media.

4) XAD-2/IR analysis - organic material from solubilized or suspended SRC-II in water can be sampled by pumping large quantities of water over $X A D-2$ resins and extracting the resin with carbon tetrachloride. The quantity of material trapped on the column is estimated using infrared absorption at $2927 \mathrm{~cm}^{-1}$.

During testing, exposure concentrations of various SRC-II components will be determined as follows:

1) Hydrocarbons - aromatic and saturate hydrocarbons are extracted from the test water using hexane. The hexane extract is concentrated, and the aromatic hydrocarbons separated from saturates using silica gel chromatography. Hydrocarbons are then quantitated using capillary gas chromatography and GCMS techniques discussed on pp. 48-51.

2) Phenols - the water sample is adjusted to $\mathrm{pH} 12+$ with $\mathrm{NaOH}$ to form the sodium phenates, and extracted with hexane to remove impurities. Acetic anhydride is then added to form phenol acetate derivatives, which readily extract into hexane. The hexane extract is concentrated and the phenols quantitated with FID capillary gas chromatography using an internal standard calibrated against a variety of methylated phenols and indanols.

3) Pyridines and Anilines - anilines and other basic nitrogen compounds, along with neutral species, are extracted from an 


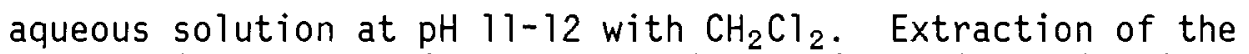
$\mathrm{CH}_{2} \mathrm{Cl}_{2}$ with $1 \mathrm{M} \mathrm{HCl}$ yields a fraction enriched in basic nitrogen compounds. Añilines in this fraction can be separated from $\mathrm{N}$-heterocycles and quantitated by GC after acetylation with acetic anhydride. Extraction of the derivatized $\mathrm{CH}_{2} \mathrm{Cl}_{2}$ solution with $1 \mathrm{M} \mathrm{HCl}$ will remove basic heterocycles and yield a $\mathrm{CH}_{2} \mathrm{Cl}_{2}$ solution containing neutral acetylated amines, which are then quantitated by GC. The procedure distinguishes between the presence of alkyl pyridines or alkyl anilines in an aqueous sample. Alkyl anilines and pyridines have similar GC and mass spectral characteristics; identification of these compound classes is difficult without prior derivatization.

4) Other compounds - it is anticipated that for most SRC-II materials, the analyses described above will account for most organic components extracted into water, unless there is substantial suspended insoluble organic material present. In that case, analytical problems are similar to those discussed on pp. 48-51, and a similar analytical strategy will be employed.

Preliminary Results. Results of acute tests with a potential SRC-II liquid product (a blend composed of 2.9 parts MD to 1 part HD) indicated median lethal concentrations $\left(L_{50}\right)$, determined by probit analysis at the $95 \%$ fiducial leve1, were 2.0 (1.8 to 2.3) ppm TOC for D. magna, 8.3 (7.9 to 8.7) ppm TOC for fathead minnows, and 10.0 (4.8 to 20.5 ) p $\mathrm{pm}$ TOC for midge larvae.

An acute test was also conducted with Prudhoe Bay crude $0 i 1$ as a reference toxicant. The stock solution, prepared in the standard manner, as for the SRC-II blend, produced a water-soluble fraction with $19 \mathrm{ppm}$ TOC (compared to the 900 to $1100 \mathrm{ppm}$ TOC produced by the SRC-II blend). The reference oil produced no mortalities in fathead minnows, daphnids or midge larvae at TOC levels producing 100\% mortality with the 2.9:1 blend. Therefore, based on TOC, the SRC-II blend appears to be more toxic than Prudhoe Bay crude. The difference in toxicity probably reflects higher concentrations of watersoluble phenolics in SRC-II preparations.

Preliminary chronic studies showed that the first extract of 2.9:1 SRC-II blend inhibited algal growth during exposure to TOC concentrations as low as $6.4 \mathrm{ppm}$, but did not inhibit algal recovery until TOC concentrations exceeded $57 \mathrm{ppm}$. Daphnia growth was inhibited at TOC concentrations as $10 \mathrm{w}$ as $0.6 \mathrm{ppm}$, about $25-\overline{33 \%}$ of the acute $L_{5}$. Survival and reproductive success of Daphnia were reduced at about $1 \mathrm{ppm}$ TOC. Additionally, emergence of midges was delayed at these low concentrations.

Chemical analysis showed that SRC-II aqueous extracts contained a complex mixture of phenols and aromatic and saturated hydrocarbons. Concentrations of total organic carbon, phenols and hydrocarbons decreased with each extraction. Changes in relative concentrations of various compound classes of phenols also occurred with each replacement. These changes in phenols were attributed to differences in the oil-water distribution coefficients as the weights of phenolic molecules increased. 
Logarithmic depuration occurred for TOC, total phenols, and phenols of lower molecular weight. Approximately linear depuration was evident for aromatic hydrocarbon classes and phenols of higher molecular weight. Phenolic compounds comprised high percentages of the TOC load of all extractions.

\section{Terrestrial Screening}

Plant Growth and Rooting. Small weighing-leaching lysimeters will be used to determine if SRC-II liquids and mineral residues (solid wastes) are deleterious to plant growth when introduced to soil in various amounts. This information is needed for soil decontamination procedures and cleanup following accidental spills in field situations.

The lysimeters are constructed of plastic irrigation pipe, nominally 1 meter long. Lysimeters are placed outdoors so that ambient effects of climate and soil conditions are presented to the growing plants. Water use by growing plants is determined by weighing. Leachates for in vitro biomedical analyses or aquatic screening assays can be obtained through a porous ceramic cup on the bottom of each lysimeter. Plants are grown from seed germination through seedling and vegetative growth, flowering, and seed-ripening stages of development. Experimental materials added to lysimeters are retrievable. Lysimeters can be opened to observe and measure root growth, as well as for customary above-ground observations and quantitative measurements.

Small lysimeters have many of the desirable experimental design features of greenhouse and growth-chamber experiments. Advantages include: 1) minimal quantitative requirements for SRC-II materials; 2) facile recovery of most test material, which allows assay of materials considered to be of high relative toxicity; 3 ) controls and treatments can be statistically replicated; 4) various concentrations of test materials can be used over a broad range of backgrounds in amounts anticipated from spills; 5) the same experimental soil (or different soils) can be used and replicated; 6) water content of soil can be carefully monitored so plants are never deficient or over-supplied with water; 7) weeds can be controlled; 8) plant harvests can be made and tissues archived or chemically analyzed; 9) seeds can be saved for further tests; and 10) observations for symptoms of chemical toxicity can be made on shoots and roots.

Barley, Hordeum vulgare, will be the experimental taxon. Observations and measurements wi 1 include: 1) evaluation of standard botanical characteristics: lesions, chlorosis, necrosis, number of flowering culms, length of seed heads, total shoot biomass, etc.; 2) performing standard chemical analyses (protein content of grain, mineral content of shoot tissue); and 3 ) evaluating biological toxicity (seed germination and in vitro bioassay).

Solids

All waste materials from SRC-II facilities are expected to be in solid or semisolid form and disposed in landfills. Solids of concern include SRC-II gasifier ash, consisting of the gasified residue from vacuum bottoms, and process water incinerator ash. Ecological screening assays for solids are shown in Table 21. 
Table 21. Phase I Ecological Screening Assays: Solid Materials

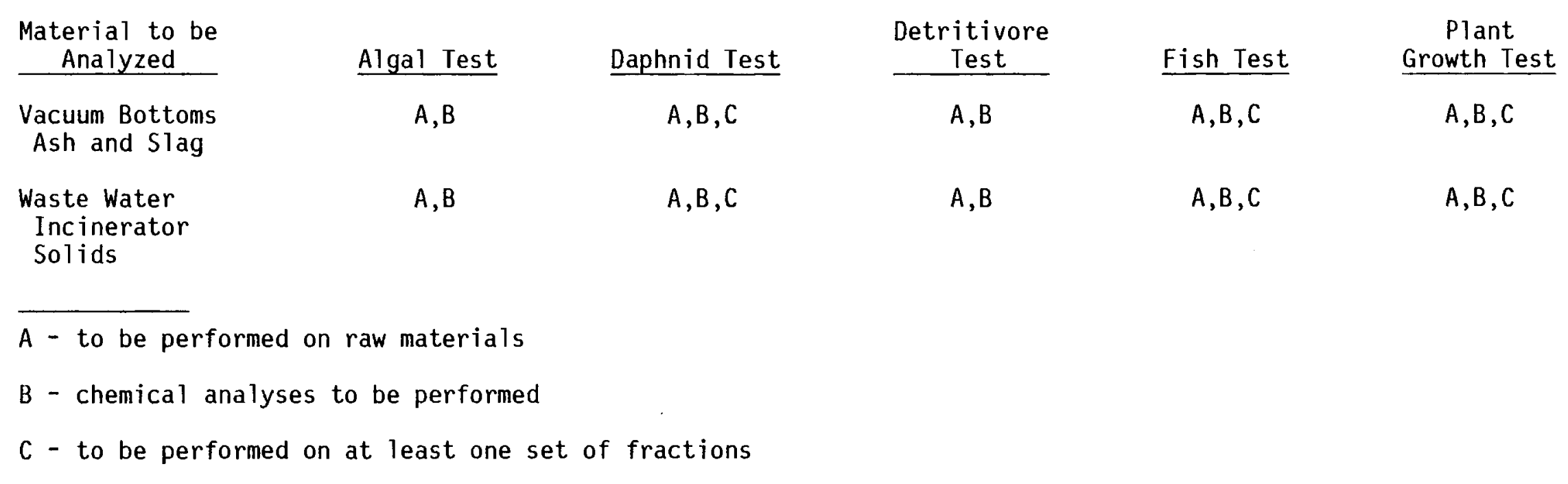




\section{Aquatic Screening}

Leachates of solid wastes will be prepared using lysimeters ( $p .70$ ) or as described on $p .89$, and assayed in the aquatic screening systems described on pp. 64-67. These assays are similar in design and purpose to analyses suggested by RCRA.

\section{Terrestrial Screening}

Small weighing-leaching lysimeters, described on $p .70$, will be used to screen for potential effects of solid wastes on plant growth and productivity.

\section{ENVIRONMENTAL ASSESSMENT/RISK ANALYSES - PHASE I}

Toward the end of Phase I research, it will be possible to define general properties of major products, process streams, and effluents anticipated from the SRC-II demonstration facility. Phase I studies will provide data from short-term screening assays on potential biomedical and ecological effects for a range of test materials within demonstration facility design specifications. Effects data on other materials presently in commerce will also be available for comparative purposes. Phase I studies will identify compounds and compound classes causing biomedical effects in simple systems. Chemistry and environmental fate studies (Phase II) will provide qualitative estimates of chemical entities of potential concern. Little or no information will be available on atmospheric emissions, either in the workplace or the environment around the facility, nor will substantial laboratory or field data on foodchain or hydrological transport of SRC-II materials be available.

Environmental assessment/risk analyses at this stage will therefore be qualitative, and will identify areas where information is needed to lower degree of uncertainty, and allow quantitative analyses of environmental risk. Data needed for environmental assessment/risk analyses of materials specific to the SRC-II process are described below, using several examples. Since analyses for certain criteria pollutants such as $\mathrm{SO}_{x}, \mathrm{H}_{2} \mathrm{~S}$, and $\mathrm{NO}_{x}$ are ongoing, specific assessments for effects of these materiałs will not be performed. However, we will use, relative to these materials, available biological and engineering information in assessment of the SRC-II process.

Phase I analyses consist of short-term screening assays to measure toxicity of major process streams, products, and solid and liquid effluents. Additionally, some chemical analyses on compounds and compound classes of potential biomedical and ecological concern may be available. The following assessment activities will be performed with this information: 1) engineering analyses of potential release situations relevant to occupational and environmental effects of major SRC-II process streams, products, and liquid and solid wastes; and 2) qualitative analyses of biomedical and ecological risk.

The nature of biomedical and ecological assessment can best be illustrated by specific hypothetical examples:

EXAMPLE 1: About percent of the female work force will be exposed to process stream $X$ during facility maintenance operations. Process stream $X$ is teratogenic in rats only at levels approaching those for acute 
maternal toxicity. Therefore, existing data suggest minimal hazard to the conceptus of female workers exposed to low doses of stream $X$. However, to confirm and quantitate this prediction, the following information will be needed:

a) Data on Teratogenic Effects of Process Stream $X$ in Another

Teratogenicity of several compounds appears to vary with species. Therefore, acute teratogenicity studies with rabbits exposed to process stream $X$ are planned in FY

\section{b) Data on Developmental Effects of Process Stream $X$}

Presently, there are no data on potential developmental effects occurring as a consequence of in utero exposure. Therefore, possible effects of process stream $X$ on anatomical, physiological, and behavioral maturation of offspring cannot be ruled out. Studies to address this question are scheduled for FY

\section{c) Data on Inhalation Exposure Effects of Process Stream $X$}

Present work on teratogenicity considers only the ingestion route of exposure. We do not anticipate that inhalation exposure would alter rat teratogenicity. For example, we would expect that the relationship between maternal toxicity and fetal effect would be similar for the inhalation route of exposure as compared with ingestion. However, differential absorption of process stream compounds from lung may result in a different teratogenic potential. Thus, work on inhalation teratogenicity of process stream $X$ is planned in FY

EXAMPLE 2: Process stream $Y$ is produced in small quantities in a vessel from which there is little chance of fugitive emission. Process stream $Y$ can easily be cleaned from the vessel and safely disposed of before maintenance. Although the material has been shown to produce significant genotoxicity in submammalian and mammalian cell assays, it does not appear to be of occupational or environmental health concern (based on existing process information). To confirm this assessment, the following information is needed:

a) Final Design Criteria for Composition and Use of Process Stream Y

Our assessment at this stage must be based on process conditions and vesse 1 construction described in Base 0 demonstration facility design. If design considerations result in changes in exposure scenarios, risk may be altered. Phase I demonstration design analyses will be available in FY

b) Information on Inhalation and Dermal Carcinogenicity of Process Stream Y

Carcinogenic potential in animal systems may differ from that derived from the in vitro systems used to date. Data on carcinogenic potential as a function of exposure route will be available in FY 
EXAMPLE 3: Relative to crude petroleum, product blend $Y$ shows significant acute toxicity to freshwater biota. Phenolic compounds appear to be primarily responsible. Based on available data, a spill of SRC-II product $b$ lend $Y$ may cause severe short-term damage in aquatic habitats, depending on the amount and conditions of the spill. The following information is needed to further quantitate and confirm this prediction:

\section{a) Engineering Estimates of Product Composition for the Demonstra- tion Facility}

Analyses of specific phenol types and concentrations are required for the four SRC-II blend options currently being considered. Other options may differ markedly in toxicity to aquatic organisms, due to phenolic composition or physical partitioning characteristics. Decisions on the final product blend are anticipated in FY

\section{b) Information on Biodegradation Rates of Phenols in Water and Sediments}

Based on available data, degree of acute risk will be a function of persistence of phenolic residues in aquatic systems. Data on fate of phenolic residues in aquatic systems is anticipated in FY

\section{c) Analyses of Long-Term Fate and Effects of Product Blend $Y$}

Severity or persistence of long-term chronic effects of product blend $Y$ in the environment may not reflect acute toxicity data for single species. Thus, multispecies testing in model ecosystems is planned in FY

EXAMPLE 4: Leachates prepared from gasifier slag $X$ show no genotoxicity in in vitro assays; contain few, if any, toxic trace metals; and have little effect on terrestrial plants and other biota in laboratory studies. Based on available data, disposal of gasifier slag poses no greater risk than disposal of fly ash from coal-fired power plants. The following analyses are needed to confirm and quantitate this prediction:

\section{a) Field Lysimeter Analyses of Gasifier Slag X}

Laboratory studies do not usually consider field environmental factors (e.g., climatic processes, soil microbial activity, physical/chemical interactions, heating and cooling cycles, and long-term geochemistry) that may alter biological availability of toxic metals and organics. Studies to address this are planned for FY

\section{b) Confirmation that Gasifier Slag $X$ will be the Primary Solid} Waste Generated by the SRC-II Demonstration Facility

Present Base-0 design for gasification of vacuum bottoms requires an $F$ gasifier. However, if a $G$ gasifier (requiring higher heats of gasification over shorter reaction times) is used, the environmental fate and effects of slag might be different. A decision on gasifier type is expected in FY 


\section{PHASE II}

Phase II biomedical and ecological studies consist of long-term, extensive analyses of effects in animal and ecological systems. These studies are labor-intensive, expensive, time-consuming, and involve long-term utilization of specialized facilities. Therefore, not all materials can be subjected to Phase II analyses, and the following criteria for selecting materials were developed:

- Data base from the Phase I bioassays and chemical analyses suggests potential effect.

- Material is produced in significant quantity.

- Material has potential for occupational/environmental exposure.

- Material can be obtained in form considered representative of demonstration/commercial facility practice.

No one of the above criteria can be considered predominant in selection of materials for Phase II analyses. For example, in certain cases, Phase II analyses may overlap Phase I analyses in time of performance because the material in question has high potential for occupational or environmental exposure. Additionally, since some Phase II studies require methods development, initial Phase II work may employ Phase I materials. In other cases, a material that shows negative results in Phase I assay systems may be produced in large quantities, thus posing significant potential for occupational and environmental exposure. In still other cases, a material produced in limited quantity may demonstrate high biological or ecological activity in Phase I assays and be of concern because limited occupational or environmental exposure may result in significant biological effect.

Phase II assays are considered by the scientific community to be the most indicative of potential biological effect to human populations and the environment. They measure the pathological end-points in animal and ecological systems that are of ultimate concern to human populations (e.g. , cancer, neurotoxicity, developmental toxicity, bioconcentration, bioaccumulation, biomagnification, etc.). As such, the data from Phase II assays will be used for a number of essential purposes:

- As a basis for determining dose-effect relationships in assessing biomedical and environmental risk.

- As a basis in determining sources of SRC-II materials needing potential control, regulation or other ameliorative actions.

- In a scientific sense, as a basis for determining the appropriateness of Phase I short-term assays for screening of chemical compounds and compound classes of concern. This is an essential step if results from short-term assays are to be used in analyses of effects of process modification/control technology and definition of specific environmental-monitoring needs. 
BIOMEDICAL STUDIES

The present slate of materials and Phase II biomedical assays are shown in Table 22. Test conditions will be similar for those assays (i.e., dermal carcinogenicity, inhalation toxicity, and transplacental carcinogenicity) to be performed by both PNL and P\&M. Phase II biomedical assays are discussed below.

\section{Dermal Carcinogenicity}

\section{Liquid Process Streams and Products}

Studies on liquids consist of applying three dose levels of each material to the shaved dorsal skin of $\mathrm{C} 3 \mathrm{Hf} / \mathrm{HeBd}$ mice (25 males and 25 females) three times a week for up to 2 years. The highest dose of test material to be used is based on: 1) the maximum concentration of test material in acetone which can be accurately and uniformly applied to the skin, and 2) lack of acute toxicity when the test material is applied at this concentration. Lower doses are 1:10 and 1:100 dilutions of the highest concentration, respectively, in acetone. Positive controls (e.g., benzo[a]pyrene and 2-aminoanthracene) are included. Exposure concentrations for positive controls are based on acute toxicity and carcinogenicity as described in the literature and/or determined in our laboratory.

Animals are observed for appearance of skin alterations such as irritation, papillomas, and tumors. Moribund animals are necropsied and gross pathology determined. Samples of tumors and other tissues, including lung, liver, kidney, spleen, and heart, are taken for histological and pathological examination.

Chemical fractions, derived by solvent extraction ( $p .45)$, are being tested for dermal carcinogenicity by this method. These analyses are essential to correlate Phase I assay results with accepted pathological endpoints. Extent of correlation will determine if Phase I assay data can be used as predictors of specific chemical compounds and compound classes of concern.

Results to date suggest that SRC-II high-boiling-point material (HD) is carcinogenic for mouse skin, whereas low-boiling material (RN) demonstrates little carcinogenicity. A crude petroleum was also found to be carcinogenic for mouse skin, but was less potent than HD.

\section{Solid Process Streams and Wastes}

A procedure similar to that followed for liquid samples will be used with solid materials. However, solid materials will be suspended in an appropriate organic or aqueous solvent as determined by analyses described on pp. 51-54. 
TABLE 22. Phase II In Vivo Assays

\begin{tabular}{|c|c|c|c|c|c|c|}
\hline $\begin{array}{l}\text { Material to be } \\
\text { Analyzed } \\
\end{array}$ & $\begin{array}{c}\text { Dermal } \\
\text { Carcinogenicity }\end{array}$ & $\begin{array}{l}\text { Inhalation } \\
\text { Toxicity }\end{array}$ & $\begin{array}{l}\text { Dominant } \\
\text { Lethality }\end{array}$ & $\begin{array}{l}\text { Developmental } \\
\text { Toxicity } \\
\end{array}$ & $\begin{array}{l}\text { Transplacental } \\
\text { Carcinogenicity }\end{array}$ & $\begin{array}{l}\text { Neurobehavioral } \\
\text { Toxicity }\end{array}$ \\
\hline Raw Naphtha & A & B & B & $A$ & B & $C, D$ \\
\hline $\begin{array}{l}\text { Middle Dis- } \\
\text { tillate }\end{array}$ & B & B & B & $A$ & B & $C, D$ \\
\hline $\begin{array}{l}\text { Heavy Dis- } \\
\text { tillate }\end{array}$ & $A, D$ & c & $A, D$ & $A, D$ & c & c \\
\hline $\begin{array}{l}\text { Liquid Pro- } \\
\text { ducts }\end{array}$ & $E$ & $E$ & $C, D$ & $C, D$ & E & $c$ \\
\hline Coal Slurry & $E$ & $c$ & $c$ & $c$ & E & $c$ \\
\hline Vacuum Bottoms & $E$ & B & c & $c$ & B & B \\
\hline $\begin{array}{l}\text { Stripper Tower } \\
\text { Bottoms }\end{array}$ & B & B & D & B & B & B \\
\hline Gasifier Slag & $D$ & c & $C, D$ & $C, D$ & B & c \\
\hline $\begin{array}{l}A=\text { performed } \\
B=\text { not to be } d \\
C=\text { to be perfo } \\
D=\text { fractions } \\
E=\text { to be perfo }\end{array}$ & $\begin{array}{l}\text { d data available } \\
\text { termined } \\
\text { med, PNL } \\
\text { extracts to be a } \\
\text { med, P\&M }\end{array}$ & yed, PNL & & & & \\
\hline
\end{tabular}


Inhalation Toxicology

\section{Liquid Process Streams and Products}

Inhalation toxicological studies usually include 3-week, 13-week, and life-time exposure periods. Rats and mice will be exposed (whole-body) in PNL chambers. Liquid aerosols will be generated using a Retec nebulizer. Measurements in the chamber will include airflow, aerosol concentration, temperature and humidity, oxygen concentration, and particle size. Several methods may be used to monitor chamber concentration, including nonspecific spectrophotometric methods, total hydrocarbon analyses and GC analyses for compounds of specific concern as determined in Phase I analyses.

Test animals will be young adult Fischer 344 rats and $\mathrm{C} 3 \mathrm{H}$ mice. For 3-week studies, animals will be exposed in groups ( 10 males and 10 females) to one of three concentrations of test material. The exposure regime is 6 hours/ day, 5 days/week for the 3 weeks. Animals are weighed prior to, and weekly during exposure, and until 4 weeks after exposure. Animals are observed for mortality, clinical signs of distress and behavioral changes.

Thirteen-week studies will be performed essentially according to Good Laboratory Practices as suggested by the U. S. Environmental Protection Agency (EPA) and the Food and Drug Administration (FDA). Exposure regime is the same as described for the 3-week exposure (i.e., 6 hours/day, 5 days/week). However, sample sizes will be increased to 35 animals/sex/dose. Exposure dose will be selected on the basis of data obtained in 3-week studies. Highest dose will be that which causes no mortality and no more than $10 \%$ weight loss in the 3-week study. Lower doses will be $4: 1$ and 16:1 dilutions of the highest dose.

Animals will be observed as described for the 3-week exposure. Additionally, hematological and blood chemistry measures will be performed at 0,45 , and 90 days exposure. Some animals will be sacrificed at termination of exposure; others will be maintained for 2 months postexposure. At sacrifice, animals will be observed for gross pathological changes, and selected tissues will be saved for histopathological analyses.

Life-time exposures will closely follow the protscol for 13-week exposures; however, sample sizes will be increased to permit appropriate statistical evaluation.

Efforts to date have developed methods for generating aerosols of heavy coal liquids and for whole-body exposure of animals to these liquids. Factors such as aerosol particle size, concentration, and fractionation of chemical constituents as a function of particle size have been measured.

Solid Process Streams and Wastes

Analyses will be performed as described above. However, aerosols will be generated using either a Trost feed-Wright dust mill or a new brush-feed generation system recently developed at PNL. 


\section{Dominant Lethality}

The dominant lethal test, using Swiss-Webster mice, permits estimates of the incidence of a specific mutation type (namely, lethality) in a mammalian species. Male animals are administered solid or liquid test materials, either orally or by inhalation (methods described on pp. 57-59 and 78), then bred to unexposed females. Lethal mutations are expressed as death of the embryo. The stage of spermatogenesis affected can be determined by the time postexposure when an increase in embryolethality is found. That is, effects on mature sperm would be observed 1 to 2 weeks postexposure. Effects on sperm in earlier stages of spermatogenesis would not be observed until 3 to 8 weeks postexposure. Since the dominant lethal test is more time-consuming and expensive than in vitro mutagenesis systems, it will be used only on a limited set of materials. Material selection for dominant lethal testing will depend on data obtained from microbial and mammalian cell culture systems and other previously discussed criteria. Preliminary results from this assay system indicate that SRC-II HD and its basic fraction induce a low level of dominant lethality in mice.

\section{Transplacental Carcinogenesis}

Exposure of a pregnant female to a carcinogenic agent can result in increased tumor incidence in offspring during later life. Studies will be performed to evaluate potential transplacental carcinogenicity of SRC-II materials. Materials will be administered to the pregnant female either throughout gestation or at selected sensitive periods of fetal development (as determined by teratogenesis studies pp. 59-60), and the animal allowed to deliver. The dam and her offspring will be maintained for lifetime observation to evaluate tumor development. Materials will be administered to mice, either orally or by inhalation, as described previously. Materials will be selected based on Phase I results and results of dermal carcinogenesis (p. 76) and developmental toxicology studies ( $p$. 79-81).

\section{Developmental Toxicology}

Postnatal consequences of prenatal exposure to SRC-II materials will be evaluated from the following: a) postnatal appearance of a standard set of anatomical markers, b) neonatal appearance of neuromuscular and neurobehavioral capabilities and $c$ ) analyses of humoral and cellular elements of the immune system.

Materials will be administered to animals by ingestion or inhalation, as described previously. Dose will be selected based on results of repeated-dose and teratogenesis studies ( $p p$. 59-60). Teratogenicity after inhalation exposure will be evaluated as part of this effort, using protocols similar to those described for 3-week inhalation studies ( $p .78$ ) and Phase I teratogenicity studies.

Anatomic and functional measures of postnatal maturation will be evaluated (Table 23). At 40 and 60 days of age, immune system measures will be evaluated. These include determination of serum immunoglobulin levels to indicate effects on humoral system response and response to mitogens, a measure of cell-mediated immunity. 
TABLE 23. Anatomic and Functional Measures of Postnatal Maturation Test Measures

\begin{tabular}{ccccc}
\multicolumn{5}{c}{ Observation Days (Age) } \\
\hline I & 7 & 14 & 21 & 35 \\
\hline & $x$ & $x$ & $x$ & $x$ \\
& $x$ & & & \\
& $x$ & & & \\
& & $x$ & & \\
& & $x$ & & \\
$x$ & $x$ & $x$ & $x$ & \\
$x$ & $x$ & $x$ & $x$ & \\
& & $x$ & $x$
\end{tabular}

$\begin{array}{lll}\text { Turnover } & x & x \\ \text { Grasp } & x & x \\ \text { Retraction } & x & x\end{array}$

Vibrissal Placing

$x$

Cliff Avoidance

Negative Geotropism

$x$

Righting

$\begin{array}{ccc}x & x & \\ x & x & x \\ x & x & x \\ x & x & x \\ x & x & x \\ & x & x \\ & & x\end{array}$

Swimming

Visual Placing

$x \quad x$

Strength

Audiogenic Seizure

Organ Weight

(a) Indicates time at which test is performed. 
Cell-mediated immunity (specifically, cell-mediated cytotoxicity) is generally thought to be mediated by three types of effector cells: a) specifically immune, mature T-cells; b) antibody-dependent, cytotoxic cells; and c) activated macrophages.

Peripheral blood lymphocytes and cells isolated from spleen, mesenteric. lymph nodes, and thymus will be used in the mitogen-induced lymphocyte activation assays. Mitogens used in our assays include concanavalin-A (Con-A) and phytohemagglutinin, which stimulate $T$-cell populations, and pokeweed mitogen, which is primarily specific for B-cells but which also stimulates a small fraction of the T-Cell population. Tubes containing diluted whole blood or tissue lymphocytes, plus the appropriate mitogen, will be incubated for 3 days at $37^{\circ} \mathrm{C}$. Cell activation will be measured by assessing incorporation of 125 I-iododeoxyuridine into newly synthesized DNA during the final 20 hours of the culture period.

Preliminary evidence suggests that rats treated prenatally with HD have deficits in air-righting and swimming capabilities at early postnatal times. Cell-mediated immunity, as measured by Con-A stimulation of peripheral blood lymphocytes was not greatly affected by any of the SRC-II materials tested (RN, MD, and HD). However, animals treated with a polychlorinated biphenyl mixture (Aroclor 1254) showed significant depression in response.

\section{Neurobehavioral Toxicology}

Based on criteria discussed previously and results from acute toxicity studies (pp. 57-59), especially clinical signs of neurotoxicity, and developmental toxicology studies, SRC-II materials will be selected for analyses of neurobehavioral toxicity. Since initiation of these assays is dependent on results from acute tests of inhaled and ingested SRC-II materials, we will describe only briefly tests to be used.

\section{Conditioned Taste Aversion}

Rats are given test substance in drinking water or food, along with access to saccharin water (usually preferred to ordinary water). The animal is then tested as to preference for saccharin water vs water. Avoidance of saccharin water indicates an association of the saccharin with the test material administered.

\section{Conditioned Avoidance Behavior}

Animals are exposed to a test material, then tested for their ability to learn to avoid electric shock in a shuttle box. Loss of this learned ability is then measured as a function of time.

\section{Learning and Memory}

Number of trials to consistently run a maze in a fixed time is a function of learning response. Changes in response after the learning experience, a function of memory, will be measured in animals exposed to SRC-II materials, and compared with that in controls. 


\section{Open Field Activity}

Animals are placed in the center of a gridded box. Number of squares traversed in 1 minute is indicative of the animal's level of exploratory behavior. Exploratory behavior in animals exposed to SRC-II materials will be compared with that in controls.

\section{Physical Endurance}

Endurance of animals exposed to SRC-II materials will be evaluated in a standard National Institute of Environmental Health and Safety (NIEHS) swimming test and compared with controls.

\section{Research Needs}

We have described, to this point, state-of-the-art analyses which will be performed to determine potential biomedical effects of materials from the SRC-II process. However, several study areas which require intensive research are not incorporated as cost or work elements of the program since they involve development of new methods. To provide a full information base for biomedical assessment and environmental management of the SRC-II process, appropriate efforts in the following areas should be initiated:

\section{Dosimetry}

Unlike radionuclides, the biological disposition or dosimetry of organic chemicals is not well known. This is true even for most pure compounds; when complex mixtures are considered, the data base is almost nonexistent. To relate biological effects to causative agents, information is needed on absorption, tissue distribution and excretion of important compounds, particularly PNAs, PAAs and $\mathrm{N}$-heterocycles. Moreover, assessment of potential effects of human exposure to SRC-II materials will necessarily be extrapolated from data on experimental animals. The extrapolation, and comparison of biological effects of SRC-II materials with materials derived from other coal conversion processes, requires extensive knowledge of pharmacokinetics, distribution and metabolism of important SRC constituents.

\section{Factors Affecting Dermal Carcinogenicity}

Dermal exposure to SRC-II materials will be a primary route of exposure for occupational populations. We have described laboratory evidence that high-boiling-point SRC-II materials are skin carcinogens in mice. Epidemiological evidence from a number of sources suggests that coal-derived materials may also be skin carcinogens in man. Therefore, it may be necessary to examine several factors that might affect the carcinogenic process. For example:

Dose Fractionation. Current experimental evidence for carcinogenicity is based on continuous HD application to mice for a prolonged period. Since this is not representative of potential human exposure situations, information is required on effects of doses administered singly, staggered over varying time frames, and on doses mixed from various process streams. 
Removal of Dose from Skin. A common industrial hygiene practice in coal facilities is to wash off skin contamination with detergent and water. The efficacy of these procedures has not been fully established. Alternate washing/solvent regimes should be analyzed for their effectiveness in ameliorating dermal carcinogenicity.

Ultraviolet Light Exposure. Skin contamination is presently monitored at coal facilities by ultraviolet (UV) light examination. Furthermore, workers at coal conversion facilities will be exposed both to skin contamination and UV light from other sources. Effects of UV monitoring procedures and/or UV light originating from other sources on response of skin to coalderived materials have not been examined carefully.

Preventative Treatment. Several materials (e.g., retinoids, betanaphthoflavone) inhibit skin carcinogenicity from pure chemicals. Their effectiveness for inhibiting skin carcinogenicity from coal liquids should be examined.

\section{Cardiovascular Effects}

Although a number of test systems are available for measuring carcinogenic/ mutagenic potential of chemical and physical agents, few reliable animal models are available for determining exposure effects on the cardiovascular system. Limited epidemiological data suggest that, in humans, organic materials may cause cardiovascular effects. Cardiovascular disease is the primary cause of death in the United States.

\section{Degenerative Diseases}

Preliminary evidence suggests that exposure to organic compounds may be associated with arthritic and other degenerative diseases involving changes in connective tissue. Currently, there are no appropriate models to study such changes.

\section{Pulmonary Physiology}

Present methods for measuring pulmonary physiological variables in small animals are expensive, insensitive and lack reproducibility. Since a number of pathological conditions in humans involve altered pulmonary function (e.g., emphysema, silicosis, and other fibrotic diseases), and since inhalation is potentially a major pathway for exposure to SRC-II materials, better methods for determining pulmonary function in small-animal systems may be required.

\section{INDUSTRIAL HYGIENE - PHASES II-IV}

Phase II biomedical studies, coupled with those in Phase I, will define biomedical risk for SRC-II materials in a demonstration/commercial facility operating under steady-state conditions. Accompanying chemical analyses may permit definition of compounds and compound classes of biomedical concern. Phase III studies that examine effects of altered plant operations on potential biomedical properties of SRC-II materials may aid in defining risk to workers when SRC-II facilities require maintenance or operate in upset or altered conditions. Qualitative and quantitative changes in compounds and 
compound classes of biomedical concern may be defined. Phase IV research will seek to develop chemical and medical methods to monitor the site and personnel and to advise and/or lessen exposure risks.

Data and methods developed in biomedical and chemical studies may allow further development of: 1) specific workplace monitoring procedures as a function of work zone within a demonstration/commercial facility operating under defined conditions, 2) definition of interim threshold limit values for compounds of concern and methods for determining workplace exposure to such compounds, and 3) clinical and epidemiological analyses relevant to the work force.

\section{ECOLOGICAL STUDIES}

\section{Biological Fate In The Aquatic Environment}

The biological fate of SRC-II liquid materials in freshwater systems will depend on a) physical and chemical properties of material entering the environment, b) quantity of material, c) physical and chemical features of the environment, d) food web (predator-type) relationships of organisms present, and e) metabolic pathways of organisms. The relative importance of each factor varies with the environment, the particular SRC-II liquid material, and the organism.

For example, fish may accumulate carbazoles or quinolines directly from the water column. However, if these compounds accumulate in sediments and are transferred to sediment-burrowing organisms that are in turn consumed by fish, food (rather than the water column) may be the more important exposure pathway. This is a distinct possibility for complex organic compounds of SRC-II origin.

Interactions of metals in SRC-II materials with biological systems are dependent on the metal form, concentration and reactive state. For example, only small fractions of most metals in water (those bound to organic ligands) are biologically available. It is not known how variable these fractions may be, or how other factors in the water column may modify bioavailability. However, when one organism eats another, the ligand-bound materials in the prey are usually more readily absorbed than non-ligand-bound materials.

Phase II ecological studies will include analyses of bioconcentration, bioaccumulation, and biomagnification processes. Ultimately, results of such research will be used to rank bioconcentration/bioaccumulation potential of several SRC-II compounds considered or determined to be of ecological or biomedical concern. Uptake and depuration constants may also be used in evaluating environmental fate through use of compartmental models.

Bioconcentration refers to the process by which chemicals enter aquatic organisms, directly from water, through the gills or epithelial tissue. Bioaccumulation includes bioconcentration and uptake of chemical materials from food sources. Biomagnification refers to the process by which tissue concentrations of bioaccumulated materials increase as they pass up food chains through two or more trophic levels. SRC-II materials to be used in studies of biological fate are shown in Table 24. 
TABLE 24. Phase II Biological Fate Studies: Liquid and Solid Materials

\begin{tabular}{|c|c|c|}
\hline $\begin{array}{l}\text { Material to be } \\
\text { Analyzed }\end{array}$ & Bioconcentration & $\begin{array}{l}\text { Bioaccumulat } \\
\text { Biomagnifica }\end{array}$ \\
\hline $\begin{array}{l}\text { SRC-II Liquid } \\
\text { Product }\end{array}$ & $A, B, C$ & $A, B, C$ \\
\hline $\begin{array}{l}\text { Hydrodesul- } \\
\text { furized } \\
\text { Naphtha }\end{array}$ & $A, B$ & $A, B$ \\
\hline Process Water & $A, B, C$ & $A, B, C$ \\
\hline $\begin{array}{l}\text { Treated Process } \\
\text { Water }\end{array}$ & $A, B, C$ & $A, B, C$ \\
\hline $\begin{array}{l}\text { Vacuum Bottoms } \\
\text { Ash and Slag }\end{array}$ & $A, B$ & $A, B$ \\
\hline $\begin{array}{l}\text { Waste Water } \\
\text { Incinerator } \\
\text { Solids }\end{array}$ & $A, B$ & $A, B$ \\
\hline \multicolumn{3}{|c|}{ A - to be performed on raw materials } \\
\hline \multicolumn{3}{|c|}{ B - chemical analyses to be performed } \\
\hline
\end{tabular}

\section{Bioconcentration}

Potential bioconcentration of SRC-II liquid materials will be measured in flow-through systems employing test organisms representing several trophic levels. Water and sediments will be treated, in separate experiments, as potential sources of contamination. Exposures with unfractionated or partially fractioned SRC-II products will be performed to validate information on specific compound classes, particularly where they represent dominant components of an SRC-II material or are known (e.g., PNAs) or suspected (e.g., PAAs) carcinogenic agents. Phase I biomedical analyses and those to be performed in Phase II will aid selection of specific chemical entities of concern. Range of test concentrations will be based on chronic toxicity data obtained from studies described on pp. 66-67. Emphasis will be on persistent organic constituents of SRC-II materials (pp. 89-93). Pertinent trace metals will also be examined with respect to speciation, complexation with organic ligands, and relationships to bioconcentration phenomena. Test procedures will be modeled after proposed American Society for Testing and Materials (ASTM) guidelines addressing bioconcentration of "simple" compounds from water. Modifications of these procedures may be necessary, because major source terms (sediment, interstitial water, and water column) will have to be partitioned with respect 
to oil, water and solid phases. The octanol:water partition coefficient has been successfully used to predict partitioning among phases of simple compounds. It may be possible to apply these methods to SRC-II materials. Corrections for interstitial water can be made using a suitable measurement for the distribution constant, $K_{d}$.

Daphnids, midge larvae, oligochaetes, freshwater clams and fish (fathead minnow, rainbow trout, channel catfish) will be organisms of primary interest. Uptake from constant exposure concentrations, and depuration (washout following removal to clean water or sediments) will be followed for up to 28 days. Rate constants for uptake and depuration for organs and whole body will be measured. Bioconcentration factors will also be calculated. Mechanisms of uptake, i.e., surface adsorption, gut loading, or lipid soluble absorption, will be identified.

\section{Bioaccumulation/Biomagnification}

Potential bioaccumulation/biomagnification will be evaluated using a simple aquatic food chain consisting of a food organism (daphnid or midge larvae) and consumer organism (fathead minnow, rainbow trout, or channel catfish). Potential bioaccumulation will be followed for up to 28 days in a flow-through system. Depuration will also be monitored. Distinction will be made between fish receiving SRC loading from the water column, and fish receiving loading from SRC-contaminated food. Particular attention will be focused on the potential for increased residue accumulation in fish (biomagnification) compared to forage species. Rate constants for uptake and depuration for organs and whole body will be measured. Mechanisms of uptake will be identified.

Water. Required chemical information will be similar to that needed for Phase I aquatic screening assays. The main difference will be the much lower concentrations of SRC materials in chronic exposure systems. This will require introduction of new techniques to enhance sensitivity for component types or to concentrate materials from very large water samples. Sample concentration techniques will involve use of XAD resin adsorption, and other solid adsorbents, including ion exchange resins. Techniques used may be based on results of studies described on pp. 37-57. Enhancement of detection sensitivity for certain components, such as phenols and primary amines, can be accomplished using derivatives such as halogenated acetates, which are extremely sensitive to electron capture gas chromatographic detectors. An alternative analysis for trace amines and phenols will be explored. The method involves selective derivatization of these compounds with fluorescent derivatives, and separation and quantitation using high-speed liquid chromatographic separations. Special gas chromatographic detectors for sulfur and nitrogen components (pp. 49-50) will also be used to enhance detection of these compounds in chronic exposure systems.

Sediments. Methods for sediment analysis will involve many of the analytical techniques described on pp. 48-51. However, problems specifically relating to sediment material must be addressed. Solvent extractions of sediments vary, depending on whether the sediment is extracted wet or dry. Although extraction of freeze-dried material is most satisfactory, the drying process can result in significant losses of volatile material. Extraction of 
wet sediment can result in losses of material due to incomplete extraction. Use of polar solvents such as methanol can hinder recovery of polar components in an analyzable form.

Analysis of sediments in chronic systems, together with associated water chemistry, will provide information concerning the availability of hydrocarbons, phenols, amines and other important SRC-II components to test organisms. The approach will also provide data on the rate at which component concentrations are altered, by chemical and/or microbial action, or physical processes such as solubilization or adsorption. Investigations of changes in composition will be closely integrated with environmental chemistry studies on sorption, photo-oxidation, solubility, and microbiology of SRC in sediment systems (pp. 89-93).

Tissues. Tissue analyses will initially emphasize phenols, $\mathrm{N}-$ heterocycles and aromatic amines. Where possible, radiolabeled compounds will be used as markers for tissue distribution in bioconcentration and bioaccumulation studies. However, availability of potentially useful, labeled compounds is limited and may require custom synthesis. Accordingly, significant analytical development may be required to perform the proposed studies. Because these efforts are generic requirements, they are not a cost element of this plan.

Numerous methods have been developed for analyzing SRC-II components in environmental samples and may be adaptable to tissue analysis. SRC-II phenols in aqueous samples have been analyzed by acetylation followed by GC analysis. Applicability of the method for tissue analysis is being explored. Alternatively, liquid chromatography with electrochemical detection is effective for phenolic compounds in various matrices and will also be attempted for tissue analyses of SRC-II phenols. Liquid chromatography with electrochemical detection may also prove useful for some types of $\mathrm{N}$-containing compounds. A procedure to detect anilines in aqueous samples by GC, following acetylation, is being developed and shows promise for tissue analysis. Similar approaches for other $\mathrm{N}$-containing compounds are being explored.

\section{Biological Fate In The Terrestrial Environment}

There are a number of possible routes for SRC-II materials to enter the terrestrial environment. Research appropriate for determining biological fate in cases of terrestrial spills is addressed on pp. 89-93, and 109-117, as is research addressing planned disposal of solid wastes. One of the more impor tant routes of entry for SRC-II materials in the terrestrial food chain may be via atmospheric emissions onto leaf surfaces.

Atmospheric emissions anticipated from the commercial SRC-II process are presently not well-defined and research priorities cannot be established. Major direct particulate emissions are expected only from coal crushing and cooling-tower drift. Indirect particulate emissions would arise primarily from resuspension of cooled vacuum bottoms (stored, perhaps, during upset), gasifier bottoms, and resuspension of solid wastes dispersed to the ground. Potential gaseous releases during routine operations may arise during coal 
drying, acid gas removal, liquid product storage, cooling-tower drift, gasification, flaring, or water treatment. Methanation processes or flue gases may also be sources. Fugitive emissions may arise from process stream leaks, high-pressure steam, heating-fluid releases, or failure of the acid gasremoval process. Materials to be analyzed relative to aerosol effects on plants include SRC-II gasifier bottoms, process water, incinerator solids, liquid product, and volatile components sorbed to atmospheric particulate matter.

Uptake of SRC-II materials intercepted by plant canopies will be determined in the laboratory. The Wright dust mill and air sampling devices will be used to generate and quantify size and concentrations of airborne particles. Canopies will be exposed under controlled conditions of temperature and moisture, using aerodynamically designed exposure systems. Test species will be determined from field surveys at the demonstration site.

For SRC-II materials having highly water-soluble components, as determined by studies described on pp. 89-93, transfer of specific inorganic and organic components from foliage to seeds and phenotypic toxicity effects (dry-matter production and seed yield) will be determined. Additionally, based on ecological, biomedical and chemical analyses described on pp. 63-72 and 76-82, specific SRC-II components or fractions may be evaluated in higher plant systems for effects on seed viability and mutagenicity.

\section{Multispecies Testing In Aquatic Systems}

A major concern not addressed in Phase $I$ is the potential for ecosystem damage. Results of Phase I studies and extant literature are being used to design a method to measure ecosystem effects. Initially, we will use artificial streams to study the interactions between SRC-II liquid products and water, sediment and organisms. Organisms will include a primary producer, benthic detritivore, and fish. This system will allow evaluation of partitioning and transport of released material into water, sediment and organisms (bioaccumulation) and measurement of effects on long-term survival, growth, feeding and population response under more natural conditions than in the laboratory. Results of these studies will be used to develop an on-site, ecosystems study using representative SRC-II materials.

\section{Laboratory Studies On Revegetation of Solid Wastes}

Background information obtained on physicochemical properties of solid wastes will be used to recommend plants appropriate to the soil (rooting substrates) and climate of the demonstration site. Measurement of plant response to inorganic and organic components in solid wastes will be an integral part of the program. Efforts will involve: a) selecting plant species and determining effects of solid waste leachates on plant growth, water, and ion fluxes; b) determining potential for plant uptake, accumulation and detoxification of organic residuals and trace metals in solid waste leachates; c) identifying native plant and genetically improved species best suited for revegetation of land disposal sites; and d) recommending preferred waste treatment or disposal scenarios for site revegetation. 
Preliminary toxicity tests will be conducted in growth chambers. The range of conditions and remedial treatments for plant growth that minimizes pollutant uptake will be studied in the greenhouse. Treatments will include various leachates (rain, surface, ground, and irrigation waters), pH control, fertilization, and soil conditioners (e.g., sludge from biodigesters). Toxic effects on plants and acceptable threshold application rates with time will be evaluated.

\section{Chemical And Microbiological Fate In Sediment And Soil Systems}

Nonoccupational health effects associated with SRC-II operation will be determined by environmental factors which govern form, transport, and persistence of SRC-II products and wastes, and which mediate exposure to man. Research will emphasize the fate of spilled SRC-II products and disposed solid wastes and will focus on water-soluble, persistent materials with greatest potential for mobility and incorporation into water and food supplies.

\section{Chemical Characterization of Water-Soluble Species}

Initially, aqueous equilibrations of SRC-II liquid product and solid wastes will be subjected to chemical analysis (Table 25) and fractionation (Figure 7). For organic compounds, methods described on pp. 44-51 for separation and analysis will be employed where applicable. However, for trace analysis of some important organic compounds in environmental samples of soils, water, and soil leachates, methods specially adapted to extraction, concentration, and specific detection may be required. Three in vitro submammalian assays will be employed (pp. 39-42) to define effects of trace metals and organic compounds. This information, in conjunction with solubility and knowledge of the biological properties of specific chemical species, will be used to limit and focus subsequent chemical analyses and investigations.

Aqueous equilibrations of SRC-II liquid products will be repeated at different temperatures and with acidic and basic waters of adjusted ionic strength to simulate different surface-water types. Several standardized conditions of temperature, $\mathrm{pH}$, and ionic strength will be selected to evaluate solubility and provide solutions for use in microbiological and sediment interaction experiments.

For solid wastes, initial efforts will include aqueous equilibration of ungasified and gasified mineral residue, fractionation, and in vitro testing. Aqueous equilibrates of residue will be prepared in batch systems under different conditions of temperature and $\mathrm{pH}$. Results from these experiments will be used to design column experiments and to modify analytical protocols, if necessary. Aqueous equilibrates of solid wastes may be significantly lower in organic material than liquid product equilibrates and may require a more refined analytical protocol. Aqueous equilibrates will be employed in microbial and soil/sediment interaction studies.

\section{Soil and Sediment Interaction}

Laboratory studies will emphasize the interaction of aqueous equilibrates of SRC-II products and solid wastes with soil materials, isolated suspended 
TABLE 25. Analyses of Solid and Liquid Phases

Solid Phase Analys is

Frequency

Mineralogy (crystalline minerals, A oxidic $\mathrm{Fe}, \mathrm{Mg}, \mathrm{Al}$ )

Particle size distribution A

Surface area A

Cation/anion exchange capacity A

Organic C A

Total N,S A

Total major elements A

$(\mathrm{Na}, \mathrm{K}, \mathrm{Ca}, \mathrm{Mg}, \mathrm{Si}, \mathrm{Ti}, \mathrm{Mn}, \mathrm{Fe}, \mathrm{Al}, \mathrm{Cl}, \mathrm{S}$ )

Total trace elements A

( $\mathrm{Li}, \mathrm{Be}, \mathrm{Sr}, \mathrm{Ba}, \mathrm{La}, \mathrm{Zr}, \mathrm{V}, \mathrm{Cr}, \mathrm{Mo}, \mathrm{W}, \mathrm{Co}$,

$\mathrm{Ni}, \mathrm{Cu}, \mathrm{Ag}, \mathrm{Zn}, \mathrm{Cd}, \mathrm{Hg}, \mathrm{B}, \mathrm{Tl}, \mathrm{Sn}, \mathrm{Pb}, \mathrm{P}$,

As, $\mathrm{Sb}, \mathrm{Bi}, \mathrm{Se}, \mathrm{F}, \mathrm{Br}, \mathrm{I}, \mathrm{Nd}, \mathrm{Th}, \mathrm{U})$

Total radioactivity (alpha, beta) M

organic materials A

Liquid Phase Analysis

Total solids A A

Organic C A

Total C, N, S A

Conductivity A A

Major cations ( $\mathrm{Na}, \mathrm{K}, \mathrm{Ca}, \mathrm{Mg}) \quad A$

Major anions $\left(\mathrm{SO}_{4}{ }^{-}, \mathrm{Cl}^{-}, \mathrm{HCO}_{3}{ }^{-}, \mathrm{CO}_{3}{ }^{-}\right) \mathrm{A}$

Minor anjons $\left(\mathrm{NO}_{3}^{-}, \mathrm{NO}_{2}^{-}\right.$, reduced $\mathrm{S}$ species, $\mathrm{M}$

$\left.\mathrm{Br}, \mathrm{F}^{-}, \mathrm{PO}_{4}{ }^{3}\right)$, $\mathrm{NO}_{2}^{-}$, reduced $\mathrm{S}$ species,

Total minor elements ( $\mathrm{Tl}, \mathrm{Mn}, \mathrm{Fe}, \mathrm{Al}, \mathrm{Li}, \mathrm{Be}, \quad M$

$\mathrm{Sr}, \mathrm{Ba}, \mathrm{La}, \mathrm{Zr}, \mathrm{V}, \mathrm{Cr}, \mathrm{Mo}, \mathrm{W}, \mathrm{Co}, \mathrm{Ni}, \mathrm{Cu}, \mathrm{Ag}$,

$\mathrm{Zn}, \mathrm{Cd}, \mathrm{Hg}, \mathrm{B}, \mathrm{To}, \mathrm{Sn}, \mathrm{Pb}, \mathrm{P}, \mathrm{As}, \mathrm{Sb}, \mathrm{Bi}, \mathrm{Se}$, I, Nd, Th, U)

Trace metal speciation: organometal complexes M

Organic fractions $M$

Organic compounds (organic acids and phenols, $M$

basic $N$ compounds and aromatic hydrocarbons)

Total Radioactivity (alpha, beta)

$A=$ planned for each SRC-II material under study

$M=$ as preliminary studies warrant 


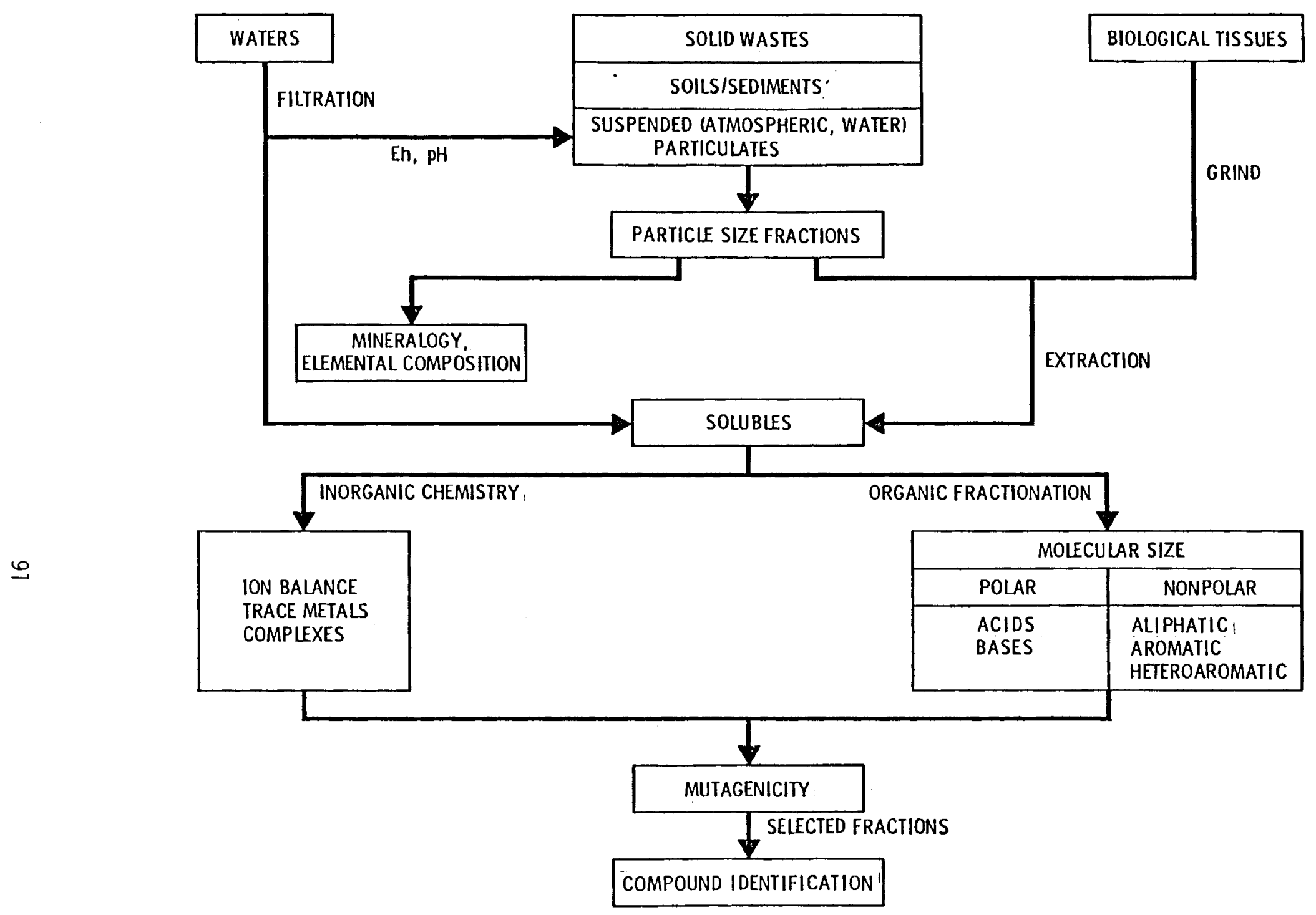

Figure 7. General physicochemical fractionation scheme for waters, solids, and biological tissues from environmental and laboratory studies. The application of common fractionation and analytical methods with emphasis on solubles allows identification of mobile, biologically available compounds, intercomparability of diverse environments, and integration of research. 
sediments and bottom sediments. These studies will identify effects of specific sorption reactions, ion or induced ion exchange reactions, solid induced fractionation reactions and microbial degradation on mobility, persistence, and toxicity of water-soluble, biologically active materials from liquid product and solid wastes. Results of these experiments will have applicability to the environmental fate and effects of biologically active compounds released under different scenarios from product spills and solid waste disposal.

Experiments will be designed to differentiate physicochemical from microbial processes. Interaction studies will be performed in parallel under sterile and nonsterile conditions using batch (suspended matter, sediments and soils) and column (soils) systems. The organic fractionation scheme will then be applied to all solutions generated to insure an integrated analytical approach. An inorganic analytical protocol will also be applied to determine $\mathrm{pH}$, Eh, major and trace elements, and anion/cation balance of solutions, and to ascertain prominent mineralogical controls on solution composition. This information is needed to accurately evaluate the chemical and microbiological mechanisms affecting sorption and persistence of the dissolved organic fraction. Use of parallel experiments should enable definition of key physicochemical and microbiological factors governing fate and persistence of specific organic compound classes or fractions identified during chemical characterization.

Soils and sediments will be selected to insure broad applicability to different geographic regions. Selection requires an understanding of prominent physicochemical mechanisms affecting sorption and retention of trace metals and organic compounds by soils and sediments. These mechanisms include cation exchange, electrostatic retention of polar compounds, lipophilic interactions with soil organic material, specific adsorption and, to a lesser extent, anion exchange. The soil and sediment characteristics most influential in regulating these mechanisms include: a) $\mathrm{pH}$-Eh, b) oxide-hydroxide content, c) clay mineral composition and content, d) bulk parent material mineralogy, e) soil texture, f) composition and quantity of organic materials, and $\mathrm{g}$ ) basic translocational or soil genetic processes. Several individual soils and sediments exhibiting some of the prominent chemical characteristics listed above will be chosen for use from the PNL inventory of national soils.

Three sets of soil materials (calcareous, acidic, and oxidic), and river sediments which range in $\mathrm{pH}$ and exhibit differing prominent physicochemical characteristics, will be subjected to detailed physical and chemical analysis. Aqueous extracts of sterile and nonsterile soils and sediments will undergo organic and inorganic analyses to define background concentrations of specific organic compounds considered biologically active and to identify the appropriate organic chemical regime for compounds of concern.

Soil studies will be conducted with batch and column systems. Batch studies will initially be performed at ambient temperature with aqueous SRC-II product extracts, or solid waste leachates, and one level of organic carbon. Aliquots will be removed, with time, for analysis. Additional extractions will be performed, if necessary, using multiple levels of organic carbon to determine adsorption isotherms, and varying temperatures to identify kinetic restraints on biological growth and adsorption. Column studies will employ a soil perfusion system where soil moisture and aeration can be controlled. Columns will be perfused with SRC aqueous extracts containing various levels 
of organic carbon. Perfusates from this system and aliquots from batch systems will be examined for Eh, pH, major and trace elements, and dissolved organic carbon, and subjected to in vitro assays, followed by organic fractionation and additional in vitro assays.

Sediment studies will be conducted in batch systems which will be continuously monitored for $\mathrm{Eh}, \mathrm{pH}$, and evolved $\mathrm{CO}_{2}$. A constant solid-to-liquid ratio (1:10) will be used. Sterile and nonsterile batch systems will contain aqueous extracts of SRC-II liquid products at various organic carbon-loading rates. Samples will be removed, with time, and characterized using the standard organic and inorganic protocol (pp. 48-51).

Specific adsorption isotherms will be calculated when necessary and sorption reactions will be tentatively identified. Additionally, effects of microbial activity on chemistry and biological activity of specific compound classes showing effects in in vitro tests will be determined.

\section{Microbial Processes}

Microbial activity is an important factor affecting persistence of organic components in the environment. The effect of microbial communities on environmental fate of water-soluble organic materials from SRC-II liquid products and solid wastes will be examined. Laboratory studies will include the batch and column systems previously described, and will be followed by field lysimeter and other field verification studies (pp. 112-117). Microbial studies will be closely integrated with chemical and soil-sediment experiments and will emphasize compounds showing biomedical or ecological effects.

Studies will include: a) measurement of microbial communities, over time, in systems containing solid waste, solid waste and soil, or SRC-II liquid products with soil or sediments; b) determination of the effects of various growth factors (nutrients, $\mathrm{pH}$, Eh, and temperature) on type and duration of microbial activity; c) measurement of the rate and extent of microbial decomposition of total residual and water-soluble organic carbon as a function of growth at different organic carbon-loading rates; d) elucidation of pertinent segments of microbial degradative pathways for individual compounds showing biological activity; and e) determination of the relationship between microbial degradation of organic materials and trace metal complexation/ mobility.

Column and batch equilibrium studies, using systems developed at PNL, will differentiate among major physicochemical factors influencing rate and course of microbial metabolism. The protocol also allows for determination of changes in metabolic pathways due to microbial succession and accumulation or removal of metabolites. Degradation of organics will be measured by monitoring total $\mathrm{CO}_{2}$ and ${ }^{14} \mathrm{CO}_{2}$ evolution in model compound studies. Analytical methods used for chemical characterization in companion studies will examine degradation and accumulation of specific organic compounds showing biological activity. Rate and extent of degradation will be examined in conjunction with soil and sediment studies to provide input to chemical and transport models. 


\section{ENVIRONMENTAL ASSESSMENT/RISK ANALYSES - PHASE II}

During Phase II research, design of the demonstration facility should be finalized and construction initiated. All process and product streams, planned liquid and solid emissions, and treatment and disposal methods should be defined. Design analyses relevant to major sources of atmospheric emissions should also be available.

Toward the end of Phase II, biomedical data should provide information on chronic effects of SRC-II materials administered to animals via inhalation and dermal exposure routes. Information may be available on the molecular form of potential releases and/or transformation products that approximate chemical entities of biomedical concern.

Some degree of quantitative environmental assessment/risk analyses will be possible for occupationally and environmentally exposed human populations. However, uncertainties may be great, and will be difficult to define due to the nature of source-term data, the difficulty of extrapolating effects on animals to man without information on comparative pathological mechanisms and dose effects, and uncertainties concerning the shape of dose-effect curves (e.g., threshold vs no threshold).

Ecological data will include information on chronic effects of SRC-II materials on selected aquatic and terrestrial biota, tested singly and in more-complex model ecosystems. Data on fate of solid-waste residues in field lysimeters, information on chemical entities of concern in an aquatic spill situation and data from ecological and chemical monitoring studies at the SRC-II demonstration facility should also be available. These data will span the preconstruction and construction phases of facility development.

Although ability to predict ecological effects and potential problems involving fate of SRC-II materials in the environment will improve in Phase II assessment, meaningful quantitation may still be lacking. Methods for measuring specific chemical materials of known biomedical and ecological effects will still be developmental. Therefore, it is doubtful that many materials of concern will have been measured. Although assessment of biomedical and ecological effects resulting from exposure to SRC-II materials through food chains will attempt to establish magnitude, results of the process will remain highly uncertain.

\section{Environmental Pathways Modeling}

The complexity of dose assessment modeling is illustrated in Figure 8. Three major submodels are shown, each requiring development and adaptation to SRC-II compounds of interest. Phase I assessment will review and advise on the design of needed ecological, biomedical, and chemical research to ensure mutual data compatibility with modeling parameters. Boxes in Figure 8 represent environmental components and arrows represent processes affecting components. We will estimate, under defined circumstances, how selected materials are released and partitioned in the environment. 


\section{Atmospheric Modeling}

Available models for predicting dispersal and deposition of airborne pollutants will be analyzed. We will review available site-specific data required to calibrate air quality models (AQM) applicable to the SRC-II process. The need for further model development and data collection will be determined. The most appropriate AQMs and data bases will be used to estimate atmospheric transport and assess health impacts from airborne emissions of the Ft. Martin, West Virginia SRC-II facility. These models will consider as variables: source term emissions; atmospheric transport via winds; diffusion through thermal and mechanical forces; transformation via photochemistry and reaction with atmospheric gases; and removal processes.

Meteorological data for AQMs can be obtained relatively easily. Given the wide range of organic and inorganic materials which may be released into the atmosphere by a large SRC-II facility, modeling efforts will concentrate on compound types that are: 1) identified through biomedical and/or ecological studies, or 2) presently mandated through existing legislation as being of potential concern. It is noteworthy that the area near the Ft. Martin demonstration facility has long been a site of mining activity and coal-fired electric power generation. Therefore, high backgrounds of coal-based pollutants may already exist, and it is important to develop a data base to define this background.

Depending on the timing of assessment and the availability of required information, estimates of atmospheric deposition may have many uncertainties. A firm definition of models to be employed is required, and the nature of input required for assessment needs further study.

\section{Chemical Fate Modeling}

Models will be developed to calculate the distribution and activities of chemical species (ions, neutrals, ion pairs, and complexes) in leachate and water samples. Calculations, which assume equilibrium in the aqueous phase, will partition concentrations of each chemical species among its monomeric forms and various soluble complexes with other ions in solution. Speciation will form the basis for evaluating availability of free and unreactive ions in solution, and for additional calculations involving mineral equilibria and the influence of mineral solubility reactions (dissolution and precipitation) on solution composition. The resultant models will be used to: a) estimate mineralogical controls on surface water, ground water, and leachate chemical speciation, b) predict later changes in solution or leachate composition, and c) interface with hydrologic models of the demonstration site to predict the environmental fate of chemical materials discharged or found in ground and surface waters.

\section{Hydrological Modeling}

Hydrological assessment will initially review available models for predicting the fate of source terms discharged or found in ground and surface waters. Pertinent archived data will be reviewed and evaluated to identify data needs for hydrological assessment. The most appropriate models and data sets will be used to estimate environmental concentrations of contaminants resulting from water transport. 


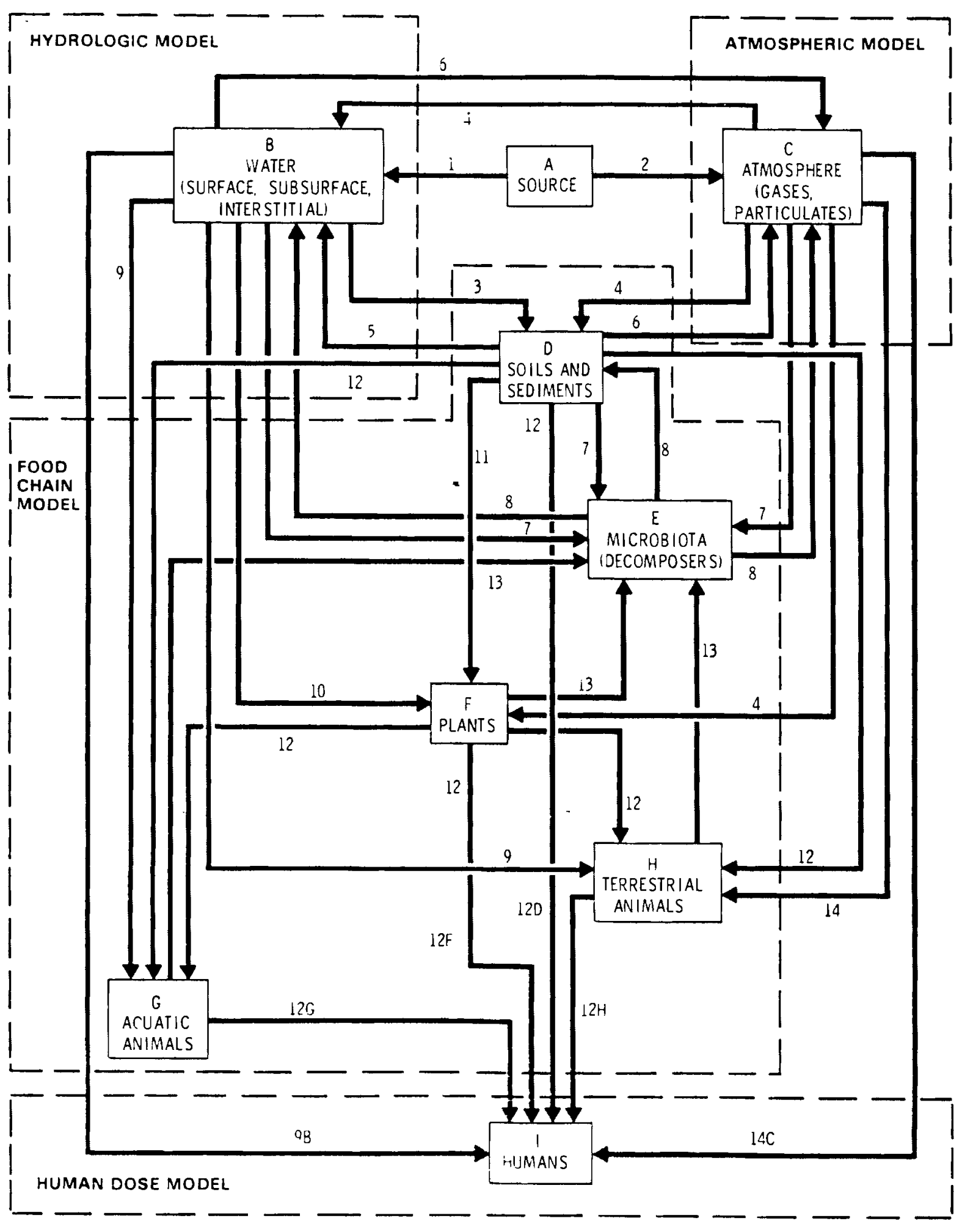

Figure 8. Environmental Dose Assessment Model 
Key for Food Transport Pathways and Processes Shown in Figure 8:

1 Aquatic discharge

2 Atmospheric discharges

3 Irrigation, water/sediment interphase exchanges

4 Surface deposition

5 Leaching, erosion, mineralization, water sediment interphase exchange

6 Resuspension/evaporation

7 Microbial incorporation

8 Microbial releases, decomposition

9 Water consumption, skin absorption

10 Irrigation plant surface exchange

11 Root uptake

12 Ingestion

13 Mortality

14 Inhalation 
Three basic categories of hydrologic models to be used are:

- overland runoff models that simulate precipitation run off from watershed areas;

- groundwater models that consider waters that are not transported overland or lost by evapotranspiration; and

- $\quad$ surface-water models that use inflows determined by overland runoff models and groundwater models, and couple this information with data on the instream base flow to the outlet of the river system modeled.

As is the case when estimating atmospheric transport, hydrological mode1ing will only consider compound classes of known biomedical or ecological concern. Background information is needed on the contribution of mining and electric-power generation effluents in the Ft. Martin area relevant to hydrological concerns. Studies relevant to the above are described in Phase IV.

Since hydrological modeling of complex organic materials is currently developmental, no decision concerning modeling approach, data required, or final form of output relevant to assessment can be made. Phase II research will provide only a qualitative assessment of SRC-II contaminant transport through surface and ground waters. However, Phase II will also define needed models and data for more complete and quantitative assessment of potential dose through surface and ground waters.

\section{Food-Chain Modeling}

General models exist for estimating food-chain transfer of radionuclides through the environment. These models will be reviewed for their applicability and, where possible, modified to consider metal and organic carcinogen food-chain transfers based on steady-state conditions. Available literature on pathways modeling and food-chain transfer data will be used with data developed in Phase I biomedical and ecological studies to evaluate and select the most appropriate food chain models. If experimental data exist on SRC-II organic materials of concern, they are certainly not as comprehensive as data on nuclear materials. Accordingly, Phase II will involve an initial qualitative (or quantitative) assessment of food-chain transport that will be highly uncertain. Definition of applicable models and data requirements cannot be made at this time. Data for food-chain transport modeling will be developed principally in Phase II and Phase IV ecological studies. As data become available, portions of the conceptual model may be quantified, and coupled to atmospheric and hydrological models to predict transfer of deleterious materials to man.

Available information will be used to describe environmental routes of potential human exposure (Figure 8 ). Additional data needs will be identified through initial modeling efforts.

Pathway models will consider site-specific factors near Ft. Martin, West Virginia. For example, models deveioped for sediment chemical processes and physiological data on materials uptake from sediments by fish and detritivores will be used to define transfer of aromatic hydrocarbons from sediments to 
organisms in the Monongahela River. Data are needed on transfer functions of materials from sediments to interstitial water to detritivores to fish.

The extent and complexity of interactions among facility effluents, ecological systems, and changing environments dictate the need to simplify approaches wherever possible. For example, because it is not feasible to obtain complete data sets on every compound, we will study selected compound classes which have been identified from studies of environmental transport and fate. Experience in radionuclide and metal pathway modeling efforts indicate that specific compounds can sometimes be grouped according to physicochemical and/or biochemical properties.

\section{Biomedical Assessment}

Assessment of human health hazards from exposure to SRC-II products and pollutants involves:

- identification of materials to which human populations are subjected, and estimation of the exposure levels to various subpopulations;

- identification of possible health hazards and estimation of the potencies of these materials; and

- coupling of exposure and potency information.

Coupling must account for such factors as route and temporal pattern of exposures and important characteristics of the exposed populations (e.g., size and age distribution), to arrive at projected measures of morbidity and mortality. The goal of the biomedical assessment will be to derive estimates of potencies of various SRC-II materials, and to relate these to exposure estimates provided by atmospheric, hydrologic, and food-chain transport studies.

The laboratory data base for biomedical assessment has been described previously. Dose estimates from all defined source terms will be in various stages of quantitation and certainty. Phase II biomedical assessments may be qualitative or quantitative; in any case, more certain than Phase I estimates.

Several dose-effect models may be used to quantitate health effects from the available data base, including probit, multi-stage, gamma, multi-hit, and time-to-tumor formation models. Rigorous analysis of appropriateness of data to model and model to data will be performed. Phase II assessment should aid the experimental program by identifying analyses required to further quantitate potential health effects.

\section{Ecological Assessment}

Most data developed for the environmental pathways model will also apply to models designed to assess ecological impacts of accidental or long-term effluent releases. Environmental assessment, unlike food-chain modeling, must consider specific toxic materials (e.g., metals, acid vapors, cresols, phenols) in a given ecological system. Data utilized must primarily define organism sensitivity (i.e., behavior or organism health), rather than just metabolism. 
Analytically, ecological assessment requires information on transfer coefficients, similar to that for atmospheric, hydrologic and food-chain transport models, and knowledge of dose-response of organisms to compounds of concern at a given site.

Steady-state modeling recommended for predicting dose to man will not be adequate to model ecosystem effects (i.e., model development, based on nonsteady-state [seasonal] assumptions may be needed). Phase II ecological assessment will initially be qualitative. However, available models will be analyzed for applicability for quantitative assessment. We will evaluate expanded model systems as they develop for use in ecological assessment.

\section{Example of Phase II Environmental Assessment/Risk Analyses}

Given the complex scenarios for potential human and ecological exposures to SRC materials, Phase II assessment will be illustrated by the following hypothetical example:

Atmospheric emissions from a wet cooling tower may be contaminated with process materials. Engineering estimates suggest that contamination may result from ppm process solvent at the point of entry to cooling water. Process solvent is mutagenic in in vitro assays; a skin carcinogen of some potency; and a weak pulmonary carcinogen in laboratory animals. Chemical analyses and in vitro biomedical assays suggest that compounds and compound types causing biomedical effects may be aromatic amines and large $(n>3)$ polynuclear aromatics. Based on the engineering estimates, it is anticipated that less than \% of original leakage will be emitted from the cooling tower.

Dose-effect assessment for inhalation risk is performed using data on emissions of known mutagens and carcinogens as a function of distance from the cooling tower. This information is extrapolated from animal data based on a linear extrapolation, not on threshold dose. This mode of data analysis suggests an $X$ percent increase in rates of pulmonary carcinogenes is, adjusted for population age at time of initial exposure. Percent increase is within the standard deviation anticipated for lung tumor incidence in any group the size of the expected target population.

Process solvent also contains ppm of phenolic compounds, and is acutely toxic to fish. This compound class is highly soluble, and worst-case estimates suggest that ppm of original leakage will be emitted from the cooling tower. Available photodecomposition and atmospheric chemistry data suggest that \% of the original dose entering the atmosphere will be chemically altered or biologically inactivated per meter of plume travel. Using a multi-hit model, surrounding natural waters would be $\%$ less toxic to fish per meter of plume travel.

On a qualitative basis, phenols decompose in water and sediments through microbial action. Therefore, effects will be contingent on phenol loads versus rates of decomposition versus periods of plant operation. 
The following uncertainties affect this assessment:

1) Extent of cooling-tower water contamination by process solvent may vary by fold, depending on maintenance status of heat exchangers and process lines.

2) Plume output is a function of overall plant heat load, which varies by orders of magnitude.

3) Nothing is known concerning atmospheric and photochemistry of compounds tentatively identified as of biomedical concern. Therefore, whether alteration would increase or decrease effective biological concentration is unknown.

4) Low potency of process solvent relative to pulmonary carcinogenicity in mice may or may not reflect pulmonary carcinogencity in man. For example, although cigarette-smoke condensate is a dermal carcinogen in mice, inhaled cigarette smoke does not appear to be a pulmonary carcinogen in mice. Thus, present data may underestimate risk to human populations from cooling-tower plume drift. Additionally, present animal models for pulmonary carcinogenesis may be poor quantitative predictors for lung tumor incidence in man.

5) Deposition of materials on crops meant for human consumption may change bioavailability and, therefore, their potential effects on man. Foliar deposition studies on fuel blend $A$ suggest that heavy coal liquids adhere to plant leaves and are not removed by washing. However, studies on ingestion of leaf tissue by animals are not planned at this time.

6) Little or no data exist on decomposition rates of phenolic species in natural waters and sediments. Therefore, no estimates of phenolic persistence and its effect on fish toxicity can be made.

7) Little or no data exist on the fate of known mutagenic and carcinogenic substances in soils, waters, and food chains. Therefore no estimate of long-term risk to man during and after plant operations can be made.

The above example is illustrative only of a possible assessment of one environmental scenario. It is noteworthy that no single generic path to overall environmental assessment may be available. Assessment will depend on the nature of exposure scenarios, the extent of the environmental data base, and the availability of appropriate models. Given the lack of standard, accepted assessment methods, assessments of different technologies (or even of the same technology, performed by different assessment groups) may not be quantitatively or (in some cases) qualitatively consistent. 


\section{PHASE III}

Phase III biomedical, ecological and chemical analyses will evaluate materials which may be produced by demonstration and commercial facilities under different conditions from those established as baseline in Phase II. Additionally, materials processed through various control technology options, or subjected to upgrading prior to end-use processes, will be analyzed. Revised versions of this program plan will deal in greater depth with exact process streams, products and wastes to be analyzed as SRC-II technology plans develop.

Research in Phases I and II will establish process, product, and waste streams of potential biomedical and ecological concern and provide data on specific chemical compounds and compound classes responsible for biological and ecological effects (e.g., mutagenicity, carcinogenicity and acute and chronic toxicity). Phase III biomedical research will primarily use in vitro assays shown to correlate with results from Phase II whole-animal assay systems and of proven utility in determining compounds of concern. Phase III ecological research will primarily use acute and chronic screening assays shown to correlate with longer-term Phase II ecosystems approaches. Since the number of materials which may require testing in Phase III may be large, analyses in animal and ecological systems will be limited to materials most likely to cause biological or ecological effects and/or most likely to be produced by a demonstration or commercial facility. Only a limited number of analyses may currently be described as appropriate to Phase III. Studies similar to those described below for biomedical concerns will also be initiated to address ecological issues.

\section{UPGRADED PRODUCTS}

To increase the utility of SRC-II liquids as refinery feed or potential final product, Bartlesville Energy Technology Center will treat SRC-II liquids by catalytic hydrogenation, and hydrodesulfurization. One set of materials, derived from a 2.9:1 blend of SRC-II middle to heavy distillate and subjected to two different hydrotreatment regimes, has been provided to PNL by UOP.

The UOP samples were subjected to biological and chemical analyses using methods described on pp. 37-51. Fractions were prepared by solvent extraction and LH-20 chromatography and analyzed by Ames assay. Results suggest that catalytic hydrotreatment lowers mutagenicity of fuels relative to feedstock by an amount proportional to the loss of chemical compounds and compound types (e.g., aromatic amines) which appear to be responsible for mutagenicity. Hydrotreatment also resulted in major losses of PNAs which were converted to more-saturated ring compounds. This result was anticipated and is of some biological interest, given the established role of PNAs in carcinogenesis.

To estabish correlation with these results in whole-animal assay systems, upgraded materials considered most likely to be produced from SRC-II products wi 11 be subjected to in vitro assay by methods described on pp. 37-51, and to analyses of dermal carcinogenicity in mice by methods described on p. 76 . 


\section{BOILING-POINT FRACTIONS}

Du Pont Co. has been performing analyses of boiling-point fractions derived from a blend of SRC-II heavy and middle distillate relative to mutagenicity in the Ames assay and carcinogenicity in mouse skin using an initiatorpromotor assay system. Results from the Du Pont study should by available in the near future.

PNL will also perform a study of boiling-point fractions using the Ames assay and chemical fractionation and analyses methods described on pp. 37-60. $P \& M$ is in the process of preparing $50^{\circ} \mathrm{C}$ boiling-point cuts, over the range $400-950^{\circ} \mathrm{C}$, of a 2.9:1 blend of middle to heavy distillate. Depending on results of analyses on the $50^{\circ} \mathrm{C}$ cuts, further fractionation involving distillation cuts, at $10^{\circ} \mathrm{C}$ increments, may be performed.

These analyses may have significance for assessment and process environmental management, since preliminary PNL results on boiling-point fractions suggest that mutagenicity resides primarily in high-molecular-weight materials which are found in high-boiling-point ends.

\section{ENVIRONMENTAL ASSESSMENT/RISK ANALYSES}

Models for determining atmospheric, hydrologic, and food-chain dose (Figure 7) will be improved in Phase III assessment. Data from Phase II ecological and biomedical assays will be included in the improved models. In particular, a considerable body of food-chain transfer data will be developed for reference compound types. Analyses suggested from Phase II assessment will be performed and results will be used in appropriate models. Analyses of effects of changing SRC-II plant operating conditions and new control technologies on biological and ecological potency will be performed. Results will be used in Phase II models and newly developed models, for comparative purposes. 


\section{PHASE IV}

HEALTH EFFECTS MONITORING

Health effects monitoring at the Ft. Lewis, WA SRC pilot plant has consisted of work-area and personnel monitoring for criteria pollutants, noise, and lighting conditions. Standard methods for analyses of site and personnel particulate loads, organic vapors, $\mathrm{H}_{2} \mathrm{~S}, \mathrm{SO}_{2}$, and $\mathrm{CO}$ have been used by $\mathrm{P} \& \mathrm{M}$ to define areas of risk and potential work-force exposure. These analyses are performed on a routine basis (monthly, quarterly or yearly, depending on area examined and nature of potential hazard), and a large body of data has been collected and reported in Quarterly and Annual Reports available to the public through DOE-Assistant Secretary for Fossil Energy. A summary of available information on SRC pilot monitoring follows.

Surveys of airborne organic vapors have indicated that in-plant concentrations of organic vapors and hydrocarbon gases were generally less than 0.1 ppm. A similar study has indicated occupational exposures to benzene were far below the l-ppm level specified in the proposed Occupational Safety and Health Administration (OSHA) standard. Suspended particulates measurements have shown some inconsistencies and are under more detailed examination. Welding fumes from cutting or welding contaminated parts can pose an exposure problem. Several potential sources of hydrogen sulfide and sulfur dioxide have been identified in the plant, but the measurements thus far indicate very low concentrations. Phenols, because of their presence in a number of process streams, pose a serious occupational skin contact hazard necessitating preventive measures and good personal hygiene. High concentrations of carbon monoxide, detected in several areas of the plant, were traced to the use of plant inert gas and readily correctable. Settleable particulates in the plant were generally lower than those reported for a nearby urban community. A noise survey detected some excessive noise problems in the plant, primarily in remote areas or in areas requiring only infrequent operator attention. A survey of lighting conditions indicated insufficient lighting in several areas; additional illumination was installed.

During initial operations, the Ft. Martin, West Virginia demonstration facility will use, at a minimum, a monitoring program similar to that employed at the pilot plant. Data confirming or negating potential health hazards for polyaromatic amines and other specific organic constituents of SRC-II materials will be used to define further specific needs for work-site and personnel monitoring at the demonstration facility. A generic program addressing instrumentation that might be used in such monitoring is underway at ORNL. The chemistry program affiliated with biomedical studies described in this document should aid in defining instrumentation and assay needs for this effort.

\section{ECOLOGICAL MONITORING - FIELD STUDIES}

Field sampling and related measurements at the Ft. Martin, West Virginia SRC-II demonstration site will allow a realistic evaluation of effects on key organisms and on integrative ecological processes which serve as useful indi-

cators of ecosystem health. To identify any abnormal variations, it is necessary to first establish the normal range of seasonal variations in selected 
ecological variables prior to facility construction and operation, then monitor these variables during facility operation. The absence of detectable effect after several years of monitoring may provide persuasive evidence that the facility is environmentally safe, provided that sampling effort was suitably designed.

However, due to the existing pollution burden at the site, and the nature of the SRC-II facility, additive effects of normal SRC-II operations may not be environmentally detectable. Additionally, it is currently not possible to identify precisely which samples must be taken and which measurements need to be made. Therefore, a large number of biotic and abiotic samples will initially be taken and archived. Based on results of Phases I-III of this program, decisions will be made on which chemical analyses to perform on archived samples, and the need for additional field studies.

Sampling design will anticipate distribution of pollutants from facility operations (Figure 9). This will be determined by presently available information on plant design, area hydrology, meteorology, and other non-SRC-II industrial activities in the area. We will concentrate on biotic sampling of representative important species to determine relative abundance and distribution at locations correlated with anticipated hydrological or atmospheric pollution gradients. "Abiotic" sampling refers to selected physical and chemical measurements at or near biotic sampling locations. Abiotic measurements will include factors controlling organic productivity or organism behavior (e.g., in aquatic ecosystems, dissolved oxygen, water-quality measurements, etc.; in terrestrial ecosystems, temperature, precipitation, humidity, etc.). If screening studies (described in Phase I, pp. 64-72) indicate that organisms are unduly sensitive to any reference compound classes (other than phenols, which will be determined), additional chemical measurements will be made.

Further chemical analyses on abiotic samples will also be initiated for compounds and compound types which are shown to have biomedical or ecological effects and are found in SRC-II materials. Laboratory bioconcentration/ bioaccumulation/biomagnification studies (Phase II, pp. 84-88) will also be used as a basis for making these measurements.

An important initial phase of this work will be detailed site observation, and evaluation of extant ecological data availajle in local universities and local resource agencies (Federal and State). This work will be coordinated with on-site monitoring studies currently being conducted by StearnsRoger, Inc.

\section{Aquatic Monitoring}

Aquatic monitoring at the proposed Ft. Martin SRC-II demonstration site will focus on potential direct discharges of SRC-II materials to the Monongahela River, or its tributaries, and include analyses of indirect releases through ground water and leachates from solid-waste disposal. Much of the food base in rivers and streams originates from allochthonous organic material. These materials may be taken directly from the water column by foraging aquatic animals or may accumulate in bottom sediments, where they are utilized by microbes and benthic detritivores. Heavy metals and organic materials which may be released from SRC-II materials also accumulate in sediments. Thus, 


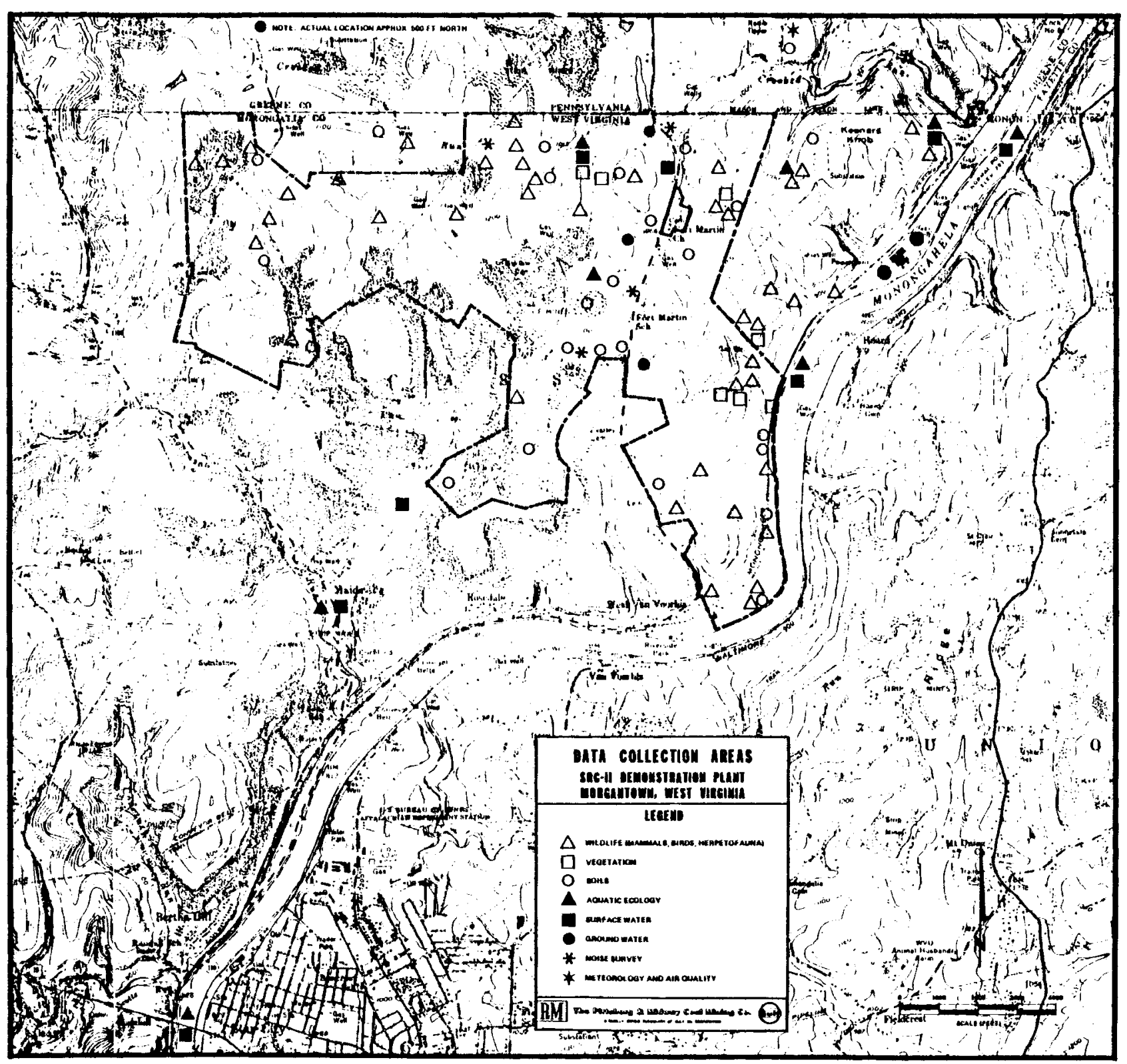

Figure 9. Map of SRC-II Demonstration Site. Monitoring stations used to collect data for Environmental Impact Statements are shown. 
sediments serve as a pollutant sink, and animals living in or on sediments serve as potential sources of pollutant uptake and entry to aquatic and terrestrial food chains.

\section{Biological Sampling Criteria}

Selection of species to be sampled will be based on:

- Occurrence;

- Known sensitivity;

- Role in ecosystem function;

- Position in food chains leading to man;

- Economic or recreational importance;

- Sampling feasibility (adequate access, adequate numbers, handling ease).

\section{Chemical Measurements on Biological Specimens}

Concentrations of several biologically active pollutants will be measured routinely. These include cadmium and mercury, and reference organic compounds for organic acids and phenols, basic nitrogen compounds, and aromatic and heteroaromatic hydrocarbons. Mercury will be measured immediately on all organisms. Specimens to be assayed for other metals may be archived. Specific organic compounds to be measured will be based on results of work described in Phases I and II. Methods for inorganic and organic analyses are described on pp. 48-51 and p. 89. Body burdens of compounds and compound classes of concern will be determined. These data will be established for selected benthic detritivores and fish in the fish-to-man food chain.

Many fish near Ft. Martin, West Virginia belong to the sunfish family (Centrarchidae). Two game species in this group, bluegill (Lepomis macrochirus) and Targemouth bass (Micropterus salmoides), will be sampled as representatives of the entire group. Both bluegill and bass are amenable to laboratory and field studies. Body burdens will also be measured in yellow and brown bullhead, and white and channel catfish. Bullheads and catfish feed on the bottom, ingest sediment, and provide another route for pollutant transport to man.

Ducks and geese, which frequent the Monongahela River and its tributaries, feed on submerged aquatic plants and a variety of invertebrates. Because they are hunted and eaten by man, they will also be monitored.

\section{Other Measurements and Samples}

The species listed above represent a small portion of the aquatic fauna at Ft. Martin. If effluent or product releases suggest the likelihood of gross ecological damage, as when accident scenarios are considered, it will be important to consider whether or not the damage is acute and whether recolonization of the affected area by unaffected upstream or downstream populations 
is possible. If damage is of a chronic nature, biological recolonization may not be possible without cleanup and mitigative action (e.g., introduction of microbes to metabolize persistent organics). Accordingly, the temporal and spatial distribution, abundance and other population characteristics (i.e., growth rates, fecundity, etc.) of selected finfish and shellfish will be determined. When selecting "target" species, such critical life-history requirements as spawning areas, nursery grounds, food habits, feeding areas, wintering areas and migration routes, and their relation to the demonstration facility will be considered. Endangered and/or threatened species and those with specific habitat requirements are of particular concern in this regard.

Terrestrial Monitoring

Terrestrial monitoring will provide the basis for differentiating between ecological changes resulting from SRC-II operations and changes due to natural variations or unrelated pollution stresses extant in the area. Field sampling can also define a zone of effects and provide plant and animal tissues for chemical analyses required in the development and validation of pathway models.

Primary effects on terrestrial communities are expected to result from: 1) episodic deposition of airborne emissions from demonstration-facility operations, codistillation from holding ponds, and resuspension from solid waste and coal piles, and 2) surface run-off and groundwater transport of pollutants resulting from leaching of waste and bulk storage areas, overflow of holding ponds, and accidental spills. Studies described below reflect primary exposure routes. Sampling design will employ a series of fixed sites at varying distances from the source of possible pollutant emissions, and will include control sites in areas relatively unaffected by plant operations. Collection of several years' data before plant construction will also provide controls in time.

Terrestrial Environment at Ft. Martin

The terrestrial environment at the Ft. Martin demonstration site is characterized by a mosaic of plant communities representative of eastern deciduous forests and small agricultural fields. Some fields have been abandoned and are undergoing the natural process of secondary ecological succession. Other fields are still in crop production. Most forest stands have been selectively logged.

Coal mining has been practiced for years and some mined lands are in various stages of revegetation. Gases, particulates and "acid rain," attributed to coal-burning, steam-electric plants, may have already impacted indigenous biological communities.

Soil and topography are the main factors responsible for the local distribution of plant communities. The stony soils and steep slopes are forested. The better soils have been or are still in crop production. Rainfall is sufficient so that irrigation is not required to raise field crops and garden plants. Rainfall percolates through the soil and contributes to ground water. 
Important game species include the white-tailed deer, squirrels and cottontails. Migratory and breeding waterfowl are associated with ponds and streams. Generally, wildlife populations at the site are like those of the surrounding nonmetropolitan areas.

Two general kinds of materials produced in the SRC-II process may be released into the surrounding terrestrial environment. Release may be purposeful, as in the disposal of solid wastes in landfills; or inadvertent, as in gaseous or liquid effluent spills. These materials may be organic rich or mineral rich (pp. 51-54).

Although organics may have the highest carcinogenic potential, little is known concerning their behavior in soils; their uptake by plant roots; whether carcinogens can be passed through food chains; or the biodegradability of organics in soils subjected to aging, wetting, drying, freezing, thawing and microbial decomposition. Additionaliy, little is known concerning potential incorporation of organics during flower production and seed set, and its effect on seed viability and germination, and seedling survival. In contrast, extensive information exists on the behavior and fate of mineral elements in the terrestrial environment, derived from years of agricultural and forestry experience.

\section{Field Experiments}

Small weighing-leaching lysimeters ( $p$. 70) will be used outdoors at the demonstration site in support of greenhouse or growth-chamber experiments to provide information on uptake and toxicity of organic-rich and mineral-rich SRC-II materials by plants. Lysimeters use site soil, site climate and siteadapted plants; are large and deep enough to allow reasonable root penetration; and provide a characteristic root-zone temperature profile and normal seasonal patterns of soil wetting, drying, freezing and thawing. Additionally, populations of soil microorganisms at the demonstration site can be maintained by placing the lysimeters in experimental arrays outdoors.

Results of Phase I studies currently underway at PNL will allow us to determine conditions for use of lysimeters at the Ft. Martin site. Phase I studies will establish types of toxic effects and dose to effect for distillation fractions and a 2.9:1 blend of MD to HD.

\section{Field Plots}

Field-plot studies differ from field experiments in that plots are not purposefully treated with SRC-II materials. Instead, the plots are strategically located in relation to the demonstration facility at places expected to receive wind-carried materials and at other places more remote and upwind from the facility. Changes in chemical composition of plant tissues and soil will be monitored in plots before and after facility operations. Background chemistry of pollutants contributed by other industrial processes will be determined. Garden vegetables will be grown in small plots, harvested, and their tissues chemically analyzed. Some samples will be archived for future analyses. Field-plot studies may also aid in establishing food-chain pathways to man. 
Other Measurements and Samples

Revegetation. SRC-II construction activities and shallow land burial will create disturbances requiring revegetation. Substantial information exists concerning revegetation of surface-mined lands in the coal regions. This information will provide guidance for practical revegetation efforts at the demonstration site.

Forest Monitoring. Forests at the demonstration site provide protection against soil erosion on steep slopes, provide habitat for wildlife, and have esthetic appeal. Additionally, wood is a valuable, renewable resource. In contrast to most crop plants, forest communities are relatively unmanaged and trees are long-lived. Because of large leaf surface areas, trees have high contact potential for airborne gases and particulates. Some gases, such as $\mathrm{SO}_{2}$ and ozone, are injurious to leaves even at low concentrations. Particles adhere to tree leaves and fall to the forest floor in autumn. Thus, the forest floor acts as a sink for airborne foliar contaminants. Over a long period of years, biologically toxic, nonbiodegradable organics and inorganics may build up in the forest floor. Decomposition of leaves and other plant materials may be slowed to the point where changes in nutrient cycling may reduce wood and leaf production in the forest stand. Without onsite field monitoring, this would not be detected. The following surveillance projects constitute an "early warning" system to detect chemical contamination ( $\mathrm{SO}_{2}$ is one airborne chemical of concern) of forests at the demonstration site:

Photographic Interpretation. False-color infrared aerial photography is a proven tool for detecting patterns of decreased vegetative vigor resulting from air pollution and/or insect pests. Photographs will be taken during the peak growing season. Areas showing unexpected changes will also be inspected on the ground to evaluate specific damage.

Visible Injury. On the ground, we will identify patterns of visible leaf injury, including chlorosis and necrosis characteristic of specific pollutants. In the absence of visible injury, alternative explanations for reduced vigor (i.e., parasite or insect infestations) will be sought. Preoperational monitoring is required to separate demonstration-facility effects from those of other pollutants originating off site.

Indicator Species. Species sensitive to $\mathrm{SO}_{2}$, such as white pine (Pinus strobus) and tulip tree (Liriodendron tulipifera), will be planted to span the potential pollutant gradient at the demonstration site. Survival, growth, and visible injury will be compared among study areas.

Litterfall. Systematic collection of litterfall will provide information on vegetative growth and reproductive success. Spring collections contain flower parts, because most trees at the demonstration site flower before leafing out. Fall collections will identify potential growth (leaf mass) and reproductive impairment (nuts and fruits). Collected materials will be archived for possible chemical analyses. Amount of litterfall can be estimated by placing collectors on the forest floor in statistically designed arrays and periodically gathering the contents. 
Leaf Decomposition. Leaves are eaten and fragmented by small invertebrates and further decomposed by microorganisms. Eventually, mineral elements bound in leaf tissues are incorporated into the soil and are available for uptake by plant roots. To determine if leaf decomposition is affected by demonstration facility operations, newly fallen leaves will be placed in nylon mesh bags and periodically weighed to determine rate and amount of breakdown in various forest stands in varying proximities to the facility.

Wildlife Monitoring. Wild mammals and birds may be affected by SRC-II construction activities. Although some wildlife habitat will be destroyed, some land will later be revegetated with plant species that provide food and/or cover for deer, squirrels and cottontails. However, demonstrationfacility operations may still have subtle effects on animal populations. One way to detect impacts on reproductive success of birds is to record number of eggs laid per female, number of eggs hatched and number of young fledged. Unhatched eggs can also be chemically analyzed.

A wildlife monitoring program in support of the Environmental Impact Statement is currently underway at the demonstration site. Data from this effort will be used to select species to be analyzed and analyses to be performed.

\section{Chemical Transport and Fate}

Phase II laboratory studies will investigate physical, chemical, and microbiological processes governing transport, persistence, and fate of trace metals and biologically active organic compounds (PNAs and PAAs) released from SRC-II liquid products and solid wastes. This will establish key controlling variables and estimate mobility and fate over a range of potential geographic, seasonal, and climatic conditions. Phase IV field studies will be designed to validate laboratory results and investigate processes under the specific confines of the local climatic, geologic, hydrologic, and biological regimes.

Investigations will be conducted at two field sites to define possible effects of product spills and disposal of gasified solid wastes on local soils, surface and ground waters. Field sites may include Ft. Lewis, Washington and Ft. Martin, West Virginia.

Field-study objectives are to identify: 1) composition, quantity, and mobility of water-soluble components of SRC-II product oils and solid waste leachates in soils, subsoils, and ground waters; and 2) presence of deleterious materials in local soils and subsurface waters relative to other sources of natural or industrial origin.

A stepwise approach is proposed to fulfill these objectives. Preliminary tasks are designed to evaluate available chemical and hydrological data on local surface and subsurface waters and to initiate limited field work to define the magnitude of potential effects on waters. Initial tasks will form the basis for deciding if a comprehensive field program is necessary.

Field studies will utilize Phase II laboratory information (pp. 89-93) and include organic and inorganic analyses to: 1) compare composition of unaffected waters with contaminated or potentially contaminated waters, and 2) define migration potential of water-soluble material from product spills or 
solid wastes through soil, subsoil, and groundwater systems. Analytical studies will identify soils and waters containing SRC-II residuals. Identification criteria may be based on the presence of trace metals or organic compounds unique to SRC-II or the presence of characteristic isomer distributions of organic compound types. The complex organic chemistry of SRC-II solid wastes and liquids suggests that multiple criteria may be necessary to evaluate potential SRC-II contamination. Field investigations entail four principal tasks. Magnitude of subsequent tasks depends on results of previous tasks.

Task I - Preliminary Evaluation of Existing Water Quality and Hydrological Data

Existing water quality data (particularly for trace metals, organic carbon, and organic compound classes identified in Phase II laboratory studies) will be reviewed and the following information evaluated:

a) well sampling procedures,

b) sample preservation techniques,

c) analytical procedures and concentrations measured,

d) usefulness of analyses performed to identify 1) present state of surface and groundwater contamination, and 2) distribution of solutes with time.

Placement and construction of surface-water monitoring sites and wells will be evaluated to identify those that are unsuitable for further use and to recommend new locations. The following questions need to be considered:

1. Were cores of subsoil lithology logged during well placement?

2. Were wells constructed to prevent interaction between surface and ground waters?

3. How were well screens constructed? Can samples be realistically obtained from discrete depths in the aquifer?

4. What type of hydrologic data were collected (i.e., transmissibility, well draw-downs)?

\section{Task II - Limited Onsite Field Program}

Limited onsite field studies, if warranted from evaluations in Task I, may be initiated to define magnitude of potential movement of solutes. Soil and groundwater samples will be collected and initially subjected to trace metal (Table 25) and organic analyses as described in Phase II (pp. 89-93). We will emphasize analyses of biologically active anionic trace metals, organic bases (anilines and pyridines), and organic acids (principally phenols) present in SRC-II products which may move through soils. Trace metals and organic compounds solubilized in significant quantities from gasified solid wastes will be included, as warranted. Detailed studies of- organic compounds 
will be conducted using derivatization techniques and specific gas chromatographic detectors, mass spectrometry, and isomer distribution patterns, using capillary gas chromatography to elucidate compositional patterns characteristic of solubles from SRC-II liquid products and, perhaps, solid wastes. Additional soil or water samples may be analyzed for hydrocarbons and less water-soluble, polar, organic materials to assess the potential of direct contamination by contact with SRC-II product (as opposed to contamination by migration). However, compound types most likely mobilized in soil or, ultimately, through chemical/microbial processes with time (as indicated from laboratory studies) will be emphasized.

\section{Product Spills - Ft. Lewis}

Soil and Subsoil Analyses. Initially, the extent of product and sour water spillage will be evaluated by shallow surface coring with a hand auger. Core samples (continuous or incremental) will then be obtained, from the soil surface to depths below the water table, in a grid over any possible spill areas as follows:

1. Cores should be obtained at the site of any product spill and the point of sour water discharge (if point sources exist).

2. Core segments will be logged, photographed, and subjected to organic and inorganic analyses.

3. Performing inorganic and organic analyses will depend on results of laboratory studies. At this site, compounds and compound classes of concern (e.g., PNAs and PAAs) will be emphasized; inorganic analysis will be of second priority. Methods will include aqueous batch equilibrations and subsequent analyses for $\mathrm{pH}$, electrical conductivity (EC), dissolved organic carbon (DOC), dissolved inorganic carbon (DIC), major cations, anions, and trace elements as identified in Table 25.

Well-Water Analyses. The existing array of groundwater wells will be sampled in the following manner to define water quality and chemical composition of ground waters both down- and up-gradient from spill and disposal sites:

1. Suitable and unsuitable wells identified in Task I will be sampled.

2. The sampling procedure includes removal of stagnant water by pumping, followed by sampling, with time, to identify compositional changes with inflow.

3. Hydrologic variables such as permeability and transmissibility would be obtained, if possible, to evaluate the wells. Standard hydrologic pumping tests will be used.

4. Water quality will be measured as described above. Inorganic analysis may emphasize identification of additional basic characteristics which may affect mobility and form of inorganic or organic constituents, or reflect additional chemical perturbations to the aquifer. 
5. Effort will be made to identify background chemical and hydrological characteristics of the prominent groundwater unit by well sampling up-gradient from the Ft. Lewis site; a subsurface access well on the Du Pont tract is one possible location.

Extractions on corings and chemical analyses on surface- and well-water samples in conjunction with laboratory studies should enable identification of existing pollution burdens. If additional studies appear warranted, information from Tasks I and II will be utilized to: 1) design a sampling program for those wells deemed useful, 2) propose additional sites for installation of groundwater access wells, and 3 ) obtain additional cores on both a temporal and spatial basis to evaluate migration rates of SRC-II solubles from product spills in soil and groundwater systems.

Solid Waste Disposal - Ft. Martin. Our approach to solid-waste studies will be similar to that described for the spill situation in Task II. Preliminary reconnaisance studies have already been initiated at the Fort Martin site, with emphasis on surface-water hydrology/chemistry.

The site is not pristine, and is affected by previous surface and subsurface coal-mining activities. The site is drained by three runs which flow into the Monongahela River: two, Robinson Run and Crafts Run, are typical acid mine drainages; the third, Crooked Run, exhibits better water quality. Solid wastes from the demonstration plant may be discharged to the region above the headwaters of Crooked Run.

Sampling locations on the three runs and the Monongahela River were chosen, and a range of water and sediment types were collected and chemically analyzed. Additionally, hydrological reconnaissance of the site was undertaken and the need for additional characterization delineated.

This information, in conjunction with laboratory studies of SRC-II gasified and nongasified mineral residues, will allow evaluation of research needs and development of proper pre- and postoperational monitoring to aid prediction of mobility of important residuals from solid wastes to waters.

\section{Task III - Comprehensive Field Program}

Based on Task II, a comprehensive field program may be undertaken to identify: (1) extent, geographic distribution, and flow rates of surface waters and groundwater plumes; and (2) movement and behavior of possible contaminants in surface waters, ground waters, and soil systems with time. Inorganic and organic chemical analyses will be similar to those outlined above. The study would include:

A. Delineation of surface waters at the Fort Martin site as to source, flow rates, and water balance.

B. Delineation of contaminated or principal groundwater plumes at selected sites through:

1. Analyses of hydrologic data to accurately assess groundwater flow patterns; i.e., a contoured flow net; 
2. Possible placement of additional wells to bracket contaminant flow;
a. Possible use of multidepth piezometers;
b. Sampling along surface-water margins to identify contaminated inflow.

C. Assessment of the mobility of solubles in surface water, soils, subsoils, and groundwaters. This will require a continuation of efforts initiated in Task II, as follows:

1. A monitoring program will be initiated to identify the flux of soluble trace metals and organic compounds observed, over time, in groundwater wells.
a. Samples will be collected monthly.
b. Organic analyses performed on a routine basis will previous task and will be indicative of SRC-II pro- emphasize select organic components identified in the duct oils (e.g., phenols and key nitrogen species).
c. Inorganic analyses, primarily in the case of solid wastes, will include $\mathrm{pH}, \mathrm{EC}, \mathrm{DOC}, \mathrm{DIC}$, and major and minor cations and anions.
d. Routine organic and inorganic protocols will be organized to minimize analytical efforts and take advantage of indicator chemical species.

2. Additional chemical analys is of core samples may be performed to furnish information on migration rates of soluble components and absorptive characteristics of local soil and subsoils.

Task IV - Modeling

If significant contamination of soils, surface and ground waters is observed, we will evaluate the feasibility of applying chemical transport modeling to enable prediction of the rate of movement and distribution of related organic compounds in local soils and ground waters.

Large leaching lysimeters will be established as sufficient gasified solid waste becomes available to: 1) demonstrate disposal feasibility, 2) validate laboratory studies of solid-waste weathering and leachate composition, and 3 ) refine the predictive model developed from laboratory studies. Field studies will be desirable to quantitate effects on leachate composition of several variables defined in laboratory studies. These include chemical/ microbial weathering, water volume, in situ heat production, water application rate and promising remedial measures; e.g., sludge disposal or soil overburden. Lysimeters will be constructed and instrumented to measure profile moisture distribution, microbial activity, temperature, and salinity. This will allow determination of the influence of measurable variables on leachability of 
organic carbon, specific organic compounds, salts, trace metals, and trace metal complexes. Measurements of incoming moisture, evapotranspiration and percolation, and knowledge of leachate composition will allow us to develop material balances on soluble residuals and make proper comparisons with laboratory studies and onsite measurements during Tasks I-III.

Although the efforts described above are comprehensive, the proposed stepwise approach will enable successive reevaluation of the need for further research after completion of each task. Chemical transport and fate studies should provide information to: 1) define immediate operational impact at specific sites, 2) estimate long-term transport and fate, 3 ) recommend modifications to existing surface and groundwater monitoring systems to establish comprehensive chemical and hydrologic networks and measure long-term effects, and 4) recommend technological changes for waste-management practices which will minimize environmental and human health effects, and permit ecological restoration as necessary.

\section{ENVIRONMENTAL ASSESSMENT/RISK ANALYSES}

Field data on SRC-II facility emissions may be available. These data, based on operating experience from a facility of near-commercial size, will aid in determining validity of previous assessments and in providing assessment of environmental effects of the commercial SRC-II process. Pathways models (Figure 8 ) used for dose assessment will be improved so that error limits for calculated exposures can be estimated. 
. 


\section{TIMELINES}

Estimated timelines for various segments of Phases I and II are shown in Figures 10-12. Timelines assume receipt of test material at time zero. To convert these to real time, see Table 1 for anticipated dates of material receipt. Because of uncertainties associated with the initiation and extent of Phases III and IV efforts, no timelines have been developed. 


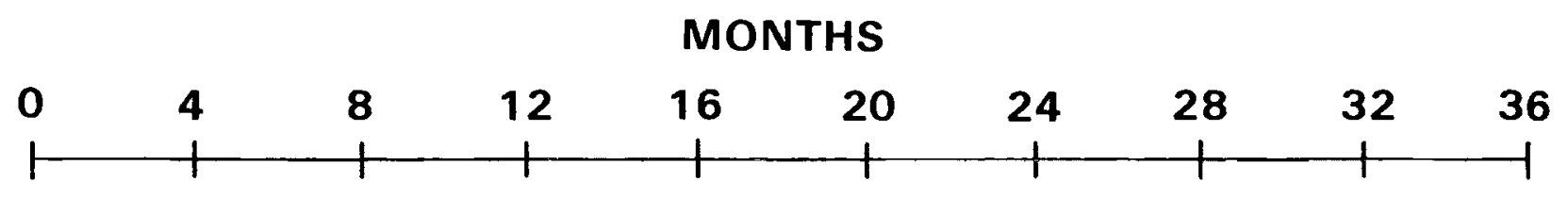

\section{PHASE I}

CHEMISTRY FOR BIOMEDICAL ASSAYS

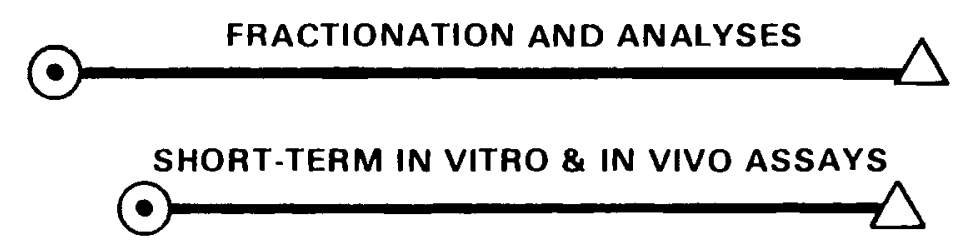

BIOMEDICAL ASSAYS

\section{CHEMISTRY FOR ECOLOGICAL ASSAYS}

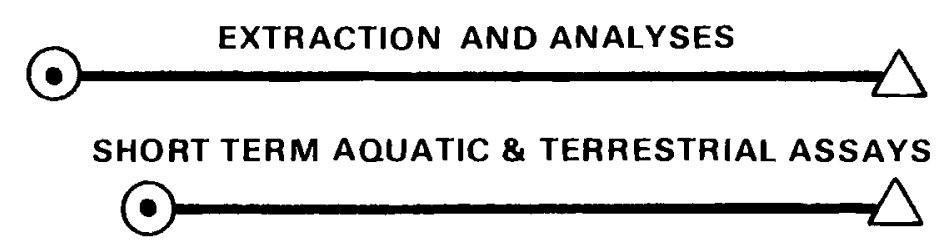

FIGURE 10. Estimated Time to Complete Phase I Biomedical and Ecological Studies, Assuming Receipt of Material At Time Zero. 


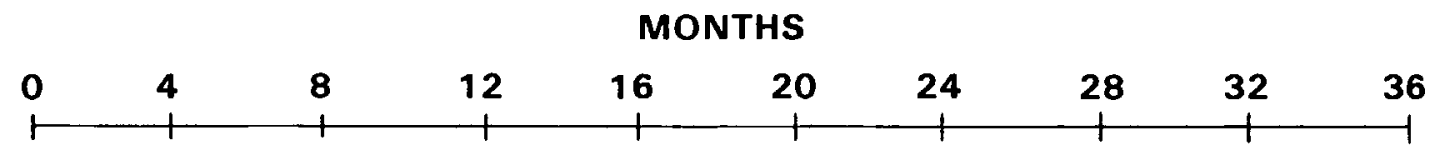

PHASE II BIOMEDICAL

DERMAL CARCINOGENICITY

INHALATION TOXICOLOGY

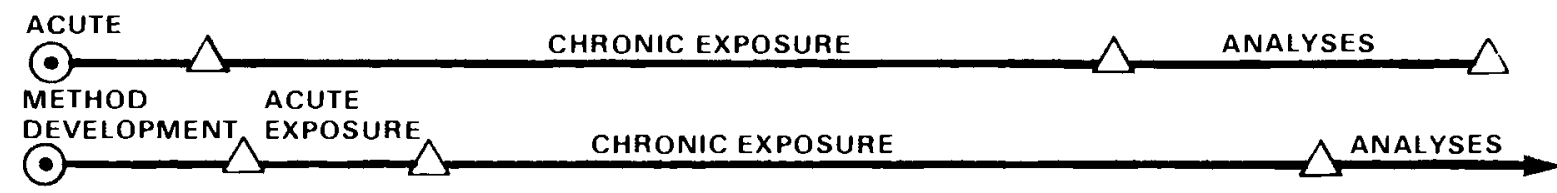

DOMINANT LETHALITY

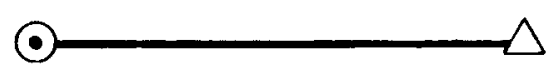

TRANSPLACENTAL CARCINOGENICITY

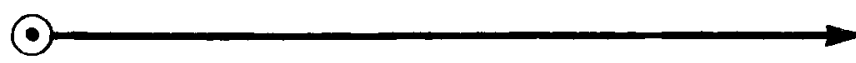

DEVELOPMENTAL TOXICOLOGY

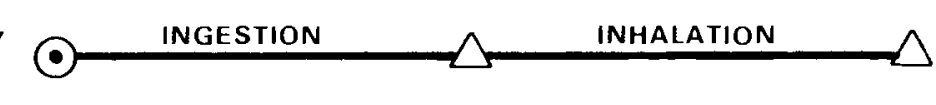

NEUROBEHAVIORAL

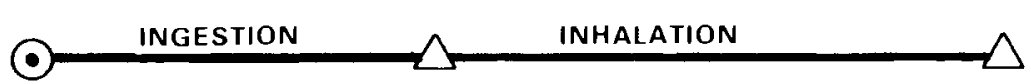

FIGURE 11. Estimated Time to Complete Phase II Biomedical Studies, Assuming Receipt of Material at Time Zero. 


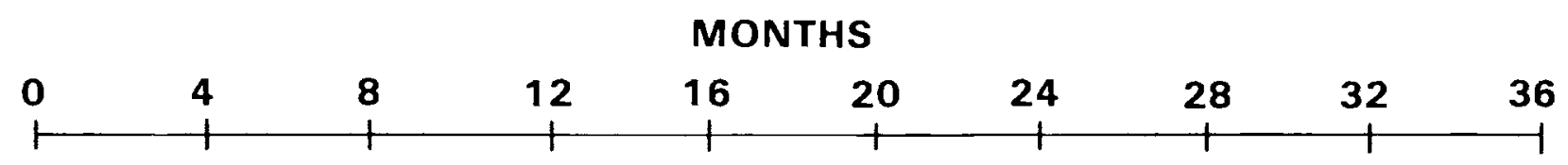

PHASE II ECOLOGY

AQUATIC \& TERRESTRIAL FATE

MULTISPECIES

$\vec{N}$ TECHNOLOGY

REVEGETATION

STUDIES

CHEMICAL TRANSPORT

\& FATE

METHOD DEVELOPMENT

ANALYSES

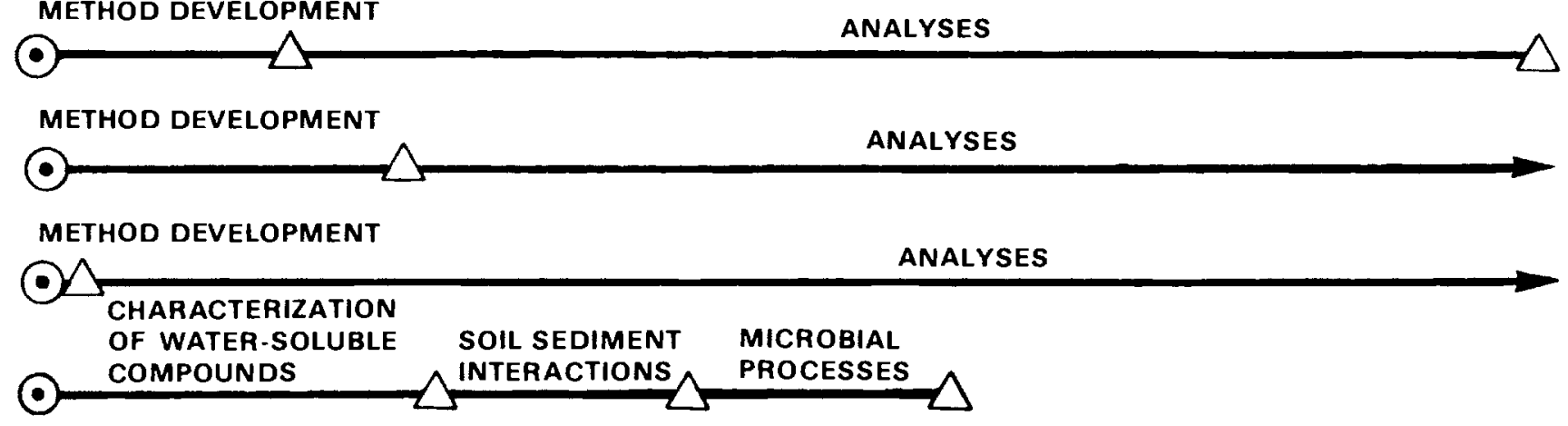

ENVIRONMENTAL

ASSESSMENT /

RISK ANALYSES

FIGURE 12. Estimated Time to Complete Phase II Ecological Studies, Assuming Receipt of Material at Time Zero. 
No. of

Copies

OFFSITE

A. A. Churm

DOE Chicago Patent Group

$9800 \mathrm{~S}$. Cass Avenue

Chicago, IL 60439

150 A. P. Duhame I

Office of the Assistant Secretary for Environment

Department of Energy

Washington, DC 20545

2 DOE Technical Information Center

J. P. Filo

Environmental Research and

Technology, Inc.

700 Fifth Avenue Building

Pittsburgh, PA 15219

W. Hubis

Gulf Mineral Resources Co.

1720 S. Bellaire St.

Denver, CO 80222

R. A. Lewis

Department of Energy/ERD

Washington, DC 20545

M. J. Massey

Environmental Research and Technology, Inc.

700 Fifth Avenue Building

Pittsburgh, PA 15219

D. K. Schmalzer

The Pittsburg \& Midway Coal Mining Co.

P. 0. Box 3396

Englewood, CO 80155

\section{ONSITE}

DOE Richland Operations Office

M. G. White

H. E. Ransom
No. of

Copies

18 Pacific Northwest Laboratory

W. J. Bair

H. Drucker (5)

W. D. Felix

R. H. Gray (5)

D. D. Mahlum

S. Marks

J. M. Nielson

J. A. Strand

B. E. Vaughan

W. C. Weimer

Publishing Coordination (2)

Technical Information (5) 
